NBER WORKING PAPER SERIES

\title{
THE POLITICAL ECONOMY OF IMMIGRATION ENFORCEMENT: CONFLICT AND COOPERATION UNDER FEDERALISM
}

\author{
Alberto Ciancio \\ Camilo García-Jimeno \\ Working Paper 25766 \\ http://www.nber.org/papers/w25766 \\ NATIONAL BUREAU OF ECONOMIC RESEARCH \\ 1050 Massachusetts Avenue \\ Cambridge, MA 02138 \\ April 2019
}

We especially thank Holger Sieg, who encouraged us to pursue this research project. We are also grateful to Elizabeth Cascio, Frank DiTraglia, Pablo Montagnes, Petra Todd, Ken Wolpin, and to participants at the Politics, Race, and the Economy session at the 2019 ASSA meetings, at USC, and Emory for their suggestions, and to the Institute for Quantitative Theory and Methods at Emory University for its financial support. We also thank the Transactional Records Access Clearinghouse (TRAC) at Syracuse University for sharing their database with us as fellows of the center. We thank Ashwin Kambhampati for excellent research assistance. The views expressed herein are those of the authors and do not necessarily reflect the views of the National Bureau of Economic Research.

NBER working papers are circulated for discussion and comment purposes. They have not been peer-reviewed or been subject to the review by the NBER Board of Directors that accompanies official NBER publications.

(C) 2019 by Alberto Ciancio and Camilo García-Jimeno. All rights reserved. Short sections of text, not to exceed two paragraphs, may be quoted without explicit permission provided that full credit, including $\odot$ notice, is given to the source. 
The Political Economy of Immigration Enforcement: Conflict and Cooperation under Federalism Alberto Ciancio and Camilo García-Jimeno

NBER Working Paper No. 25766

April 2019

JEL No. D73,D78,H73,H77,J15,J61,K37

\begin{abstract}
We study how the shared responsibilities over immigration enforcement by local and federal levels in the US shape immigration enforcement outcomes, using detailed data on the Secure Communities program (2008-2014). Tracking the movement of arrested unlawfully present immigrants along the several steps of the immigration enforcement pipeline, and exploiting a large shift in federal enforcement priorities in mid 2011, we disentangle the three key components of the variation in deportation rates: federal enforcement efforts, local enforcement efforts, and the composition of the pool of arrestees. This decomposition allows us to recover the local (county) level response to changes in federal enforcement intensity. Among urban counties, 80 percent, mostly Democratic but with small shares of Hispanics, exhibit strategic substitutabilities. The inverse relationship between federal and local efforts allowed most counties to reduce opposition to the policy, and was accompanied by an increased alignment of local and federal preferences. The federal level was very effective in directing its enforcement efforts towards counties where it expected local collaboration, but conflict was mostly driven by a change in the types of unlawfully present immigrants it prioritized for removal.
\end{abstract}

\author{
Alberto Ciancio \\ Population Studies Center \\ University of Pennsylvania \\ ciancio@sas.upenn.edu \\ Camilo García-Jimeno \\ Institute for Quantitative Theory and Methods \\ Emory University \\ Tarbutton Hall, of. 217B \\ 1555 Dickey Dr. \\ Atlanta, GA 30307 \\ and NBER \\ camilo.garcia-jimeno@emory.edu
}




\section{Introduction}

A long tradition in the social sciences has studied the allocation of tasks and policies across different levels of government in the context of federalism and decentralization (Hooghe and Marks (2003); Inman and Rubinfeld (1997b); Oates (1999)). Scholars have emphasized that the extent of decentralization should be driven by the degree of spatial heterogeneity in preferences and the salience of local information, because the social value of locally tailored policies must be traded-off against the benefits of coordination when externalities are important, or against scale economies in public goods provision (Tullock (1969)). From a positive standpoint, the existence of such trade-offs suggests that we should observe more decentralization and more conflict where there is more preference heterogeneity (Besley and Coate (2003); Strumpf and Oberholzer-Gee (2002)), and increased spatial sorting across jurisdictions where policy is more decentralized, as people will then find it valuable to vote with their feet (Tiebout (1956)).

Other important aspects of federalism, however, have not received as much attention. In several dimensions of policy, rather than allocating disjoint tasks to different levels of government, both the federal and the local levels undertake overlapping actions that jointly determine policy outcomes (either because it is difficult for the federal level to implement policy without the aid of the local level ${ }^{1}$, or because the local level is able to exercise some discretion). Moreover, the local level is often not just an agent of the federal level. In the US, for example, this is clearly established in the 9th and 10th Amendments to the Constitution, which allocate to the states and the people any rights not explicitly delegated to the federal government. In such circumstances, we may expect coordination to take place when local and federal-level preferences are aligned. Otherwise, the local level may partly or fully undo the actions of the federal level $^{2}$. As such, variation in the extent of preference alignment between levels of government should be a major driver of the heterogeneity in policy outcomes across jurisdictions.

In this paper we explore precisely this possibility by studying immigration enforcement policy in the US. Immigration enforcement is an ideal policy setting to study strategic interactions under federalism. Although from a legal standpoint immigration policy falls under the purview of the federal government ${ }^{3}$, in practice many margins of its enforcement are directly and indi-

\footnotetext{
${ }^{1}$ In Federalist No. 44, James Madison recognized that in many instances the federal government would be dependent upon state and local governments to cary out policy, which in his view justifies the Supremacy Clause of the Constitution (Madison (1788)). In the case of immigration enforcement which will concern us here, while the payroll of ICE in 2010 was approximately 20 thousand employees, the number of state and local law enforcement officers across the US was more than 800 thousand (Reaves (2010)).

${ }^{2}$ De Tocqueville raised this issue early on: "Among the weaknesses inherent in all federal systems, the most obvious of all is the complexity of the means it employs. This system necessarily brings two sovereignties into confrontation" ((DeTocqueville, 2003 [1840], p.192)). Recently, legal scholars concerned with the lack of uniformity in the application of the law have also pointed out that when the local level can act as a gatekeeper of federal responsibilities, law enforcement will be geographically less systematic (Motomura (2011)).

${ }^{3}$ Under current law immigration violations are federal offenses. Current federal immigration law is regulated by the 1952 Immigration and Nationality Act, its 1965 amendments, the Immigration Reform and Control Act
} 
rectly affected by local-level decisions. Moreover, demographics, partisanship, and proximity to borders all shape local preferences over immigration policy. As a result, there is ample variation in the extent of alignment of preferences over immigration enforcement between the federal and the local levels (counties in the US).

Although we expect strategic interactions between levels of government to arise in many settings, a central challenge is to understand the nature of the strategic environment, and to distinguish the different margins of enforcement from each other and from the underlying economic environment shaping both policy choices and policy outcomes. Perhaps except for Bohn et al. (2015); García-Jimeno (2016); Knight (2002), there is scant empirical literature exploring these issues or highlighting how strategic responses across levels of government are key to understand heterogeneity in policy outcomes.

More precisely, we consider the enforcement of immigration policy under the Obama administration during the period of operation of the Secure Communities program. Under this program, whose rollout began under the George W. Bush administration, the fingerprints of every person arrested by local police are automatically sent to the Department of Homeland Security's Immigration and Customs Enforcement agency (ICE), where they are automatically compared with a variety of law enforcement databases to establish the immigration status of the arrestee. This allows ICE to locate potential targets of deportation, without requiring the acquiescence of local law enforcement. ICE then has full discretion to issue or not a detainer request to the jail where the arrestee is being held. The detainer asks local law enforcement to hold the arrestee for up to an additional 48 hours, giving ICE time to take the arrestee into federal custody. At this point a deportation process may begin. Between 2009 and 2014 under the Secure Communities program, ICE issued 485 thousand detainers, held in custody 479 thousand people (with and without issued detainers), and removed 396 thousand individuals. ${ }^{4}$

Our main interest is to understand how the observed variation in the outcomes of immigration enforcement itself (removal rates of unlawfully present immigrants) is shaped by the intensity of immigration enforcement at the local and federal levels. To do this we exploit several unique features of the design of the Secure Communities program and how ICE operates. These allow us to disentangle the three main components of the variation in removal rates: the composition of the pool of individuals subject to potential removal, federal immigration enforcement intensity, and local immigration enforcement intensity.

The period covered by the Obama administration is especially convenient for our purposes because midway into the eight-year term, the administration undertook a major shift in immi-

of 1986, the Personal Responsibility and Work Opportunity Reconciliation Act of 1996, the Illegal Immigration Reform and Immigration Responsibility Act of 1996, and the REAL ID Act of 2005.

${ }^{4}$ These are numbers for interior removals; they do not include border removals (source: FOIA requests to the Department of Homeland Security). 
gration enforcement policy at the federal level ${ }^{5}$. The new guidelines explicitly advocated a shift in the focus of federal enforcement efforts away from the prosecution of unlawfully present immigrants accused of misdemeanors and minor crimes, and towards those accused of serious crimes. Trends in average federal immigration enforcement outcomes indeed show a dramatic reversal following the policy change, allowing us to leverage this large change in the overall intensity of federal immigration enforcement to trace the heterogeneous responses of local immigration enforcement to it.

Our starting point is to exploit the institutional details of the immigration enforcement process by modeling its main component: the pipeline taking unlawfully present immigrants arrested by local law enforcement into ICE custody, and subsequently into being (or not) deported. ${ }^{6}$ The immigration enforcement process effectively operates in a cascade fashion. After an individual is arrested by local law enforcement for any of a variety of possible offenses, government agents at the local and federal levels undertake efforts that may result in this individual being taken (or not) into federal custody. At that stage, the federal level, immigration courts and the immigrant (or his legal representation) jointly undertake efforts that determine whether he or she is removed from the US. Thus, observed removal rates depend on local and federal enforcement efforts, on how these interact along the immigration enforcement pipeline, and on the underlying composition of the pool of arrested illegally present individuals (because their characteristics may make them more or less favored by the local and federal levels). The key empirical challenge, thus, is to disentangle the roles of local and federal immigration enforcement efforts on the one hand, and of the composition of the arrest pool on the other, as drivers of the observed variation, across time and jurisdictions, in the observed removal rates. This is particularly difficult because local and federal enforcement choices are likely endogenous to each other (for example if the local level strategically responds to choices of the federal level), and are likely dependent on the characteristics of the arrest pool.

The unique institutional details of the Secure Communities program allow us to isolate enforcement choices from selection (unobserved characteristics of the pool of arrested undocumented individuals), and to isolate local from federal enforcement decisions. The automatic receipt of fingerprints by ICE after a local arrest implies that local level enforcement choices have no (direct) effect on the likelihood of a detainer request, allowing us to isolate federal enforcement efforts from this first step in the process. After a detainer request has been issued by ICE, the local level has full discretion to comply with the request (by holding the arrestee

\footnotetext{
${ }^{5}$ See the policy memoranda issued by ICE's director John Morton (Morton (2011a,b)).

${ }^{6} \mathrm{~A}$ parallel branch of federal immigration enforcement consists in the raiding of homes and workplaces by ICE. Because this branch of immigration enforcement does not involve the local level, we do not consider it here directly. For a discussion of the increasing use of ICE raids during the Bush administration, see Schmall (2009). During the Obama administration, however, ICE raids were a small component of all federal immigration enforcement activity: between 2009 and 2016, only 12 percent of removed individuals were in ICE custody as a result of a raid (our own estimate based on Freedom of Information Act requests to ICE).
} 
until ICE picks him up) or not (by releasing the arrestee before ICE picks him up), allowing us to isolate the local enforcement efforts from this second step in the process. Tracing how the composition of the pool of arrestees is filtered through the several steps of the immigration enforcement process (arrests to detainers, detainers to custodies, custodies to removals), we are also able to disentangle the variation in the composition of the pool of arrestees from the variation in these enforcement choices.

We use a rich data set of detailed information on the universe of fingerprint matches under Secure Communities, the issuance of ICE detainers, the number of individuals under ICE custody, and the number of removals covering the period 2009-2014. We complement these data with information on a variety of county-level demographics.

We first show that federal immigration enforcement did weaken considerably after the policy change, but that it cannot fully account for the pattern of changes in immigration enforcement outcomes along the deportation pipeline. In particular, strong selection forces in the composition of the pool of individuals facing prospects for removal, possibly endogenous to the changes in enforcement, were present. We also show that the choices of the local level had screening effects explaining part of these selection patterns, and that the changes in local immigration enforcement are related to local characteristics.

We then estimate our model of the immigration enforcement pipeline under Secure Communities, and find most counties exhibit strategic substitutabilities in their response to federal enforcement efforts. This is true for cases of individuals accused of both minor and serious crimes. We find that local responses, however, were heterogeneous: more democratic and less Hispanic counties were more eager to undo the federal enforcement efforts by weakening their collaboration with ICE. We also find that increased conflict between local and federal levels was mostly driven by a change in the profile of immigration cases prioritized by ICE.

Our results highlight how conflict over policy across vertical jurisdictional levels constitutes a first-order driver of the heterogeneity in the outcomes of the policies. They also suggest that the implementation of enforcement technologies that become too effective may lead to reactive responses when there is conflict over the outcomes of such enforcement. Secure Communities is a case in point, as its effectiveness in detecting illegally present immigrants required a large countervailing response by localities opposed to harsh immigration enforcement, and eventually led to the official demise of the policy itself.

Our paper contributes to the broader economics literature studying the effects of policy changes and interventions. A first concern emphasized early on by Rosenzweig and Wolpin (1986) in the context of family planning subsidies, is related to the presence of spatial heterogeneity that may be correlated with the take-up or the intensity of the policy in question (see also Lalive and Zweimuller (2004); Meyer (1995)). Besides this form of selection, heterogeneity in the effects of the policies themselves is also a concern. If the unobserved heterogeneity is 
varying over time, using jurisdiction-level fixed effects has significant limitations (Besley and Case (2000)). In our context, the response of the local level to the federal level is both a main source of heterogeneity in the intensity of enforcement of the federal policy (the federal level is likely choosing based on how it expects the local level to react), and a main source of heterogeneity in the effects of the policy (complementarities or substitutabilities between federal and local enforcement margins in the determination of the outcomes of interest may be present.) By studying an institutional environment with features of federalism and policy overlap across levels of government, our methodological contribution relative to this literature is to address these concerns by leveraging the details of the institutional setting.

This allows us to make an empirical contribution to several areas of inquiry. Within the the literature on federalism and decentralization (Inman and Rubinfeld (1997a); Lockwood (2002); Strumpf and Oberholzer-Gee (2002)) we point to the local-federal alignment in preferences as a key political economy consideration for understanding variation in policy choice and policy outcomes. To the best of our knowledge ours is the first study recovering the enforcement responses of the local level to changes in federal-level enforcement. Because all interior enforcement of immigration in the US relies on the contact of illegally present immigrants with law enforcement, we also build on and contribute to the literature on the economics of crime and immigration. This literature has pointed out that toughened immigration enforcement drives immigrants towards illegal activities (Freedman et al. (2018)). Looking specifically at Secure Communities, however, both Miles and Cox (2014) and Treyger et al. (2014) find no effects of the program on crime rates. We show that differences in immigration enforcement preferences over immigrants with different criminal offense accusations are an important driver of the conflict between the federal and the local levels.

We also contribute to the literature on the political economy of immigration policy and law enforcement. ${ }^{7}$ Scholars have studied the correlates of local and state-level immigration legislation (Boushey and Luedtke (2011); Lewis and Ramakrishnan (2007); Steil and Vasi (2014)). Their findings suggest that the presence of a large immigrant community and of Hispanics correlates strongly with policies weakening immigration enforcement ordinances. The ethnic identity of local law enforcement is also correlated with the willingness to enforce immigration policies (Lewis et al. (2013)). Republican support, in contrast, is correlated with the adoption of stronger immigration enforcement policies, particularly in communities experiencing fast growth of the immigrant population (Ramakrishnan and Gulasekaram (2013)). Using a regression discontinuity design, however, Thompson (2018) finds no evidence of differences in

\footnotetext{
${ }^{7} \mathrm{~A}$ recent related literature studies how immigrants and their families alter their economic choices in response to increased immigration enforcement, for example in school attendance (Dee and Murphy (2018)), geographic mobility (Amuedo-Dorantes et al. (2013)), or social welfare program enrollment and take-up (Alsan and Yang (2018); Vargas (2015); Watson (2014)). Most of this literature suggests these behavioral responses are the result of "chilling effects", as immigrants perceive interaction with government officials more risky.
} 
compliance with detainer requests between barely elected Democratic or Republican sheriffs. Naturally, these are counties with highly competitive elections, where sheriffs of any party may have strong incentives to follow median-voter preferences closely.

Finally, a small literature has proposed modeling preferences over law enforcement to rationalize the observed patterns of policing and crime. An early example is Davila et al. (1999), who argue that the behavior of the Immigration and Naturalization Service (INS) was consistent with an objective function that privileged maximizing revenue instead of minimizing the size of the illegally present population. More recent research estimating models of law enforcement choice and crime include Imrohoroglu et al. (2000), Fu and Wolpin (2018), and García-Jimeno (2016). Here we emphasize the importance of preference alignment when enforcement can be influenced by federal and local levels, and highlight the local-level trade-off between increased immigration enforcement and the efficiency of law enforcement.

The remainder of this paper proceeds as follows. In section 2 we discuss immigration policy in the US, with a focus on the Secure Communities program. We introduce and describe the data in section 3. Based on our background discussion and on the main patterns in the data, section 4 develops a model of the immigration enforcement pipeline, and section 5 discusses identification and estimation. In section 6 we then present our main results and discuss its implications. Finally section 7 concludes. We present proofs and additional tables, figures, and data description in the online appendices.

\section{Immigration Policy under Secure Communities}

The centralization of immigration policy and its enforcement in the US occurred gradually, possibly starting with the 1849 Supreme Court decisions in Smith v. Turner and Norris v. Boston, the so called Passenger Cases. ${ }^{8}$ There the court established that levying state taxes on ships of immigrant passengers violated the 9th and 10th clauses of Article 1 of the Constitution. This was reinforced by two more decisions 25 years later. ${ }^{9}$ And although the Immigration Act of 1882, the first national-level piece of immigration legislation in the US, allocated all power in determining the excludability and deportability of aliens to the federal level, it also

\footnotetext{
${ }^{8}$ According to Gulasekaram and Ramakrishnan (2015), the absence of an explicit mention of Immigration Law in the Constitution made it a subject of gradual evolution. As a result, the limits of federal and local enforcement have been decided through precedent over "...more than 135 years of jurisprudence negotiating the proper scope of state and local immigration policies."

${ }^{9}$ In Henderson v. Mayor of the City of New York (1875) the court ruled that other forms of state-levied taxes were unconstitutional as well. In Chy Lung v. Freeman (1876) the court also struck down an 1874 California law requiring certain immigrant passengers -those deemed likely to become a public charge or "lewd women"to post bonds at their time of arrival.
} 
left most practical enforcement to state-level officials (Hirota (2013); Hutchinson (2016)) ${ }^{10}$. Congress passed an additional piece of legislation in 1891 that completed the nationalization of immigration enforcement. This law granted wide discretion to immigration officers regarding admission of immigrants, raising early concerns about due process that reemerged recently under the Secure Communities program. ${ }^{11}$

States and localities only began regaining a significant role in immigration policy with the 1986 and 1996 legislative overhauls of immigration law. Both acknowledged the potential for local involvement in immigration enforcement. The Immigration Reform and Control Act (IRCA) of 1986 legalized almost three million unlawfully present immigrants but introduced employment restrictions for new ones. It also created the Criminal Alien Program (CAP), still in operation. Under CAP, local officials in prisons, jails, and courthouses share lists of inmates and allow ICE to perform interviews, after which ICE may issue detainer requests. ${ }^{12}$

The Illegal Immigration Reform and Immigrant Responsibility Act (IIRIRA) of 1996, in turn, allowed states and localities to participate in immigration enforcement. Section 287(g) of the law allowed for cooperation agreements with the federal government, whereby local law enforcement officials received training and authority to enforce federal immigration law. This included the authority to screen individuals for their immigration status, investigate cases, issue detainers, arrest and issue charges for immigration violations, and access DHS's databases. Approximately three percent of counties eventually entered into a $287(\mathrm{~g})$ agreement, most of them after the $9 / 11$ terrorist attacks. 287(g) agreements were gradually phased out during the Obama administration in tandem with the rollout of Secure Communities (Kalhan (2013)). ${ }^{13}$ Beyond these agreements, several states made further attempts at direct immigration enforcement. In 1993 California passed legislation mandating cooperation between state prisons and federal im-

\footnotetext{
${ }^{10}$ The 1882 legislation marked the beginning of what historians of US immigration policy call the Exclusion Era (Zolberg (2006)).

${ }^{11}$ Subsequent court rulings further expanded the role of the federal level in immigration policy. Landmark rulings like Chae Chan Ping v. US (1889), challenging the Chinese Exclusion Act of 1882, provided for federal immigration control to be absolute, exclusive, and beyond judicial review, shifting the basis for the federal prerogative in immigration from the earlier Commerce Clause rationale to a stronger national sovereignty justification (Gulasekaram and Ramakrishnan (2015)). This legal doctrine is called "plenary federal immigration power". Such a trend was reinforced in 1907 under Roosevelt's administration with the establishment of the Immigration Commission and the Naturalization division (Zolberg (2006)). Two subsequent landmark rulings constraining the role of the state and local levels are Hines v. Davidowitz (1941) and Plyer v. Doe (1982). In Hines the Court struck down a Pennsylvania law requiring aliens to register with the state and carry documentation; in Plyer, the Court ruled that states and local governments cannot deny public education to unlawfully present children, striking down a Texas law with such purpose. There, the roles of states and localities were limited to the regulation of some aspects of the everyday lives of immigrants under what is called 'alienage law' (employment, property ownership, access to welfare benefits).

${ }^{12}$ Through CAP, ICE has presence in every state and federal prision in the US, and in more than 300 local jails. Currently CAP accounts for around half of all individuals taken into ICE custody (Guttin (2010); Kalhan (2013))

${ }^{13}$ The Trump administration, however, has begun implementing new $287(\mathrm{~g})$ agreements. As of 2018,78 such agreements are in place (see: https://www.ice.gov/287g).
} 
migration authorities. California voters then approved Proposition 187 in 1994, requiring that state officials report suspected unlawful presence to federal authorities (Gulasekaram and Ramakrishnan (2015)). This proposition was struck down by the courts, but it did trigger similar efforts in Arizona, Florida, and Texas.

\subsection{The Secure Communities Program}

Conflict over immigration policy has grown considerably in the 21st century, as local, state, and federal levels have all attempted to exert increasing influence over immigration enforcement. This may have been driven by the rising numbers of unlawfully present immigrants -from around 3 million in 1990 to about 12 million in 2008-, increased political polarization and partisanship, or the drastic changes in the structure of employment in the US economy. ${ }^{14}$ Local preferences over immigration policy have grown more heterogeneous across space, leading to sharp contrasts and reversals in the alignment of preferences between the federal and local levels.

From one side, states like Arizona led the charge on anti-immigration legislation. This state's SB 1070 bill, passed in 2010, became the most prominent piece of legislation empowering local law enforcement to participate in immigration enforcement. ${ }^{15}$ Colorado, Alabama, Georgia, and South Carolina undertook similar 'copycat' attempts (Gulasekaram and Ramakrishnan (2015)). SB 1070 was particularly controversial; it required state and local police officers to determine the immigration status of stopped or arrested individuals, and for immigrants to carry alien registration documents. It also provided officers with arrest discretion based on their assessment regarding the removability of a stopped non-citizen, leading to the possibility of warrantless arrests. The bill was, in fact, challenged in court for this reason on the basis of due process considerations. It was also challenged by the Obama administration as an encroachment over federal authority, and most of its provisions struck down by the Supreme Court. On the opposite extreme, several cities and counties have approved "sanctuary" ordinances requiring their law enforcement officials not to collaborate with federal immigration enforcement efforts, and to explicitly ignore immigration violations. Sanctuary legislation is not new -some cities passed similar ordinances in the 70s-90s-. In recent years, however, new forms of non-cooperation emerged, partly as a response to federal enforcement efforts under the Bush and Obama administrations.

Possibly the most prominent federal effort in immigration enforcement in this period is the

\footnotetext{
${ }^{14}$ Using regression analysis for the US, both Gulasekaram and Ramakrishnan (2015) and Steil and Vasi (2014) find that partisan share of the electorate is a robust predictor of the adoption of local immigration legislation in this period. Fasani (2009) finds in the Italian context that increases in labor demand led to significant falls in deportations of immigrants between 1994 and 2004 and suggests a political economy mechanism for this effect.

${ }^{15}$ The bill's explicit purpose was "attrition through enforcement", and was motivated by the premise that the enforcement inaction of the federal level required the local level to step in.
} 
Secure Communities program, the main focus of our attention in this paper. ${ }^{16}$ The program oversaw the largest expansion of local immigration enforcement in U.S. history (Kalhan (2013)). Participation in Secure Communities is mandatory. Its rollout began in 2008, but the program was officially discontinued in November 2014 after significant controversy and local and state resistance. ${ }^{17}$ However, the Priority Enforcement Program (PEP), a program in the same sprit and relying on the same institutional structure, replaced Secure Communities. Despite its demise, Secure Communities constituted a radical innovation, on both the institutional and the technological fronts. We now go on to describe how the program operated. ${ }^{18}$

\subsubsection{First Step: The Federal Level}

Secure Communities restricted significantly the ability of local police to exercise discretion over immigration enforcement. Under standard procedure following a local law enforcement arrest for any reason, the arrestee's fingerprints are scanned and checked against the FBI's identification and criminal records database (IAFIS) during booking. Under Secure Communities, upon receipt of these fingerprints, the FBI directly and automatically transmits them to the DHS for comparison against its Automated Biometric Identification System (IDENT) ${ }^{19}$. If there is a match to an unlawfully present individual, or even if there is no match but the individual has no known place of birth, the system automatically flags the record and notifies ICE. ICE itself then undertakes further checks on its own and other databases, and informs the corresponding

\footnotetext{
${ }^{16}$ ICE designed Secure Communities in response to a 2008 Congressional directive to "identify every criminal alien, at the prison, jail, or correctional institution in which they are held." (see Consolidated Appropriations Act of 2008).

${ }^{17}$ In the memorandum officially ending the Secure Communities program, the Secretary of Homeland Security Jeh Johnson argued that "The goal of Secure Communities was to more effectively identify and facilitate the removal of criminal aliens. But the reality is the program has attracted a great deal of criticism, is widely misunderstood, and is embroiled in litigation; its very name has become a symbol for general hostility toward the enforcement of our immigration laws. Governors, mayors, and state and local law enforcement officials around the country have increasingly refused to cooperate with the program, and many have issued executive orders or signed laws prohibiting such cooperation" (see Johnson (2014)).

${ }^{18}$ The Trump administration subsequently re-labeled PEP as Secure Communities.

${ }^{19}$ IDENT currently holds around 150 million records, and grows at around 10 million new entries per year. It contains information of any individual who has had contact with DHS, including visa applicants in other countries, non-citizens traveling through the US, non-citizens applying for asylum or other benefits, unlawfully present immigrants apprehended at the border, anyone participating in 'trusted traveler' programs, parents who have adopted children abroad, naturalized citizens, and anybody whose fingerprints have been collected through Secure Communities. It aggregates information from ICE, the Customs Border Protection, the US Coast Guard, the US Citizenship and Immigration Services, the Department of State, the Department of Defense, the Department of Justice (including all FBI databases), Interpol, the Five Country Conference (an information sharing agreement between the US, the UK, Australia, Canada and New Zealand), and the Preventing and Combating Serious Crime international agreement (see Privacy Office, US Department of Homeland Security, Privacy Impact Assessment for the Automated Biometric Identification System (IDENT) 11-15 (2012), Office of Inspector General, US Department of Homeland Security, Operations of United States Immigration and Customs Enforcement's Secure Communities 4-5 (2012), and DHS, Privacy Impact Assessment for the Automated Biometric Identification System (2012)).
} 


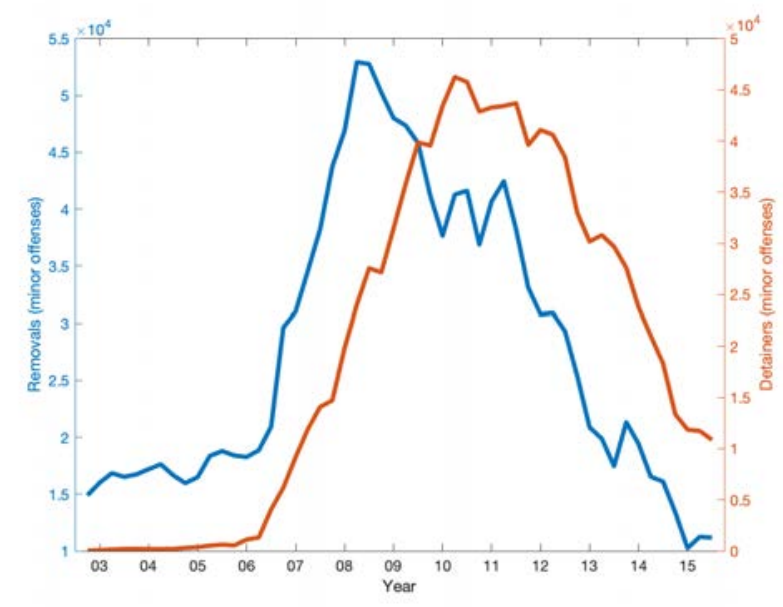

(a) Minor offenses

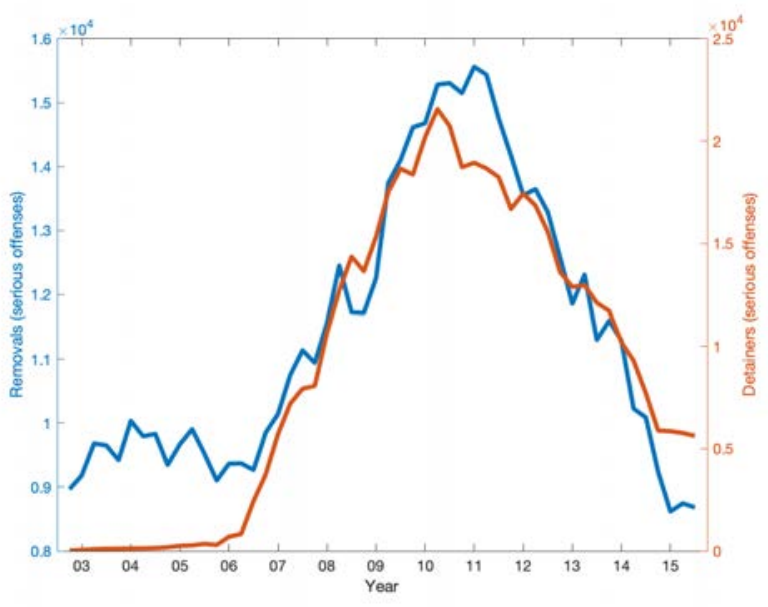

(b) Serious offenses

Figure 1: Number of Detainers and Removals, 2003-2015. Figure (a) shows the aggregate number of detainers issued (red) and removals (blue) for arrestees charged with minor (levels 2 and 3) offenses. Figure (b) shows the aggregate number of detainers issued (red) and removals (blue) for arrestees charged with serious (level 1) offenses. Data are aggregated at the quarterly level. Source: TRAC.

ICE field office about any relevant findings. ${ }^{20}$ The field office then decides whether or not to submit a detainer request to the local jail where the arrestee is being held. In this way, under Secure Communities immigration status verification became routine part of law enforcement. As a crucial first feature of the program, it effectively eliminated all local-level discretion over immigration status verification: the local level can no longer affect the likelihood that the federal level learns about the immigration status of an arrestee. ${ }^{21}$ This is in sharp contrast to the ample local discretion possible under CAP or $287(\mathrm{~g}){ }^{22}$

Once ICE officials have identified a person of interest being held at a local detention facility, they must decide whether or not to issue a detainer. Detainers are addressed to the local law enforcement agency, requesting to hold the arrestee in custody for up to an additional 48 hours. This gives ICE officers time to take the arrestee into custody. The detainer issuance decision is complex. ICE officials must evaluate all the information they have (and do not have) about the arrestee. This includes the severity of the offenses charged and any other prior criminal history, the individual's likelihood of being removed once under federal custody, and the availability of

\footnotetext{
${ }^{20} \mathrm{ICE}$ is organized geographically into 24 federal enforcement districts (see Figure B.2).

${ }^{21}$ Facing some challenges to this aspect of the policy (e.g., Santos v. Frederick County Board of Commissioners (2013), Doe v. Immigration and Customs Enforcement (2006)), DHS explicitly makes it clear that "a jurisdiction cannot choose to have the fingerprints it submits to the federal government processed only for criminal history checks" because "the sharing [of fingerprints] was ultimately between the FBI and DHS". (see Verini (2012) and Kalhan (2013).

${ }^{22}$ The only possibility here would be for the officers to not collect the fingerprints of an arrestee they believe may by illegally present in the country. This would constitute malpractice and would not allow the police to establish the criminal status of the individual in custody, making it impractical (Gulasekaram and Ramakrishnan (2015)). On the other hand, the arresting behavior of the police may have changed in response to the introduction of Secure Communities, which constitutes a first order source of selection which we will deal with below.
} 
resources required to deploy a team that picks up the individual in the local detention facility. ICE officers follow a series of priority guidelines issued by ICE directors. They are also likely to have strategic considerations in mind: issuing a detainer request effectively 'alerts' the local level of the federal level's interest in the arrestee. If ICE officers deem the locality immigrant friendly, they may expect local law enforcement to expedite the release of the arrestee in response to the detainer. Such complete discretion over the issuance of detainer requests is the second key feature of the institutional design of the program.

The main source of variation we exploit in the paper is the drastic change in the official priority guidelines for prosecutorial discretion undertaken by the Obama administration in the summer of 2011. The first two years of the Obama administration continued a trend of strengthened federal immigration enforcement, with increasing numbers of detainer requests and removals across the US. ${ }^{23}$ Increased federal enforcement led to pressure from local governments and immigration advocacy groups, which, together with the forthcoming presidential election, were key factors explaining the policy change. Figure 1 plots the aggregate trends in the number of detainers and removals by offense severity (see below), showing the striking reversal around mid 2011. The new policy guidelines, outlined in a series of memos by ICE director John Morton, were predicated upon refocusing federal efforts and resources away from the prosecution of unlawfully present immigrants accused of minor offenses or just immigration violations, and towards those accused of serious crimes. According to Morton,

"ICE must prioritize the use of its enforcement personnel, detention space, and removal assets to ensure... the agency's enforcement priorities, namely the promotion of national security, border security, public safety, and the integrity of the immigration system... Because the agency is confronted with more administrative violations than its resources can address, the agency must regularly exercise 'prosecutorial discretion',... the authority of an agency charged with enforcing the law to decide to what degree to enforce the law against a particular individual" (Morton (2011a)).

The memo goes on to specify which ICE officers are allowed to exercise discretion, and a long list of criteria for them to follow. Additional memos provided further instructions on the subject (Morton (2011b)). In practice, the Secure Communities program used a four-level classification for offenses. Level 1 being the most serious, includes convictions for homicide, kidnappings, sexual assault, terrorist activity among others. Levels 2 and 3 include convictions for less serious crimes such as burglary, theft, traffic offenses, small drug offenses, and immigration violations among others (for the full list of categories of offenses, see ICE (2008)). Level 4 includes individuals that have not been yet convicted. The new guidelines redirected federal enforcement towards level 1 offenses. Our empirical strategy below will rely on this distinction.

\footnotetext{
${ }^{23}$ Compared to the pre-program period, Secure Communities saw a tenfold increase in the number of detainers issued by ICE (Kalhan (2013)).
} 


\subsubsection{Second Step: The Local Level}

Local law enforcement is able to exercise discretion over immigration outcomes as well, but in the next stage of the process. Once ICE has submitted a detainer request, local law enforcement is free to decide whether to 'honor' it by holding the arrestee until pick up by ICE, or not to honor it by either releasing the arrestee before ICE shows up, or by refusing to hand over the immigrant to ICE. This margin of discretion is significant because at this stage of the process, localities have a considerable informational and strategic advantage over federal officials. Moreover, after some legal disputes, the courts made it clear that detainers are not binding, and constitute only suggestions of collaboration. ${ }^{24}$ Thus, the third key feature of Secure Communities is the complete discretion of the local level after a detainer has been issued.

This is also the stage at which the extent of preference alignment between the local and the federal levels is made manifest: because ICE moves first when deciding whether to issue a detainer or not, any arrestee for whom a detainer is issued is necessarily highly desired by the federal level, irrespective of ICE officers' beliefs about how the local level may react. This need not be the case for arrestees for whom ICE abstains from issuing a detainer; this set will include all arrestees ICE is uninterested in, and other arrestees which are of interest but for whom the agency issued no detainer based on strategic considerations. If the preferences of the local level are aligned with those of the federal level, local officials will be likely to honor the detainer request. Otherwise (i.e., the characteristics of the arrestee are such that the local level would rather not see this arrestee under ICE custody), we may expect the local officials not to honor the detainer. As a result, the rate of compliance with detainer requests will be informative about the extent of alignment of preferences between the local and federal levels.

Variation in local cooperation is partly driven by local preferences over the presence of illegally present immigrants. It also depends on the costs of compliance. First, holding arrestees for longer is expensive, and diverts resources from law enforcement towards immigration enforcement. Moreover, localities also expressed concern about how participation in immigration enforcement would erode community trust on law enforcement. Indeed, conflict over Secure Communities grew rapidly as the federal government rolled it across the US. Several advocacy groups such as the National Day Laborers Network organized a resistance movement, focused on crafting legislation and lobbying local governments. In its non-cooperation ordinance, for example, the Cook county, IL council argued:

\footnotetext{
${ }^{24}$ Several appeals and state supreme court rulings have affirmed the right of local level agencies to exercise discretion at this point under the anti-commandeering doctrine founded on the Tenth Amendment, making it clear that ICE detainers cannot be mandatory (See Galarza v. Szalczyk (2014), Jimenez-Moreno et al. $v$. Napolitano et al. (2014), Buquer v. City of Indianapolis (2011), or Printz v. United States (1997) among others). ICE officials themselves have acknowledged that detainers constitute only a collaboration suggestion. Moreover, some counties have argued that holding an arrestee who has not otherwise been charged with a crime, in response to a detainer request, may constitute a due process violation (Manuel (2012); Pham (2006)).
} 
“... it costs Cook county approximately $\$ 43,000$ per day to hold individuals 'believed to be undocumented' pursuant to ICE detainers, and Cook county can no longer afford to expend taxpayer funds to incarcerate individuals who are otherwise entitled to their freedom... having the sheriff of Cook county participate in the enforcement of ICE detainers places a great strain on our communities by eroding the public trust the sheriff depends on to secure the accurate reporting of criminal activity and to prevent and solve crimes..." (Cook county board of commissioners, Sept. 7, 2011)

Most of this legislation has the purpose of limiting the extent to which the local level collaborates in honoring ICE detainers. Some of the ordinances and regulations instruct local police to honor only detainers for arrestees charged with serious crimes. The best known example is California's TRUST Act, passed in 2013. In other cases, local police is instructed to never comply with any ICE detainer request. ${ }^{25}$

\subsubsection{Third Step: ICE Custody and Removal}

Arrestees in local detention facilities are taken into ICE custody in two ways. They may be picked up by ICE officers pursuant to a detainer request, which we refer to as the 'detainer track'. Or they may be picked up by ICE officers who show up to a local jail or prison unannounced in search for unlawfully present individuals. We refer to this as the 'direct track'. A key distinction between both tracks is that for arrestees with an issued detainer, the likelihood they are taken into ICE custody depends exclusively on the local level's decision on detainer compliance. For arrestees for whom no detainer was issued, both federal and local efforts will shape the likelihood of being taken into ICE custody. ${ }^{26}$ This distinction and availability of data from both tracks will be crucial for the identification strategy we lay down below.

In either case, individuals under ICE custody go on to a deportation proceeding involving immigration court. It is worth pointing out that under US law, immigration courts are not part of the judicial branch. Rather, they constitute a division within the Department of Justice, and thus, are part of the federal executive branch. As such, we may expect the outcomes at the removal stage to be correlated with the patterns of federal immigration enforcement earlier in the process, even though immigration courts are expected to apply the law uniformly and respect due process and fair treatment. Unlawfully present individuals under ICE custody are free to waive their right to an immigration proceeding, in which case they are directly removed. A host of legal aid organizations provide council to those who do not waive their right

${ }^{25}$ The following counties passed some variation of non-cooperation regulation: Santa Clara, CA, Cook, IL, Miami-Dade, FL, Newark, NJ, Champaign, IL, Amherst, MA, Berkeley, CA, Los Angeles, CA, Milwaukee, WI, New York, NY, Multanomah, OR, Alameda, CA, Orleans parrish, LA, San Francisco, CA, Sonoma, CA, San Bernardino, CA, Mesilla, NM, San Miguel, NM, Taos, NM, King, WA, Philadelphia, PA, Washington, DC. Connecticut also passed a TRUST Act in 2014 (Gulasekaram and Ramakrishnan (2015)).

${ }^{26}$ This will depend on the implicit or explicit negotiation between local and federal law enforcement at the time when ICE officers show up in a local detention facility. 
and are unable to hire private counsel. Although technically possible, the IIRIRA restricted considerably the possibility of appeals in the immigration court system, as it strips the federal courts of jurisdiction to hear legal challenges to deportation decisions (Zolberg (2006)). ${ }^{27}$

\section{Data Description}

We use two sets of data: First, detailed information on all cases of unlawfully present individuals along the immigration enforcement pipeline during the period of operation of Secure Communities. This includes counts of local law enforcement arrests of unlawfully present individuals, of detainer requests issued by ICE, of individuals under ICE custody, and of removals from the US. Second, data on county characteristics that may be relevant determinants of local preferences over immigration enforcement outcomes.

\subsection{Data Description and Sources}

\subsubsection{Data on the Immigration Enforcement Pipeline}

Our data on the immigration enforcement pipeline comes from two main sources. First, a series of Freedom of Information Act (FOIA) requests to DHS, from which we obtained data from the Secure Communities program at the county level, covering the period October 2008 to February 2015. These detailed data include the number of fingerprint submissions from local detention facilities, the number of matches to the DHS's IDENT database, the number of detainers issued by ICE, the number of individuals in ICE custody ${ }^{28}$, the number of removals, and the ICE level of priority based on crime severity. For our purposes, we will consider level 1 as serious crimes, and levels 2 and above as minor crimes. We use the number of fingerprint matches as our measure of local arrests of unlawfully present individuals. ${ }^{29}$ Second, we collected data from the Transactional Records Access Clearinghouse (TRAC) at Syracuse University. Based on several FOIA requests, TRAC has built updated record-by-record datasets of detainers, removals and Secure Communities removals with information from 2002 to the present. All datasets have information on the most serious crime conviction, priority level for ICE, country of birth, age, and sex of the immigrant.

\footnotetext{
${ }^{27}$ This was reaffirmed by the Supreme Court in 1999.

${ }^{28}$ More specifically, the information from these FOIAs report the number of arrests made by ICE and not the number of people under ICE custody. However, individuals arrested by ICE under the Secure Communities program are held in custody, so that under Secure Communities, ICE arrests and ICE custodies should coincide.

${ }^{29}$ Naturally, false positives can arise when ICE flags a US citizen by mistake. Similarly, false negatives can arise when ICE fails to flag an unlawfully present immigrant. The former are likely to establish their citizenship later, and the latter will not be subject of ICE prosecution so these cases will introduce little error on our counts of detainers, custodies, and removals. On the other hand, fingerprints from an arrestee may be submitted multiple times. We have no reason to believe such occurrences may be related to immigration enforcement concerns. We are unable to identify any such cases from these data.
} 
Combining these two sources, and aggregating the data at the county-semester level, we reconstruct measures by crime severity (serious and minor) of counts of arrests of unlawfully present individuals, detainers issued by ICE, individuals entered into ICE custody following a detainer request, and removed individuals under ICE custody for whom the federal agency issued a detainer request. The TRAC dataset allows us to assign the detainer requests to counties, and to establish whether a given removal followed a detainer request or not. Most importantly, this dataset allows us to assign ICE custody and removals cases to the detainer and the direct tracks (the data from DHS does not contain this information). We do the assignment by applying the TRAC-based shares of individuals under ICE custody or removed with detainers to the FOIA-based counts. Overall both sources agree, although we need to undertake some adjustments (described in Appendix C) in a subset of cases where inconsistencies arise.

In Table 1 we present descriptive statistics for the several stages of the immigration enforcement process. The table reports counts of events, where the unit of observation is the countysemester, and divide the data between the pre and post policy guidelines change. Panels A and $\mathrm{B}$ contain information on arrests tagged as minor offenses, of which the largest component is an immigration violation (without any other cited offense). Panels C and D contain information on arrests tagged as serious offenses. The number of observations in the pre guidelines regime is smaller than in the post guidelines change period for two reasons: first, the pre period covers five semesters, while the post period covers seven semesters. Second, enrollment into the Secure Communities program, albeit mandatory for the counties, happened gradually as ICE rolled out the program starting in October 2008. By January 2013 all US counties were enrolled, and by the time of the policy change in June 2011, more than 70 percent of the US population was living in counties enrolled in the program (see Figure B.1 in Appendix B). Naturally, the timing of enrollment into Secure Communities is correlated with key county characteristics. Particularly predictive is the share of Hispanics (see Cox and Miles (2013)). Indeed, DHS possibly targeted counties for enrollment as a function of its own objectives, so entry into the sample is an important source of selection that may be reflected in these tables. ${ }^{30}$

Throughout this paper we restrict attention to counties with an estimated share of undocumented immigrants above median (1 percent of the population), and thus, where there can be some federal-local conflict over immigration. Elsewhere immigration enforcement is not a locally salient issue, and we observe no variation in immigration outcomes. We construct a measure of the undocumented share in each county using three sources: the share of Hispanic non-citizens from the 2010 census, the number of tax returns filed without a social security number from Brookings ${ }^{31}$, and state-level estimates of illegally present population from Warren

\footnotetext{
${ }^{30}$ Neither Cox and Miles (2013) nor us find the county-level Democratic share to be predictive of Secure Communities activation after controlling for the Hispanic share.

${ }^{31}$ See https://www.brookings.edu/interactives/earned-income-tax-credit-eitc-interactive-and-resources/.
} 


\begin{tabular}{|c|c|c|c|c|c|}
\hline \multicolumn{6}{|c|}{ Minor offenses } \\
\hline Panel A: & \multicolumn{5}{|c|}{ 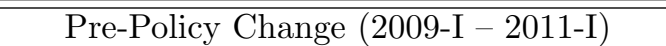 } \\
\hline & Mean & Std. dev. & Min. & Median & Max. \\
\hline Arrests & 265.8 & 1105.0 & 0 & 18 & 17268 \\
\hline Detainers & 61.2 & 236.8 & 0 & 4 & 4250 \\
\hline Custodies with detainer & 19.8 & 78.9 & 0 & 1 & 1175 \\
\hline Removals with detainers & 10.9 & 62.3 & 0 & 0 & 1027 \\
\hline Custodies without detainer & 37.6 & 166.7 & 0 & 2 & 3037 \\
\hline Removals without detainer & 31.8 & 155.8 & 0 & 0 & 2632 \\
\hline Observations & & & 1966 & & \\
\hline \multirow[t]{2}{*}{ Panel B: } & \multicolumn{5}{|c|}{ Post-Policy Change (2011-II - 2014-II) } \\
\hline & Mean & Std. dev. & Min. & Median & Max. \\
\hline Arrests & 113.0 & 578.6 & 0 & 14 & 17786 \\
\hline Detainers & 24.7 & 128.0 & 0 & 2 & 4131 \\
\hline Custodies with detainer & 8.21 & 56.5 & 0 & 0 & 2430 \\
\hline Removals & 4.06 & 6 & 0 & 0 & 1490 \\
\hline Custoc & 14.1 & 62.9 & 0 & 2 & 2666 \\
\hline Removals without detainer & 10.6 & 49.8 & 0 & 1 & 1852 \\
\hline Observations & & & 10040 & & \\
\hline \multicolumn{6}{|c|}{ Serious offenses } \\
\hline Panel C: & \multicolumn{5}{|c|}{ Pre-Policy Change (2009-I - 2011-I) } \\
\hline & Mean & Std. dev. & Min. & Median & Max. \\
\hline Arrests & 51.8 & 249.9 & 0 & 3 & 3746 \\
\hline Detainers & 13.5 & 69.0 & 0 & 0 & 1376 \\
\hline Custodies & 6.99 & 32.0 & 0 & 0 & 493 \\
\hline Remor & 3.32 & 22.8 & 0 & 0 & 403 \\
\hline Custoc & 14.6 & 84.4 & 0 & 0 & 1573 \\
\hline Removals without detainer & 11.9 & 77.7 & 0 & 0 & 1507 \\
\hline Observations & & & 2002 & & \\
\hline \multirow[t]{2}{*}{ Panel D: } & \multicolumn{5}{|c|}{ Post-Policy Change (2011-II - 2014-II) } \\
\hline & Mean & Std. dev. & Min. & Median & Max. \\
\hline Arrests & 52.0 & 303.7 & 0 & 4 & 9148 \\
\hline Detainers & 8.51 & 57.6 & 0 & 0 & 1999 \\
\hline Custodies with detainer & 3.54 & 29.5 & 0 & 0 & 1289 \\
\hline Removals with detainers & 1.66 & 16.9 & 0 & 0 & 734 \\
\hline Custodies without detainer & 7.02 & 37.4 & 0 & 1 & 1271 \\
\hline Removals without detainer & 5.60 & 33.6 & 0 & 0 & 1189 \\
\hline Observations & & & 10202 & & \\
\hline
\end{tabular}

Table 1: Descriptive Statistics for Immigration Enforcement Variables. The table presents summary statistics for the variables related to the immigration enforcement process under Secure Communities. We report counts of events aggregated at the county-semester level of observation. All variables in panels A and B refer to minor offenses (level 2-4 under ICE's classification). All variables in panels C and D refer to serious offenses (level 1 under ICE's classification). Panels A and C report summary statistics from 2009-I to 2011-I (before the June 2011 policy guidelines change). Panels B and D report summary statistics from 2011-II to 2014-II (after the June 2011 policy guidelines change). Arrests are measured as the number of fingerprint matches under Secure Communities. Our source for arrests, detainers, and ICE custodies is a FOIA to DHS. Our source for removals and for classifying ICE custodies between those with and without detainers is TRAC. 
and Warren (2012). We explain the details of our construction of this measure in Appendix C. In our sample, the mean undocumented share is 2 percent.

Table 1 illustrates the sequential filtering of arrests along the stages of the immigration enforcement pipeline, as well as its two 'branches': some individuals enter ICE custody following a detainer request (the detainer track), others do so in the absence of a detainer request (the direct track). Numbers are, naturally, larger for minor offenses. Falls in all variables are more pronounced for minor than for serious offenses, however, suggesting a shift away from enforcement over minor crimes, just as the policy guidelines intended. The tables also highlight the quantitative importance of the direct track in accounting for ICE custodies and removals.

\subsubsection{County Characteristics}

Lastly, we collected an array of county-level characteristics. We report summary statistics for all these variables in Panel A of Table B.1. To capture political preferences, we focus on the Democratic share of votes from the 2008 and 2012 presidential elections, using David Leip's atlas of US presidential elections. ${ }^{32}$ Besides the well established county-level correlations between local immigration enforcement regulations and Republican vote share, this relationship holds as well at the individual level: the 2015 American Trends Panel survey from the Pew Research Center, for example, found 71 percent of Republican voters believe that immigrants in the US make crime worse, compared to 34 percent of Democratic voters. ${ }^{33}$

We also use other demographic characteristics taken from the American Community Survey 2006-2010 waves, as sources of variation in preferences over immigration enforcement: population, Hispanic share, share of adults with a bachelors degree, and share of employment in the services sector. Finally, Table B.1 also reports summary statistics for whether the county is considered rural, the county's distance to its corresponding ICE district headquarters (see Figure B.2), and for the presence of 287(g) agreements (see Mayda (2006), for a discussion of the correlates of preferences over immigration policy).

\subsection{Patterns of Immigration and Law Enforcement Outcomes}

We now present descriptive results illustrating the main changes in the patterns of immigration enforcement outcomes following the policy guidelines change. Together, these results motivate our subsequent empirical strategy and modeling approach.

\footnotetext{
${ }^{32}$ See www.uselectionatlas.org.

${ }^{33}$ see http://www . pewresearch.org/fact-tank/2015/09/30/on-views-of-immigrants-americans-largely-split-along-party-lines/.
} 


\subsubsection{Immigration Enforcement}

Our purpose is to establish how immigration enforcement outcomes changed at each step along the immigration enforcement pipeline following the 2011 guidelines. Along the detainer track, we must assess at what rates local arrests translated into detainer requests, detainer requests translated into ICE custodies, and ICE custodies translated into removals. Along the direct track, we must assess at what rates local arrests without detainers translated into ICE custodies, and ICE custodies translated into removals. To do this in a flexible way, we focus on measuring the average slope of the relationship between the outcome of a given step of the process, $y_{c t}$, and its corresponding baseline, $B_{c t}$. For example, in the first step of the direct track, we are interested in how many detainer requests take place per unlawfully present immigrant in police custody. Estimating a fixed effects model, we can recover the average rate at which baseline events translate into outcome events, and also any differences in this rate between the pre and post policy guidelines change periods. Our models take the form

$$
y_{c t}=\alpha_{c}+\tilde{\alpha}_{t}+\beta B_{c t}+\gamma\left(B_{c t} \times \text { Guidelines }_{t}\right)+\mathbf{x}_{c t}^{\prime} \boldsymbol{\eta}+\epsilon_{c t}
$$

where $y_{c t}$ is an immigration enforcement outcome (detainers, ICE custodies, removals), and $B_{c t}$ is its corresponding baseline variable along the pipeline (arrests in the case of detainers, detainers in the case of ICE custodies, ICE custodies in the case of removals). $\mathbf{x}_{c t}$ is a vector of controls that includes log population, and interactions between time period dummies and each of the following time-invariant county characteristics: state dummies, ICE federal district dummies, undocumented share of the population, Hispanic share of the population, Democratic party share of the presidential vote, share of the population with a bachelors degree, a dummy for rural counties, and log distance to the corresponding ICE district headquarters. Periods when the baseline variable is zero do not contain information on the rate at which enforcement is happening, so the models here only include observations for which $B_{c t}>0$.

We estimate $\gamma$ for the different steps of the deportation process. We use a standard inverse hyperbolic sine transform over the $y_{c t}$ and $B_{c t}$ counts, so the coefficients can be interpreted approximately as elasticities. Notice, however, that these coefficients do not have a causal interpretation: they will reflect equilibrium changes in enforcement by federal and/or local levels in response to the change in the guidelines, as well as equilibrium changes in the composition of the pool of baseline cases along dimensions relevant for enforcement decisions. This heterogeneity represents characteristics of the arrestees over which the local and federal levels have differing preferences regarding their willingness to see a removal taking place. The pool of arrestees changes endogenously for several reasons. First, secular demographic patterns, such as the steady growth of the Central American population in this period, can impact the composition of the pool of arrestees. Second, keeping constant the composition of the pool of 


\begin{tabular}{|c|c|c|c|c|c|c|c|c|}
\hline \multirow[t]{4}{*}{ Panel A: } & \multicolumn{8}{|c|}{ Detainer Track } \\
\hline & \multicolumn{4}{|c|}{ Minor offenses } & \multicolumn{4}{|c|}{ Serious offenses } \\
\hline & $(1)$ & $(2)$ & $(3)$ & (4) & $(5)$ & $(6)$ & $(7)$ & (8) \\
\hline & Detainers & Custodies & Removals & Removals & Detainers & Custodies & Removals & Removals \\
\hline Arrests & $\begin{array}{c}0.614 \\
(0.028)\end{array}$ & & & $\begin{array}{c}0.187 \\
(0.025)\end{array}$ & $\begin{array}{c}0.275 \\
(0.031)\end{array}$ & & & $\begin{array}{c}0.005 \\
(0.024)\end{array}$ \\
\hline Arrests $\times$ Guidelines & $\begin{array}{l}-0.066 \\
(0.017)\end{array}$ & & & $\begin{array}{c}0.001 \\
(0.022)\end{array}$ & $\begin{array}{c}0.029 \\
(0.022)\end{array}$ & & & $\begin{array}{c}0.102 \\
(0.020)\end{array}$ \\
\hline Detainers & & $\begin{array}{c}0.648 \\
(0.030)\end{array}$ & & & & $\begin{array}{c}0.637 \\
(0.036)\end{array}$ & & \\
\hline Detainers $\times$ Guidelines & & $\begin{array}{l}-0.046 \\
(0.025)\end{array}$ & & & & $\begin{array}{l}-0.056 \\
(0.031)\end{array}$ & & \\
\hline Custodies & & & $\begin{array}{c}0.579 \\
(0.041)\end{array}$ & & & & $\begin{array}{c}0.287 \\
(0.046)\end{array}$ & \\
\hline Custodies $\times$ Guidelines & & & $\begin{array}{c}0.009 \\
(0.038)\end{array}$ & & & & $\begin{array}{c}0.136 \\
(0.039)\end{array}$ & \\
\hline Observations & 11269 & 8243 & 6294 & 11269 & 9656 & 5433 & 4010 & 9656 \\
\hline Adjusted $R^{2}$ & 0.90 & 0.84 & 0.84 & 0.80 & 0.86 & 0.83 & 0.82 & 0.81 \\
\hline \multirow[t]{4}{*}{ Panel B: } & \multicolumn{8}{|c|}{ Direct Track } \\
\hline & \multicolumn{4}{|c|}{ Minor offenses } & \multicolumn{4}{|c|}{ Serious offenses } \\
\hline & (1) & & $(2)$ & & $(3)$ & & (4) & \\
\hline & Custodies & & Removals & & Custodies & & Removals & \\
\hline Arrests (no detainer) & $\begin{array}{c}0.391 \\
(0.027)\end{array}$ & & $\begin{array}{c}0.297 \\
(0.032)\end{array}$ & & $\begin{array}{c}0.325 \\
(0.033)\end{array}$ & & $\begin{array}{c}0.163 \\
(0.036)\end{array}$ & \\
\hline Arrests (no detainer) $\times$ Guidelines & $\begin{array}{c}-0.088 \\
(0.020)\end{array}$ & & $\begin{array}{l}-0.028 \\
(0.024)\end{array}$ & & $\begin{array}{c}-0.053 \\
(0.025)\end{array}$ & & $\begin{array}{c}0.052 \\
(0.028)\end{array}$ & \\
\hline Observations & 10476 & & 10476 & & 8797 & & 8797 & \\
\hline Adjusted $R^{2}$ & 0.88 & & 0.87 & & 0.85 & & 0.85 & \\
\hline
\end{tabular}

Table 2: County Fixed Effects Models for the Steps of the Immigration Enforcement Process The table shows regression coefficients for panel fixed effects models for the different steps of the immigration enforcement process by type of arrest according to ICE's classification. All models include county fixed effects, semester fixed effects, log population, and interactions of semester fixed effects with the following time-invariant covariates: state dummies, federal enforcement district dummies, undocumented share of the population, Hispanic share of the population, Democratic party share, share of the population with a bachelors degree, a dummy for rural counties, and $\log$ distance to the corresponding ICE district office. Panel A presents results for the detainer track, while Panel B presents results for the direct track. Arrests correspond to the number of fingerprint matches under Secure Communities. Custodies and Removals in Panel A correspond to those for which a detainer was issued. Custodies and Removals in Panel B correspond to those for which no detainer was issued. Guidelines is a dummy variable indicating the semesters after the policy guidelines change under the Obama administration. All models exclude observations for which the baseline regressor is zero. Standard errors are robust to arbitrary heteroskedasticity, and clustered at the county level 
immigrants arrested, federal and local preferences over the deportability of different types of immigrants may change. For example, under the 2011 guidelines ICE prioritized immigrants without American-born children. Third, immigration enforcement itself can alter the composition of the pool of arrestees: it can undermine community collaboration with law enforcement relevant for efficient policing, and it can shift the supply of crime through both deterrence and incapacitation. For example, suppose the guidelines led to weakened local immigration enforcement, and that this improves policing efficiency, leading to higher apprehension rates for minor offenses. The pool of arrestees will become selected towards these kinds of offenses, which are on average less likely to be requested by ICE. Thus, in the regression of detainers on arrests, $\gamma$ will be negative partly as a result of weakened enforcement, and partly because the pool of arrestees endogenously shifted toward people over which ICE has little interest. Moreover, each step of the immigration enforcement process will generate selection in the downstream steps. This is especially clear when, for example, changes in the arrests-to-detainers stage lead to zero detainers, so that we no longer have information about enforcement rates in the detainers-to-custodies stage.

Because the new guidelines emphasized a shift in immigration enforcement from minor to serious offense cases, in Table 2 we report estimates of the models in equation (1) separately for these two categories. In columns 1-4 of panel A and columns 1-2 of panel B we report estimates for cases tagged as minor offenses. In columns 5-8 of panel A and columns 3-4 of panel B we report the corresponding estimates for cases tagged as serious offenses. All models we report include county fixed effects, the full battery of time (semester) fixed effects capturing the common trends we illustrated in Figure 1, all time-cross-state and time-cross-enforcement district fixed effects, and all interactions between time fixed effects and county characteristics. We believe this leaves changes in local and federal enforcement intensities, and changes in the composition of the pool of individuals moving along the immigration enforcement pipeline as the only remaining trends in relevant unobservables. The standard errors are all clustered at the county level and robust to arbitrary heteroskedasticity.

\section{Minor Offenses}

Along the detainer track, column 1 of panel A show a significant coefficient on the interaction term: in the post guidelines change period, the rate at which arrests for minor offenses translate into detainer requests for the average county falls by more than 10 percent of the pre guidelines rate $(-0.066($ s.e $=0.017)$ relative to a baseline of $0.614($ s.e. $=0.028)$ ). After controlling for the vast array of trends along observables which we include in these models, this quantitatively large fall suggests that ICE did comply with the policy guidelines, by weakening enforcement towards minor crimes through the channel of reduced numbers of detainer requests. 
The next column reports estimates for the second step along the detainer track, where the local level has discretion to comply or not with the detainer requests. In the post-guidelines period, detainers also translate into ICE custodies at a smaller rate on average $(-0.046$, s.e $=0.025$ relative to a baseline of 0.64 , s.e $=0.03$ ), although this difference is significant at the ten percent level only. This less precisely estimated fall may be masking heterogeneous responses to the federal enforcement change, across counties with different preferences. It may also be driven by a significant change in the pool of unlawfully present individuals: although these are people detained for minor offenses, the federal level may already have screened out the least severe of these offenses when reducing the issuance of detainers.

Column 3 then moves towards the last step of the immigration enforcement process, where only immigration courts with perhaps some influence by ICE determine the rate at which unlawfully present immigrants in ICE custody are removed. We do not find this rate to be any different between the pre and the post guidelines periods. On the one hand, the immigration courts, which are also part of the federal branch, may have weakened their enforcement standards as well. On the other, the pool of individuals reaching the immigration court proceedings stage in the post-guidelines period may be composed of individuals with characteristics more favorable to deportation. As a complement to these results, column 4 reports the compounded effects implied by the full detainer track pipeline, looking at changes in the rate at which arrests of unlawfully present immigrants translate into final removals. Removals per arrest are indistin-

guishable between pre and post-guideline change periods for the average county. Considering how quantitatively large the federal policy change was, this suggests strong selection forces at play over the pool of people being taken through the immigration enforcement pipeline.

Columns 1 and 2 in panel B report analogous results for the direct track, still among cases of unlawfully present immigrants arrested for minor offenses. In this track, the post-guidelines change period also saw a large and precisely estimated fall in the rate at which arrests translate into ICE custodies $(-0.09$, s.e. $=0.02)$. This fall is proportionally larger than the one observed along the direct track.

\section{Serious Offenses}

In columns 5-8 of panel $\mathrm{A}$ we move on to present the main patterns on immigration cases tagged as serious offenses. The 2011 policy guidelines advocated a strong shift towards immigration enforcement of serious offenses cases. Column 5 reports a positive coefficient on the differential rate at which local arrests translate into ICE detainer requests, but the estimate is not statistically significant $(0.029$, s.e. $=0.022)$. The large fall in the raw numbers of detainers issued by ICE, which we illustrated in Figure 1 above, makes this finding particularly striking. It suggests large changes in the composition of the pool of illegally present individuals arrested 
for serious crimes.

While similar to the patter for minor offenses, in the post-guidelines period the rates at which detainers translate into ICE custodies are smaller (see column 6). In contrast, at the ICE custody stage we observe a large post-guidelines increase of around 50 percent in the rate at which individuals are removed (see column 7 , where the coefficient on the interaction term is 0.136 , s.e. $=0.039$ compared to a baseline coefficient of 0.287 , s.e. $=0.046$ ). A similarly large change at the ICE custody stage can be seen along the direct track. In column 3 of panel B we show that along the direct track, on average each arrest led to less ICE custodies after the guidelines were issued: despite this, each arrest led to more removals in the postguidelines period. Part of this pattern may be driven by a strongly selected pool of arrestees with characteristics highly amenable to deportation, and part by increased enforcement across the board at the immigration court stage.

A comparison between the detainer and no detainer tracks for serious offenses also suggests an enforcement response from the local level. If federal enforcement behaved similarly along both the detainer and the direct tracks, then the lower rates at which detainers and arrests translate into ICE custodies suggest a resistance response by the local level to the shift in enforcement towards serious crimes. Moreover, the local level is likely to have resisted the removal of the least serious among these serious offenses cases. This has a screening effect, selecting the pool of those who reach the immigration court stage towards individuals the immigration courts are eager to remove.

\section{A Model of the Immigration Enforcement Pipeline}

Following our discussion above, we now present a model of the immigration enforcement process under Secure Communities. The model will allow us to disentangle the three key sources of variation in the patterns of immigration enforcement outcomes we described in section 3: local enforcement, federal enforcement, and selection in the composition of the pool of unlawfully present immigrants moving along the immigration enforcement pipeline. It explicitly models how arrested individuals are filtered along this pipeline, and captures the key features within its different stages we highlighted above as critical for our empirical strategy. Most importantly, by incorporating time-varying unobserved heterogeneity in the composition of the pool of arrested unlawfully present individuals, the model allows for misalignment of preferences over removals between the federal and the local levels. Because the 2011 change in policy guidelines explicitly proposed directing federal enforcement efforts towards arrestees accused of serious crimes, we condition the immigration enforcement process on the (observed to us) crime severity, effectively allowing both the federal and the local levels to choose different intensities of immigration enforcement towards serious and minor offenses. 


\subsection{The Immigration Enforcement Process}

Arrested unlawfully present immigrants vary in observed and unobserved (to us) characteristics. Conditional on their observed characteristics, most prominently the seriousness of the offense for which they were arrested, the local and federal levels may agree or disagree on whether the individual should be high or low priority for removal. Because the relevant conflict between local and federal levels revolves around whether a given individual be removed, the table at the top of Figure 2 fully describes the distribution of the relevant unobserved heterogeneity in the pool of arrestees in a given county and time period. ${ }^{34} \pi^{L \ell}$ is the fraction of arrestees who are low priority for ICE $(L)$ and low priority for the county $(\ell)$, while $\pi^{H h}$ is the fraction of arrestees who are high priority for both $\operatorname{ICE}(H)$ and the county $(h)$. The higher these fractions, the more aligned the preferences of the federal and the local level. In contrast, $\pi^{L h}$ is the fraction of arrestees whom ICE is not interested in removing $(L)$, but whom the local level would prefer were removed $(h) . \pi^{H \ell}$ is the fraction of arrestees whom ICE would like to remove $(H)$, but the local level would not want to see removed $(\ell)$. The higher these fractions, the more misaligned the preferences of the federal and the local level.

Our detailed knowledge of the immigration enforcement pipeline allows us to track how the pool of arrestees is filtered along the process itself. For our purposes it will be important to distinguish between two possible "tracks" along which an unlawfully present arrestee may move along the process. This will allow us to separately distinguish the federal and local immigration enforcement efforts.

\subsubsection{The Detainer Track}

Along the first track, which takes place through the Secure Communities program, the ICE district office is automatically informed about the arrest of an unlawfully present individual, and decides whether to issue a detainer. Recall that under Secure Communities the local level (the jail or prison where the individual is under arrest) has no discretion over whether it reports the presence of the arrestee to ICE, as fingerprints are automatically sent to ICE by the FBI. Detainers are not issued for type $L$ arrestees: $\mathbb{P}($ Detainer $\mid L)=0^{35}$. For type $H$ arrestees, ICE issues a detainer with a probability that depends on the current intensity of federal immigration enforcement: $\mathbb{P}($ Detainer $\mid H)=f$. Conditional on observed characteristics, this probability is constant within time periods (in our baseline empirical application, this will correspond to semesters). The Obama guidelines introduced in 2011, for example, directly changed $f$.

Assumption 1. ICE does not condition on the local level preference type $\{h, \ell\}$.

\footnotetext{
${ }^{34}$ All variables are indexed by county and time period $(c, t)$. Because it does not lead to any confusion, we omit those indices in this subsection.

${ }^{35}$ Notice that this is not an assumption. It simply corresponds to what the definition of an $L$ type is.
} 
Pool of Arrestees

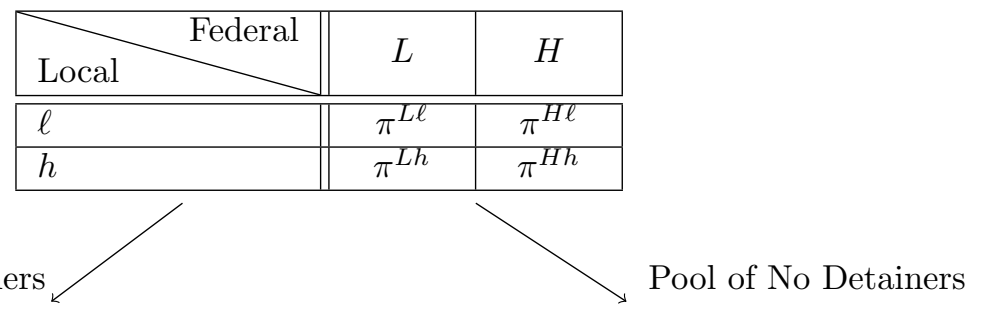

Pool of Detainers

\begin{tabular}{|l||c|}
\hline Local Federal & $H$ \\
\hline \hline$\ell$ & $\pi^{H \ell} /\left(\pi^{H \ell}+\pi^{H h}\right)$ \\
\hline$h$ & $\pi^{H h} /\left(\pi^{H \ell}+\pi^{H h}\right)$ \\
\hline
\end{tabular}

Pool of ICE Custodies

\begin{tabular}{|l||c|}
\hline Local & $H$ \\
\hline \hline$\ell$ & $g \pi^{H \ell} /\left(g \pi^{H \ell}+\pi^{H h}\right)$ \\
\hline$h$ & $\pi^{H h} /\left(g \pi^{H \ell}+\pi^{H h}\right)$ \\
\hline
\end{tabular}

Pool of Removals

\begin{tabular}{|l||c|}
\hline Local Federal & $H$ \\
\hline \hline$\ell$ & $q^{\ell} g \pi^{H \ell} /\left(q^{\ell} g \pi^{H \ell}+q^{h} \pi^{H h}\right)$ \\
\hline$h$ & $q^{h} \pi^{H h} /\left(q^{\ell} g \pi^{H \ell}+q^{h} \pi^{H h}\right)$ \\
\hline
\end{tabular}

\begin{tabular}{|l||c|c|}
\hline Local Federal & $L$ & $H$ \\
\hline \hline$\ell$ & $\frac{\pi^{L \ell}}{1-\left(\pi^{H h}+\pi^{H \ell}\right) f}$ & $\frac{(1-f) \pi^{H \ell}}{1-\left(\pi^{H h}+\pi^{H \ell}\right) f}$ \\
\hline$h$ & $\frac{\pi^{L h}}{1-\left(\pi^{H h}+\pi^{H \ell}\right) f}$ & $\frac{(1-f) \pi^{H h}}{1-\left(\pi^{H h}+\pi^{H \ell}\right) f}$ \\
\hline
\end{tabular}

Pool of ICE Custodies

\begin{tabular}{|l|c|}
\hline Local Federal & $H$ \\
\hline \hline$\ell$ & $k \pi^{H \ell} /\left(k \pi^{H \ell}+\pi^{H h}\right)$ \\
\hline$h$ & $\pi^{H h} /\left(k \pi^{H \ell}+\pi^{H h}\right)$ \\
\hline
\end{tabular}

Pool of Removals

\begin{tabular}{|l||c|}
\hline Local & $H$ \\
\hline \hline$\ell$ & $q^{\ell} k \pi^{H \ell} /\left(q^{\ell} k \pi^{H \ell}+q^{h} \pi^{H h}\right)$ \\
\hline$h$ & $q^{h} \pi^{H h} /\left(q^{\ell} k \pi^{H \ell}+q^{h} \pi^{H h}\right)$ \\
\hline
\end{tabular}

Figure 2: The Immigration Enforcement Pipeline. The figure shows a flow chart of the immigration enforcement pipeline together with the distribution of unobserved heterogeneity along the process. The left side of the chart illustrates the detainer track. The right side of the chart illustrates the direct track. $L$ and $H$ represent low and high priority arrestees for the federal level. $\ell$ and $h$ represent low and high priority arrestees for the local level. The $\pi$ 's represent the shares of each type in the population of arrestees. $f$ is the probability of detainer issuance by the federal level, $g$ is the probability ICE custody following a detainer, $k$ is the probability of ICE custody in the absence of detainer, and $q^{\ell}, q^{h}$ are the probabilities of removal from the US for individuals in ICE custody of types $H \ell$ and $H h$.

This is a weak assumption. First, recall it is conditional on the seriousness of the alleged offense. Moreover, from the point of view of ICE, all $H$ types are on average equally desirable irrespective of their local type $h$ or $\ell$-this is precisely the definition of an $H$ type-. $\{h, \ell\}$ are residual characteristics of the arrestee directly relevant for the local level only. Assumption 1 thus amounts to ruling out commitment by ICE, at the stage in which it is informed about a person of interest and must decide to act on this information. ${ }^{36}$ It follows that

$$
\mathbb{P}(\text { Detainer } \mid \text { Arrest })=\left(\pi^{H \ell}+\pi^{H h}\right) f \equiv P_{D \mid A}
$$

\footnotetext{
${ }^{36}$ For example, ICE agents could have an ex-ante incentive to promise the local level they will not issue detainers for individuals ICE believes the local level would not want to remove, in exchange for local-level collaboration in other dimensions. When a fingerprint match arrives, we believe it unlikely that ICE agents will be able to keep such a promise.
} 
We observe $P_{D \mid A}$ at the county $\times$ time period level. Equation (2) shows that $P_{D \mid A}$ can vary over time either through changes in federal immigration enforcement $f$, or through changes in the composition of the pool of arrestees. Even when comparing the pre-guidelines period to the post-guidelines period, we cannot directly attribute changes in the rate at which arrests translate into detainer requests to changes in federal enforcement; the composition of the pool of local arrest may have changed as well, for example if the arresting behavior of local law enforcement or the elasticity of crime by unlawfully present immigrants changed in response or in anticipation to the changes in federal law enforcement. Key to our empirical strategy will be to disentangle the changes observed after the introduction of the guidelines between selection (changes in the distribution of arrests), and enforcement.

After ICE has issued detainers, the resulting distribution of detainers can be represented by the second table to the left of Figure 2. This distribution does not depend on $f$ because the federal level does not select detainers based on the local level preferences. It also does not have any $L$ types, which the federal level has filtered out. At this point along the pipeline, the county-level law enforcement authorities must decide whether to honor the detainer. $H h$ types are arrestees the county is happy to hand in to ICE, so $\mathbb{P}(\mathrm{ICE}$ Custody|Detainer, $H h)=1$. In contrast, there is conflict over the $\ell$ types. The county does not want to comply with such detainer requests. Thus, the county's willingness to enforce immigration can be captured by the conditional probability of honoring such detainers: $\mathbb{P}(\mathrm{ICE}$ Custody|Detainer, $H \ell)=g$. As such, the probability of observing detainers translate into ICE custodies is

$$
\mathbb{P}(\mathrm{ICE} \text { Custody } \mid \text { Detainer })=1 \times \frac{\pi^{H h}}{\pi^{H \ell}+\pi^{H h}}+g \times \frac{\pi^{H \ell}}{\pi^{H \ell}+\pi^{H h}} \equiv P_{C \mid D}
$$

We also observe $P_{C \mid D}$ at the county $\times$ time period level. $P_{C \mid D}$ can vary over time either because among $H$ types the pool of arrestees is shifting between $h$ and $\ell$ types, or because local immigration enforcement $g$ is changing, or both: changes in the rate at which detainers translate into ICE custodies may be driven by changes in local enforcement or selection. Crucially, the full discretion of the local level in honoring detainers provides us with an exclusion restriction: $P_{C \mid D}$ does not vary with federal immigration enforcement $f$.

As a result of this sequential filtering induced by the issuance of detainers by ICE and the subsequent compliance decision of the county, the composition of the resulting pool of arrestees in ICE custody is described by the third table to the left in Figure 2. Once in ICE custody, the removal decision depends on an interaction of efforts made by ICE and the immigration courts. At this point, every individual in custody is an $H$ type, so from ICE's point of view all are equally removable. Preferences of the court system, however, may be somewhat misaligned with ICE's, so removal rates may vary with the remaining source of unobserved heterogeneity, namely the preferences of the local level. Of course, at this stage the county has no further 
influence in the removal decision.

For $j \in\{\ell, h\}$, we denote by $q^{j}=\mathbb{P}$ (Removal|ICE Custody, Detainer, $j$ ) the probability of removal of an $H j$ type in custody for whom a detainer was issued. Both of these conditional probabilities will in general be interior because the courts' preferences may not perfectly align with either the local or the federal level's preferences. They will depend on the intensity of federal enforcement, and on the preferences of the district courts. They will not, however, depend on local level immigration enforcement, which constitutes an additional exclusion restriction implied by the immigration enforcement process. We can express the conditional probability of a removal among those individuals in ICE custody for whom a detainer was issued as

$$
\mathbb{P}(\text { Removal|ICE Custody, Detainer })=q^{\ell} \frac{g \pi^{H \ell}}{g \pi^{H \ell}+\pi^{H h}}+q^{h} \frac{\pi^{H h}}{g \pi^{H \ell}+\pi^{H h}} \equiv P_{R \mid C, D}
$$

We also observe this conditional probability. It will vary with court and federal immigration enforcement (through $\left(q^{\ell}, q^{h}\right)$ ), with local immigration enforcement (through $g$ ), and with the distribution of types in the pool of arrestees. Equation (4) reveals an important pattern of selection induced by the structure of the immigration enforcement process: if the courts' preferences are strongly aligned with the county's preferences $\left(q^{h}>q^{\ell}\right)$, then all else equal, a fall in local immigration enforcement, $g$, will increase $P_{R \mid C, D}$ even if the distribution of types and court and federal enforcement remain constant. The reason is a screening effect from local immigration enforcement over the pool of people in ICE custody: when the county reduces enforcement, the share of $H \ell$ individuals handed into ICE custody falls. The pool of custodies becomes selected towards $H h$ individuals, which courts are more willing to remove.

\subsubsection{Partial Identification from the Detainer Track}

Our analysis allowed us to relate three observable conditional probabilities, $\left(P_{D \mid A}, P_{C \mid D}, P_{R \mid C, D}\right)$ to four enforcement intensity rates $\left(f, g, q^{\ell}, q^{h}\right)$ and the fraction of $H \ell$ and $H h$ types in the pool of arrested immigrants. We can conveniently re-express them in the following way:

$$
\begin{aligned}
& x_{1} \equiv P_{D \mid A}=\left(\pi^{H \ell}+\pi^{H h}\right) f \\
& x_{2} \equiv P_{D \mid A} P_{C \mid D}=\left(g \pi^{H \ell}+\pi^{H h}\right) f \\
& x_{3} \equiv P_{D \mid A} P_{C \mid D} P_{R \mid C, D}=\left(q^{\ell} g \pi^{H \ell}+q^{h} \pi^{H h}\right) f
\end{aligned}
$$

Equations (5)-(7) provide us with two independent relationships between these observable probabilities and unobservable enforcement rates: Taking the ratio of equations (5) and (6) for county-time periods with a positive number of ICE custodies, 


$$
\frac{\pi^{H h}}{\pi^{H \ell}}=\frac{x_{2}-x_{1} g}{x_{1}-x_{2}} .
$$

Taking the ratio of (6) to (7) for county-time periods with a positive number of removals,

$$
\frac{\pi^{H h}}{\pi^{H \ell}}=\frac{\left(x_{3}-x_{2} q^{\ell}\right) g}{x_{2} q^{h}-x_{3}} .
$$

Equating these ratios we obtain the following relationship between $\left(g, q^{\ell}, q^{h}\right)$ and observables:

$$
g=\frac{x_{3}-x_{2} q^{h}}{x_{3}-x_{2} q^{\ell}-x_{1}\left(q^{h}-q^{\ell}\right)}
$$

Crucially, this relationship does not depend on the composition of the pool of arrestees $\left(\pi^{H h}, \pi^{H \ell}\right)$. By exploiting the variation across steps of the immigration enforcement process under the detainer track, we are able to obtain a relationship between local and court-enforcement probabilities that is purged of any selection issues. This is convenient because $\left(\pi^{H h}, \pi^{H \ell}\right)$ is unobserved and can be correlated with the enforcement choices at all the different stages. The manifold described by equation (10) provides a partial identification set for the three probabilities, provided that $x_{1}, x_{2}, x_{3}>0$. Finally, notice also that the ratio $\pi^{H h} / \pi^{H \ell}$ is a measure of the extent of preference alignment between the federal and the local levels. From equation (8), if we can recover $g$, we will also have recovered the preference alignment ratio non-parametrically.

\subsubsection{The Direct Track}

Parallel to the Secure Communities program, which relies on the issuance of detainers and local-level collaboration, ICE also directly visits jails and prisons attempting to directly bring unlawfully present individuals into custody. The Criminal Alien Program (CAP) is one of the main enforcement vehicles through which these efforts are implemented. By its very nature, this track is much less structured than the detainer track. As a result, we will need to make a few additional assumptions about the process. In the first place, we will assume that the ICE district office first considers whom to issue detainer requests for. The 'direct track' is possibly employed over those for whom no detainer was issued. Recall that resource and political economy constraints limit the extent to which ICE issues detainers towards $H$ types. However, it may still desire to take some of the remaining $H$ types into custody through other means.

Assumption 2. ICE employs the direct track over arrestees for whom no detainers were issued.

This is effectively a timing assumption. Under Assumption 2, the leftover pool of arrested individuals over which the direct track may apply can be represented by the distribution in 
the second table to the right of Figure 2. Similar to the detainer track, only $H$ types are at play because ICE has no interest over $L$ types. Although ICE and the county have aligned preferences over the $H h$ types, ICE has limited resources and will in general not be undertaking visits to all prisons continually. We will call $v^{d}$ the district level probability that ICE visits a jail or prison. Conditional on a visit, the local level will want to collaborate over any $H h$ types requested. Thus, unconditionally, $\mathbb{P}(\mathrm{ICE}$ Custody $\mid$ No Detainer, $H h)=v^{d}$. In contrast, the local level may attempt to resist handing over $H \ell$ arrestees. We will call $k$ the probability that an $H \ell$ type is successfully taken into ICE custody conditional on a visit. Thus, unconditionally, $\mathbb{P}(\mathrm{ICE}$ Custody $\mid$ No Detainer, $H \ell)=v^{d} k$. As such,

$$
\mathbb{P}(\mathrm{ICE} \text { Custody } \mid \text { No Detainer })=v^{d} \frac{(1-f) \pi^{H h}}{1-\left(\pi^{H h}+\pi^{H \ell}\right) f}+v^{d} k \frac{(1-f) \pi^{H \ell}}{1-\left(\pi^{H h}+\pi^{H \ell}\right) f} \equiv P_{C \mid N D}
$$

In general $k$ will depend on both federal and local-level immigration enforcement efforts, and thus, should be correlated with $f$ and $g . P_{C \mid N D}$ is observable. It varies with federal immigration enforcement efforts (through $v^{d}, k$, and $f$ ), with local immigration enforcement efforts (through $k$ ), and with the composition of types in the population of arrestees. As a result of this filtering, the resulting pool of individuals in ICE custody from the direct track is represented by the third table to the right of Figure 2. This distribution does not depend on $v^{d}$ because the likelihood of a prison visit applies equally for both $h$ and $\ell$ types. Once in ICE custody, ICE and the court system determine whether these individuals are deported. Our last substantial assumption will be that once under ICE custody, conditional on observables and type $\{h, \ell\}$, the track through which the arrestee reached ICE custody is irrelevant for the removal decision:

Assumption 3. The probability of removal conditional on being under ICE custody does not depend on the track. For $j \in\{h, \ell\}$,

$$
\mathbb{P}(\text { Removal } \mid I C E \text { Custody, Detainer }, j)=\mathbb{P}(\text { Removal } \mid \text { ICE Custody, No Detainer, } j) \equiv q^{j} \text {. }
$$

We believe assumption 3 is very weak. Once in ICE custody, all unlawfully present individuals are $H$ types that federal law enforcement is interested in removing. The submission of a detainer is likely to signal a special interest of ICE in the unlawfully present individual. Conditional on crime severity, however, it is unclear that the courts would want to discriminate between people already in federal custody simply because they landed into ICE custody with the use of a detainer or not. Moreover, recall from section 3 that both detainer and direct tracks exhibit very similar patterns of change in the rates at which ICE custodies translate into removals, suggesting similar behavior by the immigration courts. Under this assumption, we 
can express the probability of a removal conditional on being in ICE custody as

$$
\mathbb{P}(\text { Removal|ICE Custody, No Detainer })=q^{\ell} \frac{k \pi^{H \ell}}{k \pi^{H \ell}+\pi^{H h}}+q^{h} \frac{\pi^{H h}}{k \pi^{H \ell}+\pi^{H h}} \equiv P_{R \mid C, N D}
$$

The probability in equation (12) is observable as well, and varies with court enforcement through $\left(q^{\ell}, q^{h}\right)$-, with federal enforcement -through $\left(q^{\ell}, q^{h}\right)$, and $k$-, with local enforcement -through $k$-, and with changes in the distribution of types.

\subsubsection{Partial Identification from the Direct Track}

Our analysis of the immigration enforcement pipeline along the direct track allows us to relate two conditional probabilities $\left(P_{C \mid N D}, P_{R \mid C, N D}\right)$ to five enforcement intensity rates $\left(v^{d}, f, k, q^{\ell}, q^{h}\right)$, and the fraction of $H \ell$ and $H h$ types in the pool of unlawfully present individuals arrested by local law enforcement. We can re-write these probabilities as:

$$
\begin{aligned}
& y_{1} \equiv P_{C \mid N D}=v^{d} \frac{1-f}{1-\left(\pi^{H h}+\pi^{H \ell}\right) f}\left[k \pi^{H \ell}+\pi^{H h}\right] \\
& y_{2} \equiv P_{R \mid C, N D} P_{C \mid N D}=v^{d} \frac{1-f}{1-\left(\pi^{H h}+\pi^{H \ell}\right) f}\left[q^{\ell} k \pi^{H \ell}+q^{h} \pi^{H h}\right]
\end{aligned}
$$

Taking their ratio for observations where the number of removals is not zero, dividing both numerator and denominator by $\pi^{H \ell}$, and using equation (8), we can replace for the preference alignment ratio $\pi^{H h} / \pi^{H \ell}$, and solve for $k$ :

$$
k=\frac{\left(x_{2}-x_{1} g\right)}{\left(x_{1}-x_{2}\right)} \frac{\left(y_{1} q^{h}-y_{2}\right)}{\left(y_{2}-y_{1} q^{\ell}\right)}
$$

Equation (15) shows that $k$ is completely pinned down by the observables of both detainer and direct tracks, and $\left(g, q^{h}, q^{\ell}\right)$. Finally, dividing equation (13) through by equation (5) and replacing for $k$ from equation (15), we can again eliminate the preference alignment ratio and obtain a relationship between $v^{d}, f, g, q^{h}$ and $q^{\ell}$ :

$$
v^{d}\left(\frac{1-f}{f}\right)=\frac{\left(1-x_{1}\right)(1-g)}{\left(x_{2}-x_{1} g\right)} \frac{\left(y_{2}-y_{1} q^{\ell}\right)}{\left(q^{h}-q^{\ell}\right)}
$$

Equation (16) shows that the inverse odds ratio of federal enforcement $f$ is pinned down up to scale by the observables of both detainer and direct tracks, and $\left(g, q^{h}, q^{\ell}\right)$. The comparison of rates at which individuals with and without detainers in ICE custody are removed contains the information that allows us to learn about $f$. 


\section{$5 \quad$ Identification and Estimation}

\subsection{Immigration Enforcement Probabilities}

The detainer and direct tracks provide us for each county-time period $(c, t)$, with three relationships (equations (10), (15), (16)) between observable conditional probabilities of transition across stages of the immigration enforcement pipeline, $\left(x_{1 c t}, x_{2 c t}, x_{3 c t}, y_{1 c t}, y_{2 c t}\right)$, and the six key unobserved immigration enforcement probabilities $\left(g_{c t}, f_{c t}, k_{c t}, q_{c t}^{\ell}, q_{c t}^{h}, v_{t}^{d}\right)$. Crucially, our strategy has allowed us to purge these relationships from the composition of the pool of arrestees $\left(\pi_{c t}^{H h}, \pi_{c t}^{H \ell}\right)$ period by period, so even changes over time in what constitutes a high or low priority individual for the federal or local levels are controlled for. When allowing for unobserved preference misalignment, the structure of the immigration enforcement process and the observed data allow us to control for selection, but it does not provide enough information to non-parametrically identify each enforcement probability separately. However, equations (10), (15), and (16) do pin down $g_{c t}, k_{c t}$ and $v_{t}^{d}\left(1-f_{c t}\right) / f_{c t}$ for any pair $\left(q_{c t}^{h}, q_{c t}^{\ell}\right)$. Moreover, for any sequence $\left\{g_{c t}\right\}_{t=1}^{T}$, we recover non-parametrically the time series of preference alignments $\left\{\pi_{c t}^{H h} / \pi_{c t}^{H \ell}\right\}_{t=1}^{T}$ using equation (8). We now characterize the identified set for $\left(q_{c t}^{h}, q_{c t}^{\ell}\right)$ :

Proposition 1. Suppose that $x_{1 c t}>x_{2 c t}>x_{3 c t}>0$ and $y_{1 c t}>y_{2 c t}>0$, and define $\underline{m} \equiv$ $\min \left\{x_{3 c t} / x_{2 c t}, y_{2 c t} / y_{1 c t}\right\}, \bar{m} \equiv \max \left\{x_{3 c t} / x_{2 c t}, y_{2 c t} / y_{1 c t}\right\}$, and $\tilde{q}=\left(x_{1 c t} y_{2 c t}-x_{3 c t} y_{1 c t}\right) / y_{1 c t}\left(x_{1 c t}-\right.$ $\left.\left.x_{2 c t}\right)\right)$. The observed vector of conditional probabilities $\mathbf{w}_{c t}=\left(x_{1 c t}, x_{2 c t}, x_{3 c t}, y_{1 c t}, y_{2 c t}\right)$ for a given county-period is consistent with any pair $\left(q^{h}, q^{\ell}\right) \in \mathcal{R}\left(\mathbf{w}_{c t}\right)$, where $\mathcal{R}\left(\mathbf{w}_{c t}\right)$ is given by:

$$
\begin{gathered}
\mathcal{R}\left(\mathbf{w}_{c t}\right)=\mathcal{R}_{1} \cup \mathcal{R}_{2}, \\
\mathcal{R}_{1}=\left\{\left(q^{h}, q^{\ell}\right): q^{h}<\underline{m}, \text { and } q^{\ell}>\max \{\bar{m}, \tilde{q}\}\right\} \\
\mathcal{R}_{2}=\left\{\left(q^{h}, q^{\ell}\right): q^{h}>\bar{m}, \text { and } q^{\ell}<\min \{\underline{m}, \tilde{q}\}\right\} .
\end{gathered}
$$

Proof. See Appendix A.

The result in Proposition 1 follows from jointly imposing all of the constraints relating observed moments to unobserved probabilities. This includes the three relationships in equations (10), (15), and (16) implied by the immigration enforcement pipeline, together with all probabilities lying inside the unit interval. Each identified set has the same geometric structure, which we illustrate in Figure 3: two disjoint rectangles, one above and one below the 45 degree line. The shape of the identified set illustrates the reason for the lack of non-parametric point identification of the enforcement probabilities from the immigration pipeline alone: observed conditional probabilities will in general be consistent with a high removal rate for $\ell$ types and a low removal rate for $h$ types, or vice versa. 


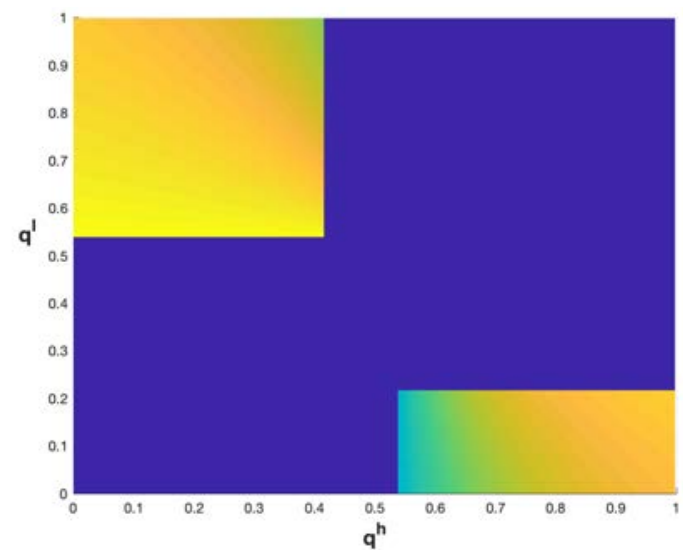

Figure 3: Example identified set for $\left(q^{h}, q^{\ell}\right)$. The figure shows the identified set for $\left(q^{h}, q^{\ell}\right)$ from a sample observation. The top left rectangle is $\mathcal{R}_{1}$. The bottom right rectangle is $\mathcal{R}_{2}$. The color shade represents the value of the implied $g$, with higher values of $g$ represented by warmer colors and lower values of $g$ represented by cooler colors. Dark blue represents the region outside the identified set.

\subsection{Recovering Enforcement Efforts}

We have not yet, however, incorporated into our analysis any of the relationships between the enforcement probabilities $\left(g_{c t}, f_{c t}, k_{c t}, v_{t}^{d}, q_{c t}^{\ell}, q_{c t}^{h}\right)$ that are also implied by the immigration enforcement process, and driven by the unobserved enforcement effort choices of the local and federal levels. First, the sources of covariation between probabilities: across the detainer and direct tracks, i) $g_{c t}$ should covary with $k_{c t}$ through the immigration enforcement effort of the local level within a county-period; ii) $f_{c t}$ should covary with $k_{c t}$ through the immigration enforcement effort of the federal level within a county-period; iii) $q_{c t}^{\ell}$ and $q_{c t}^{h}$ should also covary with $f_{c t}$ through the immigration enforcement effort of the federal level within a county-period. Second, the following exclusion restrictions: i) $g_{c t}$ should not vary with federal enforcement efforts; ii) $f_{c t}$ should not vary with local enforcement efforts; iii) $v_{t}^{d}$ should not vary across counties within a federal enforcement district; iv) $q_{c t}^{\ell}$ and $q_{c t}^{h}$ should not vary with local enforcement efforts.

We exploit the information from these additional implications of the deportation process through parametric restrictions. We denote the local level enforcement effort by $\epsilon_{c t}$, and the federal level enforcement effort by $\xi_{c t}$. It will be computationally convenient to model the enforcement probabilities as logistic functions of observable county characteristics $\mathbf{x}_{c t}$, and the corresponding enforcement efforts. We can directly work with the log odds forms:

$$
\begin{aligned}
& \log \left(\frac{f_{c t}}{1-f_{c t}}\right) \equiv \tilde{f}_{c t}=\mathbf{x}_{c}^{\prime} \boldsymbol{\beta}^{f}+\xi_{c t} \\
& \log \left(\frac{g_{c t}}{1-g_{c t}}\right) \equiv \tilde{g}_{c t}=\mathbf{x}_{c}^{\prime} \boldsymbol{\beta}^{g}+\epsilon_{c t}
\end{aligned}
$$




$$
\begin{aligned}
& \log \left(\frac{k_{c t}}{1-k_{c t}}\right) \equiv \tilde{k}_{c t}=\mathbf{x}_{c}^{\prime} \boldsymbol{\beta}^{k}+\kappa_{\epsilon} \epsilon_{c t}+\kappa_{\xi} \xi_{c t}+\eta_{c t} \\
& \log \left(\frac{q_{c t}^{\tau}}{1-q_{c t}^{\tau}}\right) \equiv \tilde{q}_{c t}^{\tau}=\mathbf{x}_{c}^{\prime} \boldsymbol{\beta}^{q \tau}+\gamma^{\tau} \xi_{c t}+\zeta_{c t}^{\tau}, \quad \tau \in\{\ell, h\}
\end{aligned}
$$

where $\boldsymbol{\beta} \equiv\left(\boldsymbol{\beta}^{f}, \boldsymbol{\beta}^{g}, \boldsymbol{\beta}^{k}, \boldsymbol{\beta}^{q h}, \boldsymbol{\beta}^{q \ell}\right)$, the $\left(\boldsymbol{\beta}, \kappa_{\epsilon}, \kappa_{\xi}, \gamma^{h}, \gamma^{\ell}\right)$ are regression coefficients, and $\left(\eta_{c t}, \zeta_{c t}\right)$ are errors. The $\zeta_{c t}^{\tau}$ are closely related to the enforcement efforts of immigration courts unrelated to ICE efforts. Recall from equation (16) that we do not directly have an expression for $f_{c t}$, but rather for $\bar{f}_{c t} \equiv v_{t}^{d}\left(1-f_{c t}\right) / f_{c t}$. Re-writing equation (17) in terms of $\bar{f}_{c t}$,

$$
\log \left(\bar{f}_{c t}\right) \equiv \overline{\tilde{f}}_{c t}=\log \left(v_{t}^{d}\right)-\mathbf{x}_{c}^{\prime} \boldsymbol{\beta}^{f}-\xi_{c t}
$$

so district fixed effects in equation (21) recover the district-level 'prison visit' probabilities.

Suppose we knew the values of $\left(q_{c t}^{\ell}, q_{c t}^{h}\right)$ for all $(c, t)$, which we collect in the vectors $\left(\mathbf{q}^{\ell}, \mathbf{q}^{h}\right)$. Then we could directly compute $g_{c t}, \overline{\tilde{f}}_{c t}$, and $k_{c t}$ for all $(c, t)$, allowing us to estimate the regressions in equations (18) and (21). From these we could then recover the $\epsilon_{c t}$ and $\xi_{c t}$ as their residuals:

$$
\hat{\xi}_{c t}=\delta_{t, o l s}^{d}-\mathbf{x}_{c}^{\prime} \boldsymbol{\beta}_{o l s}^{f}-\overline{\tilde{f}}_{c t}, \quad \hat{\epsilon}_{c t}=\tilde{g}_{c t}-\mathbf{x}_{c}^{\prime} \boldsymbol{\beta}_{o l s}^{g}
$$

where $\delta_{t, o l s}^{d}$ are federal district by period fixed effects. A plot of the $\epsilon_{c t}$ on the $\xi_{c t}$ over time for a given county would then reveal the shape of the county's best response. The vectors of immigration enforcement efforts $\hat{\boldsymbol{\xi}}\left(\mathbf{q}^{\ell}, \mathbf{q}^{h} ; \mathbf{W}, \mathbf{X}\right)$ and $\hat{\boldsymbol{\epsilon}}\left(\mathbf{q}^{\ell}, \mathbf{q}^{h} ; \mathbf{W}, \mathbf{X}\right)$ are thus closed-form functions of $\left(\mathbf{q}_{c t}^{\ell}, \mathbf{q}_{c t}^{h}\right), \mathbf{W}=\left(\mathbf{w}_{1}, \ldots, \mathbf{w}_{n}\right)$ where $\mathbf{w}_{c}=\left(\mathbf{w}_{c 1}^{\prime}, \ldots, \mathbf{w}_{c t}^{\prime}\right)^{\prime}$, and $\mathbf{X}=\left(\mathbf{x}_{1}^{\prime}, \ldots, \mathbf{x}_{n}^{\prime}\right)^{\prime}$. Using these enforcement efforts as regressors, we could then estimate regressions (19)-(20). The minimized sums of squared residuals of these regressions are thus closed-form functions of $\left(\mathbf{q}_{c t}^{\ell}, \mathbf{q}_{c t}^{h}\right), \mathbf{W}$, and $\mathbf{X}$ exclusively:

$$
\begin{aligned}
\mathcal{S}^{k}\left(\mathbf{q}^{\ell}, \mathbf{q}^{h} ; \mathbf{W}, \mathbf{X}\right) & =\sum_{c} \sum_{t}\left(\tilde{k}_{c t}-\mathbf{x}_{c}^{\prime} \boldsymbol{\beta}_{o l s}^{k}-\kappa_{\epsilon, o l s} \hat{\epsilon}_{c t}-\kappa_{\xi, o l s} \hat{\xi}_{c t}\right)^{2} \\
\mathcal{S}^{\ell}\left(\mathbf{q}^{\ell}, \mathbf{q}^{h} ; \mathbf{W}, \mathbf{X}\right) & =\sum_{c} \sum_{t}\left(\tilde{q}_{c t}^{\ell}-\mathbf{x}_{c}^{\prime} \boldsymbol{\beta}_{o l s}^{q \ell}-\gamma_{o l s}^{\ell} \hat{\xi}_{c t}\right)^{2} \\
\mathcal{S}^{h}\left(\mathbf{q}^{\ell}, \mathbf{q}^{h} ; \mathbf{W}, \mathbf{X}\right) & =\sum_{c} \sum_{t}\left(\tilde{q}_{c t}^{h}-\mathbf{x}_{c}^{\prime} \boldsymbol{\beta}_{o l s}^{q h}-\gamma_{o l s}^{\ell} \hat{\xi}_{c t}\right)^{2}
\end{aligned}
$$

We can define $\mathcal{S}=\mathcal{S}^{k}+\mathcal{S}^{\ell}+\mathcal{S}^{h}$, and proceed to choose the vectors $\left(\mathbf{q}^{\ell}, \mathbf{q}^{h}\right)$ to maximize the fit of equations (19)-(20) over the identified sets $\mathcal{R}\left(\mathbf{w}_{c t}\right)$ for each observation:

$$
\min _{\left(\mathbf{q}^{\ell}, \mathbf{q}^{h}\right) \in \times_{c t} \mathcal{R}\left(\mathbf{w}_{c t}\right)} \mathcal{S}\left(\mathbf{q}^{\ell}, \mathbf{q}^{h} ; \mathbf{W}, \mathbf{X}\right)
$$

This is a high-dimensional search. However, our objective function is in closed form, and easily 
evaluated at any given $\left(\mathbf{q}^{\ell}, \mathbf{q}^{h}\right)$. It is also strictly convex and thus has a unique minimum. Moreover, the search over each element of the vectors $\left(\mathbf{q}^{\ell}, \mathbf{q}^{h}\right)$ is highly constrained by its corresponding identified set $\mathcal{R}\left(\mathbf{w}_{c t}\right)$. Our ability to go from the partial identification result in Proposition 1 to the point identification result from the solution to equation (22) relies on two features of equations (17)-(20): i) the exclusion restrictions provided by the immigration enforcement pipeline allowing us to recover the unobserved enforcement efforts of the local and federal levels at a given pair $\left(\mathbf{q}^{\ell}, \mathbf{q}^{h}\right)$; ii) the assumption that the coefficients $\boldsymbol{\beta}$ on the county characteristics in these equations (which capture the heterogeneity along observables in the response of the enforcement probabilities to the local and federal efforts) are homogeneous across counties. The constancy of these coefficients across counties implies that at a given $\left(\mathbf{q}_{-c t}^{\ell}, \mathbf{q}_{-c t}^{h}\right)$ for all county-periods except for $(c, t)$, the implied value of $\boldsymbol{\beta}$, common across all observations, pins down what the best pair $\left(q_{c t}^{\ell}, q_{c t}^{h}\right) \in \mathcal{R}\left(\mathbf{w}_{c t}\right)$ must be for solving equation (22).

We use a particle swarm optimizer to minimize equation (22), which is ideal for optimizing a high-dimensional function inside a bounded support. We implement this procedure separately for minor and serious offenses, recovering federal immigration enforcement efforts over minor and serious offense cases $\left(\boldsymbol{\xi}^{m}, \boldsymbol{\xi}^{s}\right)$, and local immigration enforcement efforts over minor and serious offense cases $\left(\boldsymbol{\epsilon}^{m}, \boldsymbol{\epsilon}^{s}\right)$. We then recover the implied immigration enforcement probabilities for minor and serious offense cases $\left\{\mathbf{g}, \boldsymbol{f}, \mathbf{k}, \mathbf{q}^{\ell}, \mathbf{q}^{h}, \mathbf{v}^{d}\right\}_{m},\left\{\mathbf{g}, \boldsymbol{f}, \mathbf{k}, \mathbf{q}^{\ell}, \mathbf{q}^{h}, \mathbf{v}^{d}\right\}_{s}$, and the corresponding strengths of covariation between these probabilities $-\left(\kappa_{\epsilon}^{m}, \kappa_{\xi}^{m}, \gamma^{\ell, m}, \gamma^{h, m}\right)$ and $\left(\kappa_{\epsilon}^{s}, \kappa_{\xi}^{s}, \gamma^{\ell, s}, \gamma^{h, s}\right)-$, together with the coefficients $\left(\boldsymbol{\beta}_{m}, \boldsymbol{\beta}_{s}\right)$ capturing the patterns of heterogeneity in the effects of local and federal enforcement efforts across observable characteristics, on the immigration enforcement probabilities.

\section{Estimation Results}

Our empirical strategy allows us to recover the local immigration enforcement response to changes in federal immigration enforcement efforts. We do so exploiting the variation in rates at which arrested unlawfully present individuals move along the deportation process, allowing us to control for selection. This strategy, however, is demanding on the data. As Proposition 1 indicates, we can only purge selection from periods in which we observe strictly positive counts of immigration enforcement activity at all stages of the immigration enforcement pipeline. This, naturally, limits the external validity of our findings. The sample for which periods with positive counts of detainers, ICE custodies with and without detainers, and removals with and without detainers are all positive, is composed of counties with relatively large populations, and relatively large populations of illegally present immigrants.

In panel B of Table B.1 we report summary statistics for the resulting sample of counties with observed data satisfying the conditions required for identification. Our estimation sample 
is composed of counties with somewhat larger populations than the average county, and 30 percent larger undocumented population than the average county (2.2 compared to 1.7 percent undocumented share). It is also slightly more educated, but not much more Democratic than the average county (43 compared to 41 percent Democratic share). However, the average county in our sample is considerably less rural than average, and has a significantly larger services sector. The results below are not representative of the smaller, more rural communities in the US. Figure B.3 similarly presents a county-level map of the US, where we highlight the counties included in this sample. Despite the limitations just highlighted, the map reveals a wide regional coverage. As expected, Texas, Florida, the Southwestern US and the Northeast are heavily represented in our estimation sample. In Appendix Table B.3 we also report summary statistics for the data moments $\mathbf{w}_{c t}$ in our estimation sample. On average, enforcement outcomes are lower in the post-guidelines period at every stage along the immigration enforcement pipeline, except for minor offenses in the direct track. Perhaps surprisingly, these average falls are larger for serious offenses. Along the detainer track, for example, the probability of a removal at the mean fell from 8.3 to 5.1 percent; it fell even more along the direct track, from 33 to 19 percent. Our empirical strategy allows us to decompose the sources of variation driving these changes.

\subsection{Enforcement Probabilities and Best Responses}

In panel $\mathrm{A}$ of Table 3 we present average estimates of the immigration enforcement rates by type of offense and period. Panel B reports the estimated coefficients from equations (19) and (20) capturing the covariation between local and federal enforcement along the detainer and direct tracks, and between federal efforts and immigration court outcomes. ${ }^{37}$ Average detainer issuance rates $f$ fell 3 percentage points for minor offenses after the guidelines were issued, and increased 2 percentage points for serious offenses. These changes are in line with the purported objective of ICE's change in guidelines, but are smaller than the guidelines themselves suggested. Especially for serious offenses, we find a large change in the average rate of compliance with detainers, $g$, which fall by 12 percentage points. On the other hand, we estimate falls in average preference alignment $\pi^{H h} / \pi^{H \ell}$ for both levels of offenses, with an especially large fall for serious offenses. This suggests that while the fall in immigration enforcement outcomes related to minor offenses following the change in guidelines was mostly driven by the relaxation of federal efforts, the fall in immigration enforcement outcomes related to serious offenses was driven by an offsetting response of the local level to increased federal efforts over these types of cases, and a concomitant increase in conflict between the local and federal levels.

It is likely that a major driving force of the fall in alignment over serious offenses was a

\footnotetext{
${ }^{37}$ In Tables Table B.4 and Table B.5 we report the corresponding estimates of the $\boldsymbol{\beta}$ coefficients on our vector of covariates in equations (17), (18), (19), and (20).
} 


\begin{tabular}{|c|c|c|c|c|c|c|c|c|}
\hline \multirow[t]{3}{*}{ Panel A: } & \multicolumn{4}{|c|}{ Pre-Policy Change (2009-I - 2011-I) } & \multicolumn{4}{|c|}{ 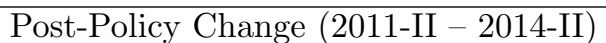 } \\
\hline & \multicolumn{2}{|c|}{ Minor Offenses } & \multicolumn{2}{|c|}{ Serious Offenses } & \multicolumn{2}{|c|}{ Minor Offenses } & \multicolumn{2}{|c|}{ Serious Offenses } \\
\hline & Mean & Std. dev. & Mean & Std. dev. & Mean & Std. dev. & Mean & Std. dev. \\
\hline$f$ & 0.24 & 0.29 & 0.05 & 0.13 & 0.25 & 0.29 & 0.06 & 0.16 \\
\hline$g$ & 0.28 & 0.26 & 0.54 & 0.31 & 0.27 & 0.27 & 0.43 & 0.29 \\
\hline$q^{l}$ & 0.51 & 0.31 & 0.43 & 0.31 & 0.57 & 0.29 & 0.49 & 0.28 \\
\hline$q^{h}$ & 0.68 & 0.28 & 0.72 & 0.28 & 0.68 & 0.25 & 0.73 & 0.28 \\
\hline$v^{d}$ & 1.83 & 2.72 & 0.41 & 0.50 & 2.19 & 4.69 & 0.52 & 0.69 \\
\hline$k$ & 0.16 & 0.31 & 0.07 & 0.23 & 0.22 & 0.34 & 0.13 & 0.30 \\
\hline$\pi^{H h} / \pi^{H \ell}$ & 0.33 & 0.89 & 0.36 & 0.99 & 0.30 & 0.65 & 0.23 & 0.68 \\
\hline Observations & & 448 & & 189 & & 900 & & 912 \\
\hline \multirow[t]{2}{*}{ Panel B: } & \multicolumn{8}{|c|}{ Coefficients of Interest } \\
\hline & & & \multicolumn{2}{|c|}{ Minor Offenses } & \multicolumn{2}{|c|}{ Serious Offenses } & & \\
\hline$\overline{\kappa_{\epsilon}}$ & & & -0.23 & $(0.020)$ & -0.22 & $(0.030)$ & & \\
\hline$\kappa_{\xi}$ & & & 1.11 & $(0.057)$ & 0.98 & $(0.052)$ & & \\
\hline$\gamma^{l}$ & & & 0.28 & $(0.071)$ & 0.13 & $(0.057)$ & & \\
\hline$\gamma^{h}$ & & & -0.21 & $(0.061)$ & -0.31 & $(0.037)$ & & \\
\hline Observations & & & \multicolumn{2}{|c|}{2348} & \multicolumn{2}{|c|}{1101} & & \\
\hline
\end{tabular}

Table 3: Summary Statistics for the Enforcement Probabilities and Estimated Coefficients. The table presents summary statistics for selected enforcement variables and the coefficient estimates for key parameters of interest. The first two columns of Panel A report means and standard deviations for minor offenses in the pre-guidelines period, i.e. from the first semester of 2009 to the first semester of 2011. The second two columns of Panel A refer to serious offenses for the same period. The first two columns of Panel B present means and standard deviations for minor offenses in the post-guidelines period, i.e. from the second semester of 2011 to the second semester of 2014 . The second two columns of Panel B refer to serious offenses for the same period. Panel C reports coefficients for the logistic regressions in equations (19) and (20), for minor and serious offenses. Standard errors for these coefficients, reported in parentheses, account for the presence of generated regressors in equations (19) and (20) (see subsection A.2).

change in what from the point of view of ICE constituted serious offenses worth pursuing. If an individual who previously was not of interest to ICE, and thus, about whom there was little disagreement between the federal and local levels, becomes of interest to ICE, this creates a divergence in the preferences of both levels over the case. The table also suggests that the federal level increased enforcement over serious offenses along both detainer and direct tracks (average $k$ increased by 4 percentage points). This is consistent with the decreased collaboration of the local level, because avoiding the use of detainers through the direct track partially allows ICE to undermine local level resistance.

Turning our attention to Panel $\mathrm{C}$, we find that federal efforts lead to a positive covariation between $f$ and $k$, while local efforts lead to a negative covariation between $g$ and $k$. The table also suggests that immigration court preferences did not change with the introduction of the federal guidelines. These also appear to be more aligned with county level than with federal level preferences: at the mean, $q^{h}>q^{\ell}$. On the other hand, we find that $\xi$ leads to a negative covariation between $f$ and $q^{h}$, and to a positive covariation between $f$ and $q^{\ell}$. In periods of strong federal enforcement, the courts do move in the direction of making more likely the removal of individuals that the local level would rather not deport. 


\begin{tabular}{lccccc}
\hline \hline & \multicolumn{3}{c}{$\begin{array}{c}\text { Dependent Variable: Local Effort } \epsilon \\
\text { Minor Offenses }\end{array}$} & & \multicolumn{2}{c}{ Serious Offenses } \\
\cline { 2 - 3 } \cline { 5 - 6 } & Pooled & County FE & & Pooled & County FE \\
& $(1)$ & $(2)$ & & $(3)$ & $(4)$ \\
\hline Federal effort $\xi$ & -1.24 & -1.43 & & -0.64 & -0.73 \\
& $(0.05)$ & $(0.06)$ & & $(0.05)$ & $(0.06)$ \\
\hline R squared & 0.24 & 0.48 & & 0.16 & 0.37 \\
Observations & & 2348 & & \multicolumn{2}{c}{1101} \\
\hline \hline
\end{tabular}

Table 4: Local Best Responses: Pooled vs. Fixed Effects. The table presents regression results for the local immigration enforcement effort of the county $\epsilon$ on the federal immigration enforcement effort of ICE $\xi$. Odd columns present pooled estimates across all counties, while even columns present county fixed-effects estimates. The first two columns present results for minor offenses, while the last two columns present results for serious offenses. Standard errors for these coefficients are reported in parentheses.

We find strong evidence of strategic substitutabilities in the response of the local level to increased federal immigration enforcement. Because our approach allows us to recover $\xi$ and $\epsilon$ at different points in time for each county, we can directly reconstruct movements along the best response curve of the county. In Table 4 we present our main estimates of the average slope of this best response across counties, from models where we regress $\epsilon$ on $\xi$ directly. We report separately the responses over each type of offense, finding substitutabilities in both cases, but larger responses for minor offenses. Even columns in the table report county fixed effects models, that effectively compute the slope for each county and average over those slopes. For minor offenses, we find that a one standard deviation higher federal enforcement leads to 1.4 standard deviations less local enforcement. For serious offenses, we find a similarly negative local level response of 0.7 standard deviations. The local level response in most counties partially undoes the federal effort. Both coefficients are precisely estimated. We argued that our empirical strategy allows us to successfully distinguish selection from enforcement. In the odd columns of the table we report the results of running a pooled regression of $\epsilon$ on $\xi$, allowing us to indirectly assess the validity of our claim: in the pooled model, county-level fixed effects are in the error term. For both levels of offenses, the magnitudes of the pooled and fixed effects coefficients are very close to each other, showing that $\xi$ is effectively uncorrelated with fixed county-level unobservables. The results from Table 4 motivate us to present in Figure 4 the scatterplots corresponding to the pooled regressions, where we distinguish between counties above median in the distribution of Democratic vote share (blue), and counties below median (red).

\subsection{Heterogeneity in the Local Enforcement Response}

How much heterogeneity is there in the nature of the local-level enforcement response? Figure 5 plots the county-level distribution of slopes, which we recover directly from fitting $\epsilon$ to $\xi$ county by county. For both minor and serious offenses cases, around 80 percent of counties exhibit 


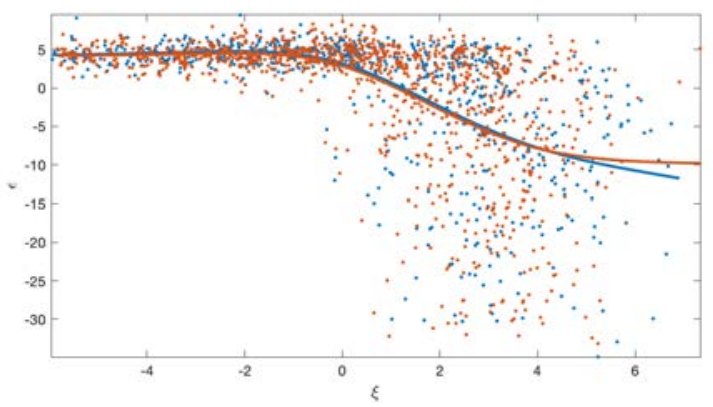

(a) Minor offenses

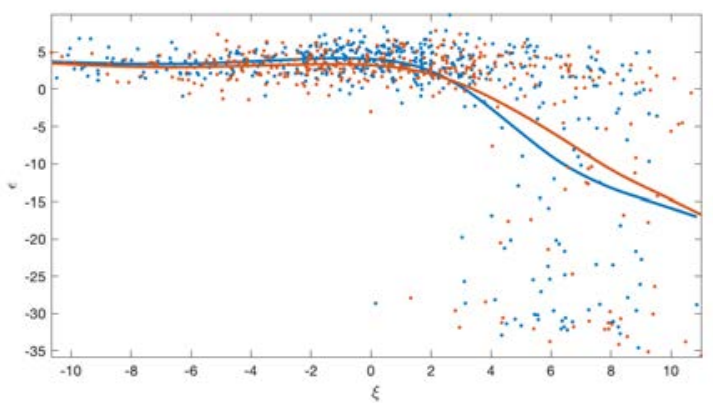

(b) Serious offenses

Figure 4: Scatterplot of Local Efforts on Federal Efforts. Panel (a) shows the scatterplot corresponding to column (1) in Table 4, plotting $\epsilon$ on $\xi$ for arrestees charged with minor (levels 2 and 3) offenses. Panel (b) shows the scatterplot corresponding to column (3) in Table 4, plotting $\epsilon$ on $\xi$ for for arrestees charged with serious (level 1) offenses. Points in blue represent counties above median Democratic vote share, and points in red represent counties below median Democratic vote share. The curves are non-parametric best-fit regression lines for each group of counties.

negative slopes, indicating strategic substitutability. The remainder 20 percent of counties show positive slopes, indicating strategic complementarity. To investigate the main drivers of the heterogeneity in the shape of these best responses, in Table 5 we present results of cross-sectional regressions for the slopes of each county's best response on a battery of county characteristics related to local preferences over immigration policy.

In columns 1 and 4 we include only a constant and the Democratic vote share (-50 percent). The constant captures the average best response slope for a perfectly competitive county. More Democratic counties exhibit significantly more negative best responses for serious offenses. In columns 2 and 5 we then add the Hispanic share of the population. Perhaps surprisingly, conditional on Democratic support, counties with larger Hispanic populations have less negative slopes for minor offenses. Lastly, in columns 3 and 6 we include the undocumented share (which is highly correlated with the Hispanic share), log population, the share with a bachelor's degree, a rural county dummy, the share of employment in the services sector, log distance to ICE and a dummy for the existence of a $287(\mathrm{~g})$ agreement. The inclusion of these controls makes the coefficient on the Democratic share negative for both kinds of offenses, making it clear that aggregate partisan preferences are the main driver of the local-level response. In counties with larger undocumented populations, in contrast, best responses are less negatively sloped. These findings highlight the importance of the local response to federal enforcement efforts, and rationalize why the outcomes of immigration enforcement under Secure Communities varied widely across space.

The policy guidelines change of 2011 advocated for a redirection of efforts away from the prosecution of minor offenses and towards serious ones. As such, throughout we have allowed for these to be two separate margins of immigration enforcement. Our estimates also allow us to explore the relationship between both of these margins. In panel (a) of Figure 6 we 


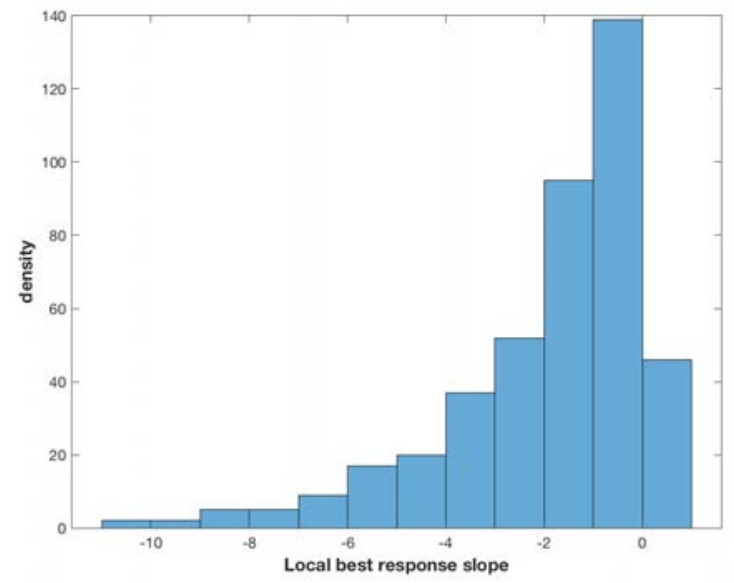

(a) Minor offenses

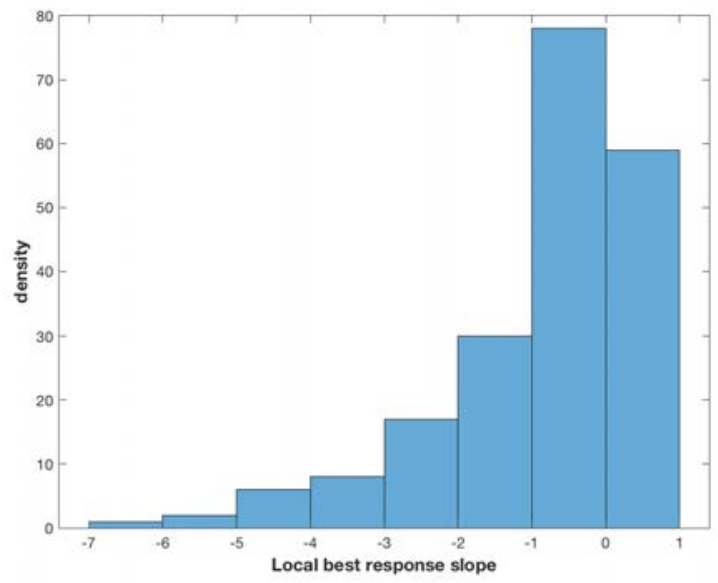

(b) Serious offenses

Figure 5: Distribution of Best Response Slopes Across Counties. The figures show the distribution of county slopes for a regression of $\epsilon$ on $\xi$. Panel (a) is for cases of arrestees charged with minor (levels 2 and 3 ) offenses. Panel (b) is for cases of arrestees charged with serious (level 1) offenses.

present a county-level scatterplot of minor and serious federal efforts. In sharp contrast to the claimed objective of the policy, we do not find a substitution between them; both efforts are positively correlated. The large fall in immigration outcomes for serious offenses that we illustrated in Figure 1, thus, was not just driven by changes in the composition of arrests of illegally present immigrants. Reassuringly, the magnitude of the correlation is indistinguishable between above (in blue) and below (in red) median Democratic support, or any other countylevel characteristic that should only be a relevant determinant of local-level preferences. In contrast, the correlation between minor and serious local efforts is much stronger for the more Democratic counties compared to the less Democratic. As panel (b) illustrates, among counties with the highest Republican support (in red), there is much more variation in enforcement towards minor than towards serious offenses. This suggests that the most Republican-leaning counties responded little to changes in federal enforcement targeted towards serious offenses. The more elastic average best response for minor offenses cases compared to serious ones (see Table 4) induced more variation in local immigration enforcement efforts across all types of counties, as panel (b) in Figure 6 illustrates.

\subsection{Patterns of Unobserved Heterogeneity}

Now we discuss our findings related to the patterns of unobserved heterogeneity in immigration enforcement. Our measure of preference alignment between the federal and local levels, $\pi^{H h} / \pi^{H \ell}$, is strongly positively correlated with federal immigration enforcement efforts $\xi$. We illustrate this in Figure 7 where we plot the unconditional scatterplots between both variables. Panel (a) presents the scatterplot for minor offenses, and panel (b) for serious offenses. We 


\begin{tabular}{|c|c|c|c|c|c|c|}
\hline \multicolumn{7}{|c|}{ Dependent Variable: County's Best Response Slope } \\
\hline & \multicolumn{3}{|c|}{ Minor Offenses } & \multicolumn{3}{|c|}{ Serious Offenses } \\
\hline & (1) & $(2)$ & (3) & (4) & (5) & (6) \\
\hline Constant & $\begin{array}{c}-1.87 \\
(0.06)\end{array}$ & $\begin{array}{l}-2.05 \\
(0.10)\end{array}$ & $\begin{array}{c}-3.91 \\
(1.35)\end{array}$ & $\begin{array}{c}-0.83 \\
(0.06)\end{array}$ & $\begin{array}{c}-0.77 \\
(0.09)\end{array}$ & $\begin{array}{c}-0.93 \\
(1.40)\end{array}$ \\
\hline Democratic party share & $\begin{array}{l}-0.17 \\
(0.42)\end{array}$ & $\begin{array}{c}-0.23 \\
(0.42)\end{array}$ & $\begin{array}{l}-1.20 \\
(0.58)\end{array}$ & $\begin{array}{l}-1.84 \\
(0.40)\end{array}$ & $\begin{array}{l}-1.81 \\
(0.41)\end{array}$ & $\begin{array}{c}-2.09 \\
(0.57)\end{array}$ \\
\hline Hispanic share & & $\begin{array}{c}1.00 \\
(0.41)\end{array}$ & $\begin{array}{c}0.74 \\
(0.53)\end{array}$ & & $\begin{array}{c}-0.31 \\
(0.34)\end{array}$ & $\begin{array}{c}-0.01 \\
(0.45)\end{array}$ \\
\hline Undocumented share & & & $\begin{array}{c}3.15 \\
(4.08)\end{array}$ & & & $\begin{array}{l}10.17 \\
(4.23)\end{array}$ \\
\hline Log population & & & $\begin{array}{c}0.19 \\
(0.09)\end{array}$ & & & $\begin{array}{c}-0.03 \\
(0.09)\end{array}$ \\
\hline Bachelor degree share & & & $\begin{array}{c}-0.41 \\
(0.91)\end{array}$ & & & $\begin{array}{c}1.71 \\
(0.85)\end{array}$ \\
\hline Rural & & & $\begin{array}{l}-0.50 \\
(0.25)\end{array}$ & & & $\begin{array}{c}-0.60 \\
(0.36)\end{array}$ \\
\hline Services share & & & $\begin{array}{c}-0.41 \\
(1.45)\end{array}$ & & & $\begin{array}{c}-0.40 \\
(1.47)\end{array}$ \\
\hline Log distance ICE office & & & $\begin{array}{c}-0.02 \\
(0.02)\end{array}$ & & & $\begin{array}{c}0.01 \\
(0.02)\end{array}$ \\
\hline 287(g) program & & & $\begin{array}{c}0.09 \\
(0.23)\end{array}$ & & & $\begin{array}{c}0.03 \\
(0.20) \\
\end{array}$ \\
\hline R squared & 0.0009 & 0.005 & 0.03 & 0.02 & 0.02 & 0.05 \\
\hline Observations & & 429 & & & 201 & \\
\hline
\end{tabular}

Table 5: Heterogeneity in Local Best Responses. The table shows regression coefficients for the slopes of the best response of $\epsilon$ to $\xi$, separately for minor and serious offenses. The dependent variable in all specifications is the slope of a regression of $\epsilon$ on $\xi$ and a constant for each county. Each observation corresponds to a county. Regressions are weighted by the number of time periods used to estimate each slope. The explanatory variables include a constant and several county characteristics. Log Population is taken from the 2010 Census. Undocumented share is an estimate of the number of unlawfully present individuals in 2010 (its construction is described in Appendix C). Democratic party share is an average of the 2008 and 2012 Democratic Presidential vote shares minus 50 percent, taken from David Leip's Electoral Atlas. Bachelor degree share is measured as the fraction of the adult population with at least a bachelor's degree. Hispanic share is measured as the fraction of the population who is hispanic. Services share is measured as the fraction of the employed population working in the services sector. Bachelor degree share, Hispanic share, and Services share are taken from the 2006-2010 waves of the American Communities Survey. Rural is a dummy variable indicating whether the county is considered non-metropolitan according to the National Center for Health Statistics at the Center for Disease Control. Distance to ICE office is measured as the log of the number of miles between the county centroid and the county centroid of the corresponding ICE district office seat, and computed directly by us. 287 (g) Program is a dummy variable indicating whether the county or any city in the county was ever part of the $287(\mathrm{~g})$ program, taken from Steil and Vasi (2014). 


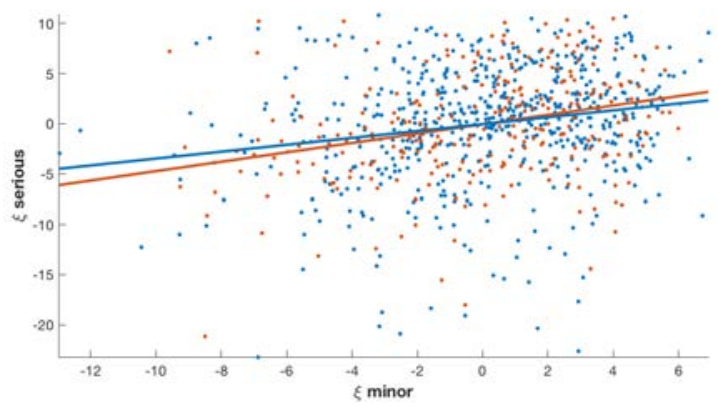

(a) Federal enforcement

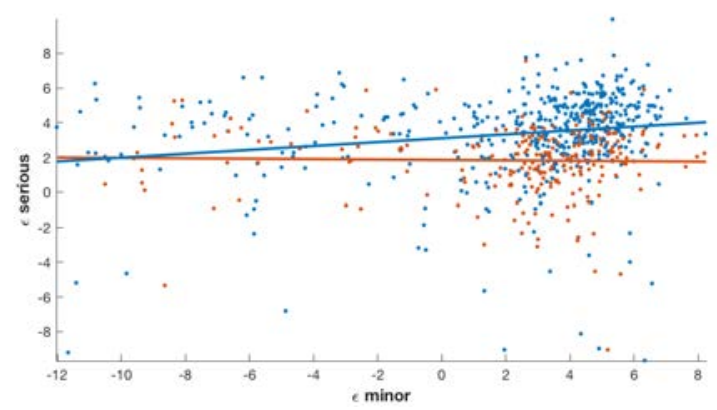

(b) Local enforcement

Figure 6: Margins of Immigration enforcement: Minor vs. Serious Offenses. Panel (a) shows a scatterplot of both dimensions of federal immigration enforcement effort $\left(\xi^{s}, \xi^{m}\right)$. Panel (b) shows a scatterplot of both dimensions of local immigration enforcement effort $\left(\epsilon^{s}, \epsilon^{m}\right)$. Points in blue represent counties above median Democratic vote share. Points in red represent counties below median Democratic vote share. The lines are best-fit regressions for each group.

confirm the robustness of this correlation in the first three columns of Table 6. There we report panel regressions of federal efforts on preference alignment. The first column reports the unconditional relationship. In the second column we include county fixed effects, which slightly increase the magnitude of the estimated coefficient. For minor offenses, the coefficient is 0.95 $($ s.e. $=0.01)$, while for serious offenses it is 0.9 (s.e. $=0.01) \cdot{ }^{38}$ This is a key result of our analysis. ICE is extremely good at targeting its enforcement efforts towards places where those efforts will be highly effective (where the composition of the arrest pool is such that ICE can expect a high degree of local-level cooperation). This is perhaps not as surprising considering the informational advantage that ICE acquired under Secure Communities and its access to massive law enforcement databases. At the same time, the strong willingness of the federal level to direct efforts toward places where it expects collaboration also indicates that the local level is a key gatekeeper for immigration enforcement.

In columns 4 to 9 of Table 6 we complement these results showing that the negative unconditional correlation between local efforts $\epsilon$ and preference alignment $\pi^{H h} / \pi^{H \ell}$ is completely driven by federal immigration efforts $\xi$. Column 4 reports the unconditional regression coefficient, which is negative and statistically significant. This is also the case after introducing county fixed effects in columns 5-6. In columns 7-9, controlling for federal efforts $\xi$, the relationship between local efforts and preference alignment vanishes. This reassures us that the best responses we recovered above can be interpreted causally, and that our model of the immigration enforcement pipeline is a good approximation to the actual operation of the process.

We conclude this section examining whether our measure of preference alignment between the federal and local levels, $\pi^{H h} / \pi^{H \ell}$, is correlated with other observables. This allows us to establish how some characteristics of the pool of unlawfully present arrestees shape the conflict over immigration policy. In Table 6 we estimate county fixed-effects regressions of $\log \left(\pi^{H h} / \pi^{H \ell}\right)$

\footnotetext{
${ }^{38}$ In column three we find no difference in this relationship before and after the change in ICE guidelines.
} 


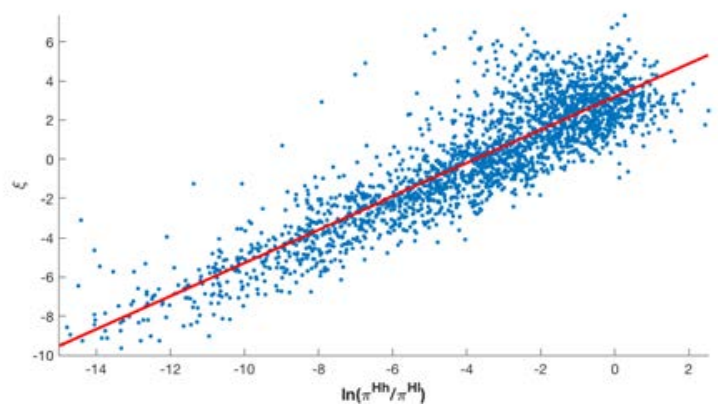

(a) Minor offenses

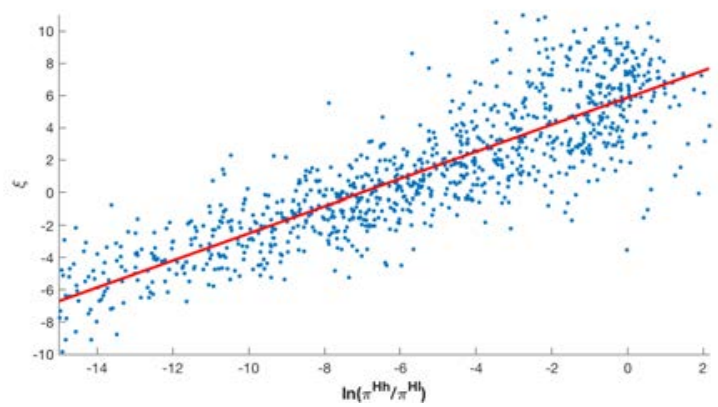

(b) Serious offenses

Figure 7: The Nature of Selection: Preference Alignment and Federal Immigration Enforcement Efforts. The figure shows the relationship between log preference alignment and federal immigration enforcement efforts, pooled across county-time periods. Panel (a) is for arrestees charged with minor (levels 2 and 3 ) offenses, and corresponds to the results reported in column (1) of panel A in Table 6. Panel (b) is for arrestees charged with serious (level 1) offenses, and corresponds to the results reported in column (1) of panel B in Table 6.

for minor and serious offenses cases on interactions between a post-guidelines dummy and either the Democratic vote share, the Hispanic population share, and the share with a bachelors degree. We then additionally include measures of three salient observed characteristics of the pool of unlawfully present arrestees which vary at the county-semester level: the fraction of detainers issued against Mexican nationals, the fraction issued against Central American nationals, and the fraction issued against unlawfully present immigrants less than 30 years old. On average Mexican and Central American nationals during our period of study constitute the bulk of unlawfully present immigrants, with the fraction of Central Americans growing over time. ${ }^{39}$ Around 65 and 18 percent of all detainers in our sample period were issued against Mexicans and Central Americans. Similarly, young individuals (less than 30 years old) constitute around 40 percent of all detainers in our estimation sample. ${ }^{40}$ Finally, because the composition of the pool of unlawfully present arrestees could be affected by community collaboration with law enforcement, we collected and use county-level data on the number of calls to 911 numbers as a proxy for the willingness to collaborate with law enforcement.

Columns 1 and 4 of Table 7 show that the more Democratic a county, the more misaligned preferences over immigration enforcement became in the post-guidelines period. In contrast, conditional on the Democratic vote share, the Hispanic share is a positive predictor of increased preference alignment in the post-guidelines period. Columns 2 and 5 then show that higher shares of Mexicans, Central Americans, and young individuals in the pool of arrestees, predict falls in preference alignment, and thus, more conflict over immigration enforcement. These averages, however, mask considerable heterogeneity; among the most Democratic counties, a large

\footnotetext{
${ }^{39}$ Central American nationals include individuals from any of the following countries: Belize, El Salvador, Guatemala, Honduras, Nicaragua, and Panama.

${ }^{40}$ Our detainer data also reports the sex of the unlawfully present arrestee. Because more than 95 percent of them are males on average, we do not include this covariate in the analysis.
} 


\begin{tabular}{|c|c|c|c|c|c|c|c|c|c|}
\hline \multirow{2}{*}{$\begin{array}{l}\text { Dependent Variable: } \\
\text { Panel A: Minor Offenses }\end{array}$} & \multicolumn{3}{|c|}{ Federal Effort $\xi$} & \multicolumn{6}{|c|}{ Local Effort $\epsilon$} \\
\hline & (1) & (2) & (3) & (4) & (5) & (6) & (7) & (8) & (9) \\
\hline $\log \left(\pi^{H h} / \pi^{H \ell}\right)$ & $\begin{array}{c}0.84 \\
(0.008)\end{array}$ & $\begin{array}{c}0.95 \\
(0.01)\end{array}$ & $\begin{array}{c}0.94 \\
(0.01)\end{array}$ & $\begin{array}{l}-1.10 \\
(0.05)\end{array}$ & $\begin{array}{l}-1.36 \\
(0.06)\end{array}$ & $\begin{array}{l}-1.30 \\
(0.08)\end{array}$ & $\begin{array}{c}-0.23 \\
(0.11)\end{array}$ & $\begin{array}{c}0.03 \\
(0.17)\end{array}$ & $\begin{array}{c}0.07 \\
(0.17)\end{array}$ \\
\hline $\log \left(\pi^{H h} / \pi^{H \ell}\right) \times$ Guidelines & & & $\begin{array}{c}0.014 \\
(0.012)\end{array}$ & & & $\begin{array}{c}-0.08 \\
(0.06)\end{array}$ & & & $\begin{array}{c}-0.06 \\
(0.06)\end{array}$ \\
\hline Federal effort $\xi$ & & & & & & & $\begin{array}{l}-1.02 \\
(0.11)\end{array}$ & $\begin{array}{l}-1.46 \\
(0.17)\end{array}$ & $\begin{array}{c}-1.46 \\
(0.17)\end{array}$ \\
\hline County fixed effects & No & Yes & Yes & No & Yes & Yes & No & Yes & Yes \\
\hline $\mathrm{R}$ squared & 0.79 & 0.93 & 0.93 & 0.20 & 0.46 & 0.46 & 0.23 & 0.48 & 0.48 \\
\hline Observations & \multicolumn{3}{|c|}{2348} & \multicolumn{6}{|c|}{2348} \\
\hline Dependent Variable: & \multicolumn{3}{|c|}{ Federal Effort $\xi$} & \multicolumn{6}{|c|}{ Local Effort $\epsilon$} \\
\hline Panel B: Serious Offenses & (1) & $(2)$ & $(3)$ & (4) & $(5)$ & (6) & (7) & $(8)$ & $(9)$ \\
\hline $\log \left(\pi^{H h} / \pi^{H \ell}\right)$ & $\begin{array}{c}0.83 \\
(0.01)\end{array}$ & $\begin{array}{c}0.90 \\
(0.01)\end{array}$ & $\begin{array}{c}0.89 \\
(0.02)\end{array}$ & $\begin{array}{c}-0.52 \\
(0.04)\end{array}$ & $\begin{array}{l}-0.65 \\
(0.05)\end{array}$ & $\begin{array}{c}-0.66 \\
(0.07)\end{array}$ & $\begin{array}{c}0.13 \\
(0.12)\end{array}$ & $\begin{array}{c}0.08 \\
(0.17)\end{array}$ & $\begin{array}{c}0.07 \\
(0.18)\end{array}$ \\
\hline $\log \left(\pi^{H h} / \pi^{H \ell}\right) \times$ Guidelines & & & $\begin{array}{c}0.020 \\
(0.014)\end{array}$ & & & $\begin{array}{c}-0.003 \\
(0.05)\end{array}$ & & & $\begin{array}{c}-0.02 \\
(0.06)\end{array}$ \\
\hline Federal effort $\xi$ & & & & & & & $\begin{array}{l}-0.77 \\
(0.14) \\
\end{array}$ & $\begin{array}{c}-0.82 \\
(0.19) \\
\end{array}$ & $\begin{array}{c}-0.82 \\
(0.19) \\
\end{array}$ \\
\hline County fixed effects & No & Yes & Yes & No & Yes & Yes & No & Yes & Yes \\
\hline $\mathrm{R}$ squared & 0.86 & 0.94 & 0.94 & 0.13 & 0.36 & 0.36 & 0.16 & 0.38 & 0.38 \\
\hline Observations & & 1101 & & & & & & & \\
\hline
\end{tabular}

Table 6: Correlation between preference alignment and immigration efforts. The table shows regression coefficients for panel regressions of federal and local immigration enforcement efforts on the log of preference alignment $\pi^{H h / \pi^{H \ell}}$. Panel A reports results for cases involving minor offenses, while panel B reports results involving serious offenses. In columns 1-3 the dependent variable is the federal effort $\xi$. In columns 4-9 the dependent variable is the local effort $\epsilon$. Columns 2 , 3, 5-9 include county-level fixed effects. Columns 3, 6, and 9 additionally include an interaction term between preference alignment and a dummy for the period following the federal guidelines change. Columns 7-9 additionally include federal immigration efforts $\xi$ as a regressor. The reported standard errors are robust to arbitrary heteroskedasticity.

share of Mexicans in the pool increases alignment. In contrast, in the most democratic counties large shares of Central American arrestees sharply decrease preference alignment. These patterns could arise if, for example, while the federal level is relatively indifferent between otherwise similar Mexicans and Central Americans, more Democratic counties are less willing to remove Mexicans, and, at the same time, do not favor the rising presence of Central American immigrants. We are unable to find a relationship between our proxy for community collaboration and preference alignment; however, the sample size for which data on 911 calls is available is small.

\subsection{Counterfactual Exercise: No Change in the ICE Guidelines}

Our empirical strategy allowed us to disentangle selection from federal and local enforcement efforts, and to estimate the local response to the federal enforcement margin. Relying on these results, we now asses the effects of the 2011 change in ICE enforcement priority guidelines by implementing a counterfactual exercise exploring how the outcomes of immigration enforcement 


\begin{tabular}{|c|c|c|c|c|c|c|}
\hline \multicolumn{7}{|c|}{ Dependent Variable: Preference Alignment $\log \left(\pi^{H h} / \pi^{H \ell}\right)$} \\
\hline & \multicolumn{3}{|c|}{ Minor Offenses } & \multicolumn{3}{|c|}{ Serious Offenses } \\
\hline & $(1)$ & $(2)$ & $(3)$ & $(4)$ & $(5)$ & $(6)$ \\
\hline Dem. share $\times$ Guidelines & $\begin{array}{c}-0.23 \\
(0.55)\end{array}$ & $\begin{array}{c}-0.25 \\
(0.57)\end{array}$ & $\begin{array}{c}6.20 \\
(2.03)\end{array}$ & $\begin{array}{c}-7.38 \\
(1.50)\end{array}$ & $\begin{array}{c}-7.19 \\
(1.54)\end{array}$ & $\begin{array}{c}12.55 \\
(5.04)\end{array}$ \\
\hline Hispanic share $\times$ Guidelines & $\begin{array}{c}0.52 \\
(0.50)\end{array}$ & $\begin{array}{c}0.51 \\
(0.50)\end{array}$ & $\begin{array}{l}-1.51 \\
(1.34)\end{array}$ & $\begin{array}{c}4.09 \\
(1.18)\end{array}$ & $\begin{array}{c}3.80 \\
(1.20)\end{array}$ & $\begin{array}{c}-2.07 \\
(3.31)\end{array}$ \\
\hline Bachelor degree share $\times$ Guidelines & $\begin{array}{c}-0.72 \\
(0.78)\end{array}$ & $\begin{array}{l}-0.72 \\
(0.77)\end{array}$ & $\begin{array}{l}-6.03 \\
(2.87)\end{array}$ & $\begin{array}{c}3.98 \\
(1.83)\end{array}$ & $\begin{array}{c}3.66 \\
(1.81)\end{array}$ & $\begin{array}{c}-9.74 \\
(6.26)\end{array}$ \\
\hline Mexican share & & $\begin{array}{l}-1.53 \\
(0.63)\end{array}$ & & & $\begin{array}{l}-2.39 \\
(1.02)\end{array}$ & \\
\hline Central American share & & $\begin{array}{l}-4.81 \\
(0.69)\end{array}$ & & & $\begin{array}{c}-5.64 \\
(1.25)\end{array}$ & \\
\hline Young share & & $\begin{array}{c}-1.32 \\
(0.4)\end{array}$ & & & $\begin{array}{c}-1.09 \\
(0.76)\end{array}$ & \\
\hline Mexican share $\times$ Dem. share & & $\begin{array}{c}6.71 \\
(3.77)\end{array}$ & & & $\begin{array}{l}15.19 \\
(6.11)\end{array}$ & \\
\hline Central American share $\times$ Dem. share & & $\begin{array}{l}-4.50 \\
(4.43)\end{array}$ & & & $\begin{array}{r}-17.69 \\
(6.33)\end{array}$ & \\
\hline Young share $\times$ Dem. share & & $\begin{array}{l}-3.33 \\
(2.59)\end{array}$ & & & $\begin{array}{l}-3.38 \\
(3.72)\end{array}$ & \\
\hline 911 calls & & & $\begin{array}{c}0.55 \\
(0.42)\end{array}$ & & & $\begin{array}{l}-1.56 \\
(1.20)\end{array}$ \\
\hline 911 calls $\times$ Dem. share & & & $\begin{array}{c}-2.72 \\
(1.59)\end{array}$ & & & $\begin{array}{c}4.12 \\
(4.51)\end{array}$ \\
\hline R squared & 0.02 & 0.03 & 0.07 & 0.04 & 0.05 & 0.15 \\
\hline Observations & 2348 & 2347 & 462 & 1101 & 1095 & 235 \\
\hline
\end{tabular}

Table 7: Correlation between preference alignment and observable characteristics. The table reports coefficients for county fixed effects models. The dependent variable in all specifications is log of preference alignment $\pi^{H h} / \pi^{H l}$, for minor offenses cases in columns 1-3, and for serious offenses cases in columns 4-6. Each observation corresponds to a county-semester. Beside the county fixed effects and semester fixed effects, the explanatory variables include county characteristics interacted with the policy change as well as several time varying county-specific covariates. Democratic party share is an average of the 2008 and 2012 Democratic Presidential vote shares minus 50 percent, taken from David Leip's Electoral Atlas. Bachelor degree share is measured as the fraction of the adult population with at least a bachelor's degree. Hispanic share is measured as the fraction of the population who is hispanic. Bachelor degree share and Hispanic share are taken from the 2006-2010 waves of the American Communities Survey. Guidelines is a dummy variable indicating the semesters after the policy guidelines change under the Obama administration. Mexican share is the fraction of detainers issued against unlawfully present Mexican nationals in a given county-semester. Central American share is the fraction of detainers issued against unlawfully present Central American nationals in a given county-semester. Young share is the fraction of detainers issued against unlawfully present immigrants less than 30 years old. The Mexican, Central American and Young shares are taken from the TRAC detainers dataset. 911 calls is the log of the total number of calls to the emergency number 911 at the county-year level. Standard errors are robust to arbitrary heteroskedasticity. 
under Secure Communities would have evolved in the absence of a change in guidelines. Recall that within our framework, the policy change manifests itself in two ways: first, changes in preferences over the pool of arrestees (and in particular over our measure of preference alignment) reflect changes in ICE removal priorities. Second, the federal enforcement efforts, which we have abstained from modeling, may have changed in response to the shock to the policy environment. In fact, the underlying relationship between preference alignment $\pi^{H h} / \pi^{H \ell}$ and federal efforts $\xi$ may have changed in the post-guidelines period.

Thus, our exercise consists in taking the recovered relationship between $\xi$ and $\pi^{H h} / \pi^{H \ell}$ across counties in the pre-guidelines period (by regressing $\xi$ on $\pi^{H h} / \pi^{H \ell}$ ), and using it to predict the federal enforcement efforts $\hat{\xi}$ in the post-guidelines period that would have occurred under the actual $\pi^{H h} / \pi^{H \ell}$ 's, were the pre-guidelines regime still to hold. In this way we hold selection constant. With these counterfactual federal efforts for the post-guidelines period we then use the best responses for each county to predict the counterfactual local enforcement efforts $\hat{\epsilon}$ that would have been observed in response to these federal efforts. ${ }^{41}$ Armed with these counterfactual $\hat{\epsilon}$ 's and $\hat{\xi}^{\prime}$ 's, and using our parameter estimates, we recover the implied counterfactual enforcement probabilities $\left\{\hat{f}, \hat{g}, \hat{k}, \hat{q}^{h}, \hat{q}^{\ell}\right\}$. Finally, combining the preference alignments recovered for all the post-guidelines periods with these counterfactual enforcement probabilities, we recover the counterfactual immigration enforcement outcomes $\mathbb{P}$ (ICE Custody|Detainer), $\mathbb{P}$ (Removal|ICE Custody, Detainer), and $\mathbb{P}$ (Removal|ICE Custody, No Detainer) using equations (3), (4), and (12). ${ }^{42}$

In Figure 8 we present the results of this counterfactual exercise. Each subfigure plots the time evolution of the cross-county distribution of one of the immigration enforcement outcomes along the immigration enforcement pipeline. The top panel presents the plots for minor offenses cases, while the bottom panel presents the plots for serious offenses cases. Panel a illustrates a 5 percentage points across the board downward shift of the distribution of $\mathbb{P}$ (ICE Custody|Detainer). In the absence of the guidelines, federal enforcement efforts $\xi^{\text {minor }}$ are predicted to be higher for most counties (see the scatterplot in Figure B.4). Strategic substitutability in the local best response of most counties implies that counties would have cut back even further on local immigration enforcement towards minor offenses cases, resulting in lower numbers of such $\ell$-type arrests being passed down into ICE custody after a detainer issuance ( $g$, on average, would have fallen considerably).

The direct consequence of lower local collaboration with ICE can be gauged in panel b. The distribution of $\mathbb{P}$ (Removal|ICE Custody, Detainer) shifts upwards by around 2 percentage points. This increase in the overall probabilities of removal at the ICE custody stage following

\footnotetext{
${ }^{41}$ Notice that while the first step where we obtain counterfactual $\hat{\xi}$ 's based on $\pi^{H h} / \pi^{H \ell}$ is purely predictive, the second step that recovers counterfactual $\hat{\epsilon}$ 's based on $\hat{\xi}$ 's is causal.

${ }^{42}$ We cannot recover the baseline rates $\mathbb{P}$ (Detainer|Arrest) or $\mathbb{P}$ (ICE Custody|No Detainer) from equations (2) and (11) of each track because we only observe $\pi^{H h} / \pi^{H \ell}$ but not $\pi^{H h}$ and $\pi^{H \ell}$ separately.
} 


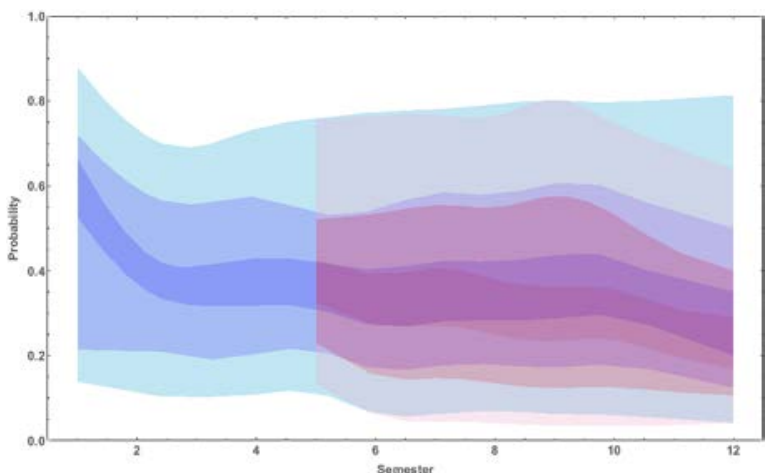

(a) $\mathbb{P}($ ICE Custody $\mid$ Detainer $)$

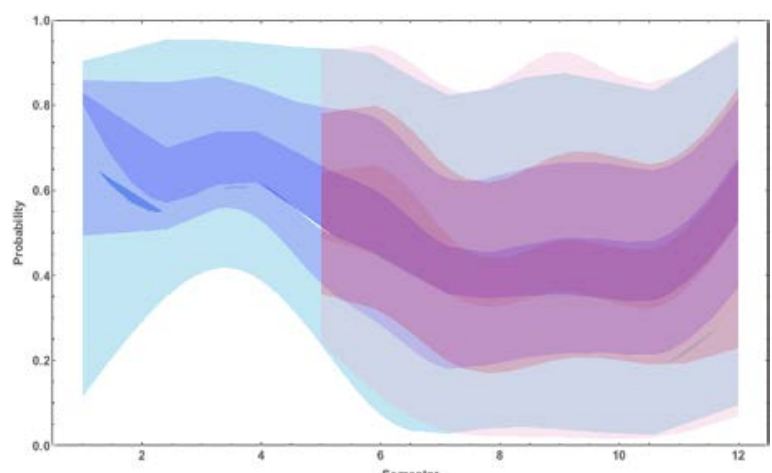

(d) $\mathbb{P}($ ICE Custody $\mid$ Detainer $)$

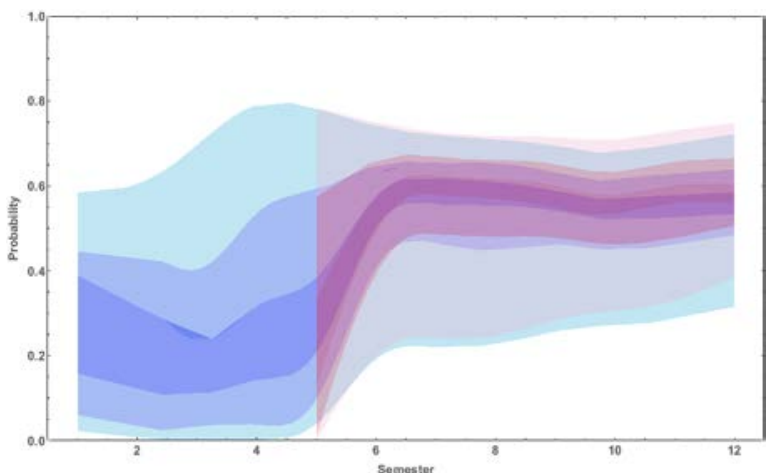

(b) $\mathbb{P}($ Removal|ICE Custody, Detainer)

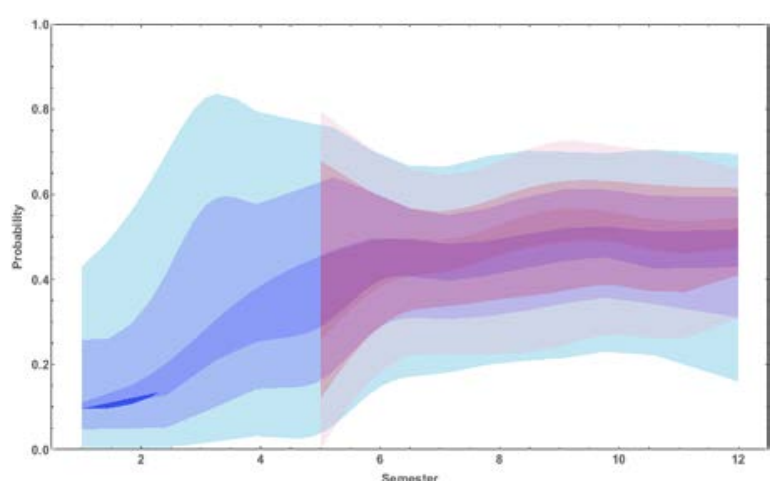

(e) $\mathbb{P}($ Removal|ICE Custody, Detainer)

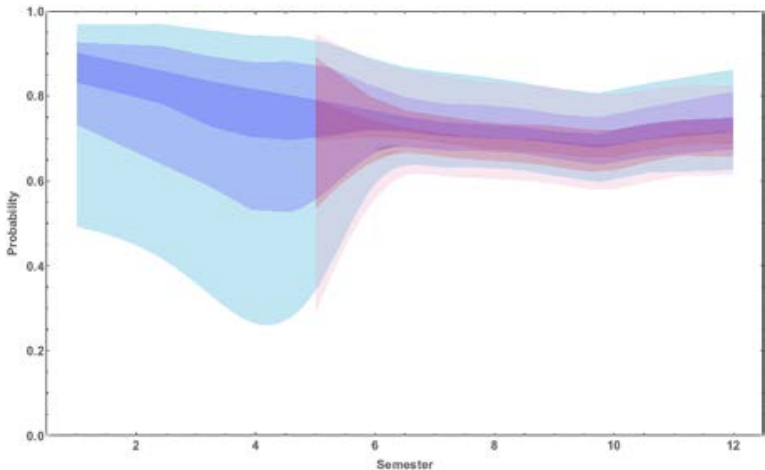

(c) $\mathbb{P}$ (Removal|ICE Custody, No Detainer)

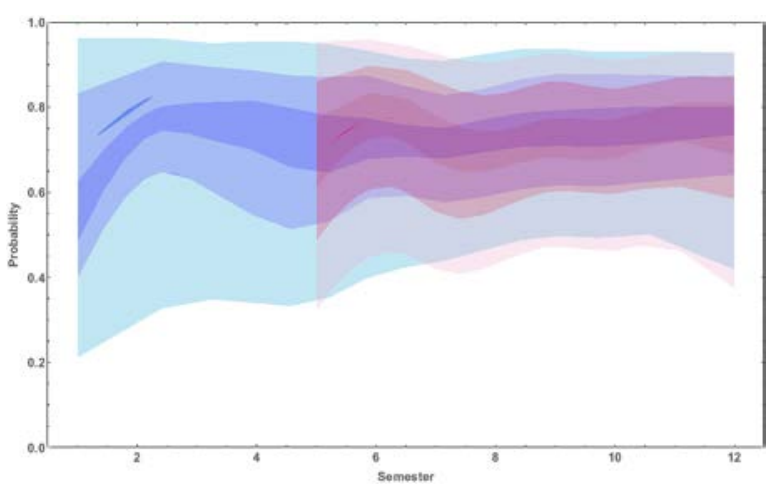

(f) $\mathbb{P}$ (Removal|ICE Custody, No Detainer)

Figure 8: Counterfactual Evolution of Immigration Enforcement Outcomes in the Absence of Guideline Changes. The figure plots the evolution over time of the distribution of immigration enforcement outcomes across counties. The distributions of outcomes predicted by the model are depicted in shades of blue. The distributions of counterfactual outcomes in the absence of guideline changes are depicted in shades of red. The lightest shade regions represent the 10th to 26 th and of blue. The distributions of counterfactual outcomes in the absence of guideline changes are depicted in shades of red. The lightest shade regions represent the 10 th to 26 th and
74 th to 90 th quantiles. The intermediate shade regions represent the 26 th to 42 nd and 58 th to 74 th quantiles. The darkest shade region represents the 42 nd to 58 th quantiles. The top three panels depict the distributions for minor offenses cases. The bottom three panels depict the distributions for serious offenses cases. 
a detainer issuance results from a selection effect that interacts with court-level preferences: the weakening of local efforts means that the pool of arrestees that moves onto ICE custody becomes selected towards more $h$ types relative to $\ell$ types. Because on average $q^{h}>q^{\ell}$ (see Table 3), the pool of unlawfully present immigrants facing the removal stage is composed of people more likely be removed, making the conditional removal rate go up. ${ }^{43}$

In contrast, the opposite pattern takes places along the direct track. Panel c illustrates that the distribution of $\mathbb{P}$ (Removal|ICE Custody, No Detainer) shifts down by 3 to 4 percentage points. This happens because along the direct track, higher federal enforcement efforts $\xi^{\text {minor }}$ and lower local enforcement efforts $\epsilon^{\text {minor }}$ both increase $k$ (see Table 3), generating a selection effect over the pool of unlawfully present immigrants in ICE custody without a detainer that shifts its composition towards relatively more $\ell$-types. Because $q^{h}>q^{\ell}$, this pool is less removable from the point of view of the courts.

Under our counterfactual, outcomes for serious offenses cases behave differently, as the bottom panels of Figure 8 illustrate. Panel d shows that the counterfactual distribution of $\mathbb{P}$ (ICE Custody|Detainer), exhibits something close to a mean-preserving spread, of around a fifth of a standard deviation of the predicted distribution. The increased variance under the counterfactual results from mean reversion of our counterfactual federal enforcement efforts: as panel b in Figure B.4 illustrates, county-periods with low predicted federal enforcement have higher than average counterfactual federal enforcement, and vice-versa. As a result, the local enforcement response is heterogeneous across counties: county-periods with relatively low predicted federal enforcement see their counterfactual local enforcement fall, while countyperiods with relatively high predicted federal enforcement see their counterfactual local enforcement increase. On aggregate, these effects do not shift the counterfactual distribution of $\mathbb{P}$ (ICE Custody|Detainer), but they do increase its variance. The magnitude of this spread, however, is not as large because, as we reported in Table 4, the average best response slope for serious offenses cases is considerably smaller than for minor offenses cases, leading to a more nuanced response from the local level.

Panel e then shows that along the detainer track, and relative to its predicted distribution in the absence of guideline changes, an upward shift of around 4 percentage points in the counterfactual distribution of $\mathbb{P}$ (Removal|ICE Custody, Detainer) takes place. This aggregate shift results from how removal rates respond to changes in federal enforcement efforts, and not from a systematic selection effect as was the case for minor offenses cases. In particular, from Table 3, notice that for serious crimes cases, $q^{\ell}$ is an increasing function, whereas $q^{h}$ is a decreasing function of $\xi^{\text {serious }}$. Thus, for counties that would have experienced increased federal efforts, on average the consequent increase in $\ell$-type removals more than offsets the decrease

\footnotetext{
${ }^{43}$ Of course, our counterfactual exercise supposes that court-level preferences remain unchanged in the absence of the guideline changes.
} 
in $h$-type removals. Analogously, for counties that would have experienced decreased federal efforts, on average the consequent increase in $h$-type removals more than offsets the decrease in $\ell$-type removals. Notice that the absence of guidelines would have magnified the local-federal conflict over immigration enforcement in the following sense: places where the local level reacts by weakening enforcement end up seeing the removal of relatively more $\ell$ types, precisely the types of unlawfully present immigrants that the county would have preferred not be removed.

Finally looking at panel f, along the direct track we observe a small downward shift of the counterfactual distribution of $\mathbb{P}$ (Removal|ICE Custody, No Detainer), particularly in the last semesters under consideration. Besides $q^{\ell}$ and $q^{h}, k$ also changes with both federal and local efforts. For serious offenses cases along the direct track, the local strategic substitutability of most counties reinforces the effect that federal efforts have on the rate at which arrested individuals move onto ICE custody (we estimate $k$ to be increasing in $\xi$ and decreasing in $\epsilon$ ). As a result, in counties where $q^{\ell}$ falls in response to weakened federal enforcement, $k$ also falls leading to relatively less $\ell$ types removed, and on aggregate a lower removal rate. Overall, this exercise illustrates that even holding the distribution of the underlying pool of arrestees constant, the selection forces induced by the immigration enforcement process under Secure Communities interact with preferences at the court stage in such way that had the guidelines not changed in 2011, the patterns of immigration enforcement outcomes resulting from the equilibrium responses of the local level would have antagonized the average large and urban county even more than we observed.

\subsection{Model Validation: The California Trust Act}

We conclude with a validation exercise for our model, based on California's Trust Act. This law passed in 2013 and came into effect on January 2014. It imposed stringent limits on locallevel collaboration with detainer requests from ICE. Under the Trust Act, local police are only allowed to honor detainers falling into a specific list of relatively serious offenses. ${ }^{44}$ Our model does not account for the passage of the Trust Act, giving us an opportunity to assess whether our estimates of local immigration enforcement efforts do capture the patterns we expected to have taken place under this law. Figure 9 presents the evolution over time of the median of our estimated local immigration enforcement efforts $\epsilon$, distinguishing between California counties (in red) and all other counties (in blue) in our sample. The vertical line indicates the activation of the Trust Act. As expected, local efforts over minor offenses cases fall sharply for California counties at the time of the policy change, which we illustrate in panel a. The Trust Act allowed local law enforcement to collaborate with ICE for the most serious offenses

\footnotetext{
${ }^{44}$ For a detailed description of the Trust Act and the list of offenses for which the county officials are allowed to cooperate with ICE, see California (2014).
} 


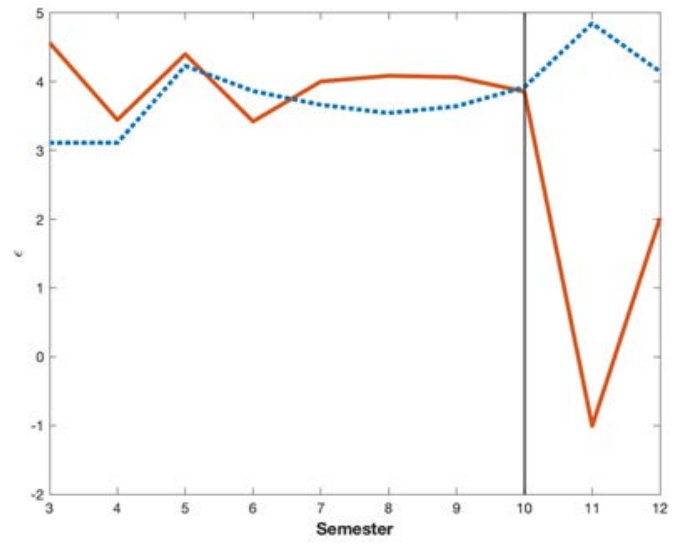

(a) Minor offenses

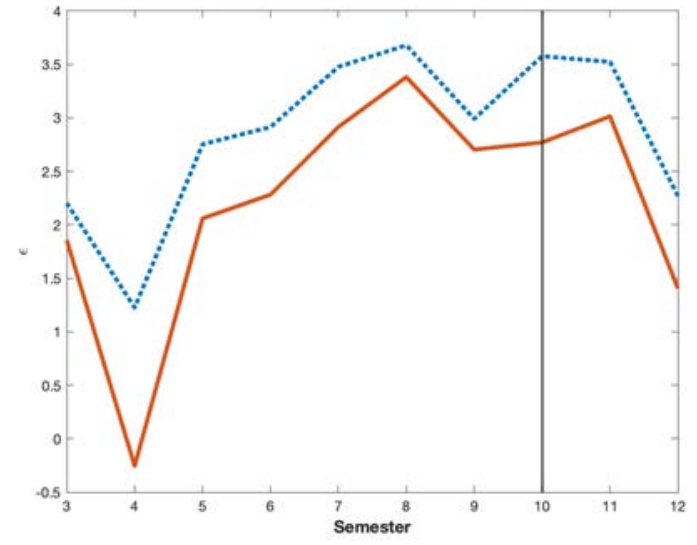

(b) Serious offenses

Figure 9: Evolution of Local immigration enforcement efforts and the California Trust

Act. The figure plots the evolution over time of the median of the estimated local immigration enforcement efforts $\epsilon$ across counties. The red line depicts the median for California counties. The blue line depicts the median for all other US counties. The vertical black line represents the semester of implementation of the Trust Act. Panel a reports the medians for minor offenses cases. Panel $\mathrm{b}$ reports the medians for serious offenses cases. The number of California counties is 30 for minor offenses and 24 for serious offenses. The number of non-California counties is 447 for minor offenses and 199 for serious offenses.

cases, however. Consistent with our expectations, panel b shows that for serious offenses cases, California counties experienced a decline in local effort not dissimilar to what happened in the rest of the US. We see these results as validating the ability of our model to capture accurately the patterns of immigration enforcement under Secure Communities.

\section{Concluding Remarks}

In this paper we study immigration enforcement under the Secure Communities program, as a window onto conflict over policy under federalism. We emphasize the importance of the strategic interaction between local and federal levels, and propose an empirical strategy to disentangle the roles of selection, local, and federal enforcement efforts, as drivers of the variation in immigration enforcement outcomes. We do this by modeling in detail the immigration enforcement process. Our strategy relies on rich data from the Secure Communities program, describing in detail the pipeline taking unlawfully present immigrants arrested by local law enforcement onto ICE custody and eventually deportation. We find strong evidence of strategic substitutabilities in the response of the local level (county) to changes in federal level immigration enforcement, particularly among the most Democratic counties. We also find that a large fraction of the variation in the observed changes in the outcomes of immigration enforcement, such as the rates at which individuals are handed into ICE custody and are deported, are driven by changes in the composition of the pool of individuals entering into the enforcement pipeline. ICE is very efficient at directing its enforcement efforts towards counties where it can expect local 
collaboration (possibly because of the considerable informational advantage it acquired under Secure Communities). In ongoing research we are exploring empirically the local-level trade-off between law enforcement and immigration enforcement. Subsequent research should also be directed at understanding the drivers of federal-level preferences over immigration outcomes.

\section{References}

Alsan, M. And C. Yang (2018): "Fear and the Safety Net: Evidence from Secure Communities," NBER Working paper no. 24731.

Amuedo-Dorantes, C., T. Puttitanun, And A. Martinez-Donate (2013): "How do Tougher Immigration Measures Impact Unauthorized Immigrants?" Institute for the Study of Labor Discussion Paper No. 7134 .

Besley, T. And A. CASE (2000): "Unnatural Experiments? Estimating the Incidence of Endogenous Policies," The Economic Journal, 110, 672-694.

Besley, T. And S. Coate (2003): "Centralized versus Decentralized Provision of Local Public Goods: A Political Economy Approach," Journal of Public Economics, 87, 2611-2637.

Bohn, S., M. Freedman, and E. Owens (2015): "The Criminal Justice Response to Policy Interventions: Evidence from Immigration Reform," American Economic Review: Papers and Proceedings, 105, 214-219.

Boushey, G. And A. LuedtKe (2011): "Immigrants across the US Federal Laboratory: Explaining State-Level Innovation in Immigration Policy," State Politics and Policy Quarterly, 11, 390-414.

California (2014): "Immigration Law -Criminal Justice and Immigration Enforcement -California Limits Local Entities' Compliance with Immigration and Customs Enforcement Detainer Requests. - Trust Act, 2013 Cal. Stat. 4650," Harvard Law Review, 127, 2593-2600.

Cox, A. And T. Miles (2013): "Policing Immigration," University of Chicago Law Review, 80, 87-136.

Davila, A., J. Pagán, And M. Grau (1999): "Immigration Reform, the INS, and the Distribution of Interior and Border Enforcement," Public Choice, 99, 327-345.

Dee, T. And M. Murphy (2018): "Vanished Classmates: The Effects of Local Immigration Enforcement on Student Enrollment," NBER Working paper no. 25080.

DeTocqueville, A. (2003 [1840]): Democracy in America, London, UK: Penguin Classics.

Fasani, F. (2009): "Deporting Undocumented Immigrants: The Role of Labor Demand Shocks," Unpublished.

Freedman, M., E. Owens, and S. Bohn (2018): "Immigration, Employment Opportunities, and Criminal Behavior," American Economic Journal: Economic Policy, 10, 117-151.

Fu, C. AND K. Wolpin (2018): "Structural Estimation of a Becker-Ehrlich Equilibrium Model of Crime: Allocating Police Across Cities to Reduce Crime," Review of Economic Studies, 85, 2097-2138.

García-Jimeno, C. (2016): "The Political Economy of Moral Conflict: An Empirical Study of Learning and Law Enforcement under Prohibition," Econometrica, 84, 511-570.

Gulasekaram, P. and S. K. Ramakrishnan (2015): The New Immigration Federalism, New York, NY.: Cambridge University Press.

Guttin, A. (2010): "The Criminal Alien Program: Immigration Enforcement in Travis County, Texas," Immigration Policy Center Special Report. 
Hill, L. And H. Johnson (2011): Unauthorized Immigrants in California: Estimates for Counties, San Francisco, CA: Public Policy Institute of California.

Hirota, H. (2013): "The Moment of Transition: State Officials, the Federal Government, and the Formation of American Immigration Policy," The Journal of American History, 99, 1092-1108.

Hooghe, L. And G. Marks (2003): "Unraveling the Central State, but How? Types of Multi-level Governance," American Political Science Review, 97, 233-243.

Hutchinson, E. P. (2016): Legislative History of American Immigration Policy, 1798-1965, Philadelphia, PA: University of Pennsylvania Press.

ICE (2008): "Immigration and Customs Enforcement Standard Operating Procedures," Government document, Washington D.C.

Imrohoroglu, A., A. Merlo, And P. Rupert (2000): "On the Political Economy of Income Redistribution and Crime," International Economic Review, 41, 1-25.

Inman, R. And D. Rubinfeld (1997a): Perspectives on Public Choice, Cambridge, UK: Cambridge University Press, chap. The Political Economy of Federalism.

_ (1997b): "Rethinking Federalism," The Journal of Economic Perspectives, 11, 43-64.

Johnson, J. (2014): "Secure Communities," Memorandum. US Department of Homeland Security.

Kalhan, A. (2013): "Immigration Policing and Federalism Through the Lens of Technology, Surveillance, and Privacy," Ohio State Law Journal, 74, 1106-1165.

Knight, B. (2002): "Endogenous Federal Grants and Crowd-out of State Government Spending: Theory and Evidence from the Federal Highway Aid Program," The American Economic Review, 92, 71-92.

Lalive, R. And J. Zweimuller (2004): "Benefit Entitlement and Unemployment Duration. The Role of Policy Endogeneity," Journal of Public Economics, 88, 2587-2616.

Lewis, P., D. M. Provine, and M. Varsanyi (2013): "Why do (Some) City Police Departments Enforce Federal Immigration Law? Political, Demographic, and Organizational Influences on Local Choices," Journal of Public Administration Research and Theory, 23, 1-25.

Lewis, P. and K. Ramakrishnan (2007): "Police Practices in Immigrant-Destination Cities," Urban Affairs Review, 42, 874-900.

Lockwood, B. (2002): "Distributive Politics and the Benefits of Decentralization," Review of Economic Studies, 69, 313-338.

Madison, J. (1788): Restrictions on the Authority of the Several States (Federalist Paper No. 44), U.S. Congress.

Manuel, K. (2012): "Immigration Detainers: Legal Issues," Crs report for congress, Congressional Research Service, Washington D.C.

MaydA, A. M. (2006): "Who is Against Immigration? A Cross-Country Investigation of Individual Attitudes Toward Immigrants," The Review of Economics and Statistics, 88, 510-530.

Meyer, B. (1995): "Natural and Quasi-Natural Experiments in Economics," Journal of Business and Economic Statistics, 13, 151-161.

Miles, T. And A. Cox (2014): "Does Immigration Enforcement Reduce Crime? Evidence from Secure Communities," The Journal of Law and Economics, 57, 937-973. 
Morton, J. (2011a): "Exercising Prosecutorial Discretion Consistent with the Civil Immigration Enforcement Priorities of the Agency for the Apprehension, Detention, and Removal of Aliens," Memorandum 10075.1, US Immigration and Customs Enforcement.

(2011b): "Prosecutorial Discretion: Certain Victims, Witnesses, and Plaintiffs," Memorandum 10076.1, US Immigration and Customs Enforcement.

Motomura, H. (2011): "The Discretion that Matters: Federal Immigration Enforcement, State and Local Arrests, and the Civil-Criminal Line," UCLA Law Review, 58, 167-206.

OAtes, W. (1999): “An Essay on Fiscal Federalism,” Journal of Economic Literature, 37, 1120-1149.

Passel, J. (2005): Estimates of the Size and Characteristics of the Undocumented Population, Washington D.C.: Pew Hispanic Center.

Pham, H. (2006): "The Constitutional Right Not to Cooperate?: Local Soveraignty and the Federal Immigration Power," University of Cincinnati Law Review, 74, 1374-1413.

Ramakrishnan, K. and P. Gulasekaram (2013): "The Importance of the Political in Immigration Federalism," Arizona State Law Journal, 44, 1431-1488.

Reaves, B. (2010): Census of State and Local Law Enforcement Agencies, Washington D.C.: Bureau of Justice Statistics.

Rosenzweig, M. And K. Wolpin (1986): "Evaluating the Effects of Optimally Distributed Public Programs: Child Heath and Family Planning Interventions," The American Economic Review, 76, 470-482.

Schmall, L. (2009): "ICE Effects: Federal Worksite Non-Enforcement of U.S. Immigration Laws, 2007-2008," University of San Francisco Law Review, 44.

Steil, J. P. AND I. B. VAsi (2014): "The New Immigration Contestation: Social Movements and Local Immigration Policy Makign in the United States, 2000-2011," American Journal of Sociology, 119, 11041155.

Strumpf, K. and F. Oberholzer-Gee (2002): "Endogenous Policy Decentralization: Testing the Central Tenet of Economic Federalism," Journal of Political Economy, 110, 1-36.

Thompson, D. (2018): "How Partisan is Local Law Enforcement? Evidence from Sheriff Cooperation with Immigration Authorities," Unpublished.

Tiebout, C. (1956): "A Pure Theory of Local Expenditures," Journal of Political Economy, 64, 416-424.

Treyger, E., A. Chalfin, And C. Loeffler (2014): "Immigration Enforcement, Policing, and Crime," Criminology and Public Policy, 13, 285-322.

Tullock, G. (1969): "Federalism: Problems of Scale," Public Choice, 6, 19-29.

VArgas, E. (2015): "Immigration Enforcement and Mixed-Status Families: The Effects of Risk of Deportation on Medicaid Use," Child Youth Services Review, 57, 83-89.

Verini, J. (2012): "Obama's Deportation Two Step," .

Warren, R. And J. R. Warren (2012): "Unauthorized Immigration to the United States: Annual Estimates and Components of Change, by State, 1990 to 2010," University of Minnesota.

Watson, T. (2014): "Inside the Refrigerator: Immigration Enforcement and Chilling Effects in Medicaid Participation," American Economic Journal: Economic Policy, 6, 313-338.

Wooldrige, J. (2002): Econometric Analysis of Cross Section and Panel Data, Cambridge, MA: MIT Press.

Zolberg, A. (2006): A Nation by Design: Immigration Policy in the Fashioning of America, Cambridge, MA: Harvard University Press. 


\section{A Online Appendix A}

\section{A.1 Proof of Proposition 1}

Given a vector of observables $\mathbf{w}=\left(x_{1}, x_{2}, x_{3}, y_{1}, y_{2}\right)$, where $x_{1}>x_{2}>x_{3}>0$ and $y_{1}>y_{2}>0$, the following is the exhaustive list of constraints on observed probabilities:

$$
\begin{array}{llll}
0<g<1 & 0<f<1 & 0<q^{\ell}<1 & 0<q^{h}<1 \\
0<k<1 & 0<v^{d}<1 & 0<\pi^{H \ell}<1 & 0<\pi^{H h}<1
\end{array}
$$

The immigration enforcement process also implies:

$$
\begin{gathered}
g=\frac{x_{3}-x_{2} q^{h}}{x_{3}-x_{2} q^{\ell}-x_{1}\left(q^{h}-q^{\ell}\right)} \\
k=\frac{\left(x_{2}-x_{1} g\right)\left(y_{1} q^{h}-y_{2}\right)}{\left(x_{1}-x_{2}\right)\left(y_{2}-y_{1} q^{\ell}\right)} \\
v^{d}\left(\frac{1-f}{f}\right)=\frac{\left(1-x_{1}\right)(1-g)}{x_{2}-x_{1} g} \frac{y_{2}-y_{1} q^{\ell}}{q^{h}-q^{\ell}}
\end{gathered}
$$

Beginning with $g>0$, from equation (A.1) we have two possible cases:

Case Ia:

$$
x_{3}-x_{2} q^{h}>0 \text { and } x_{3}-x_{2} q^{\ell}-x_{1}\left(q^{h}-q^{\ell}\right)>0 \text {, or }
$$

Case Ib:

$$
x_{3}-x_{2} q^{h}<0 \text { and } x_{3}-x_{2} q^{\ell}-x_{1}\left(q^{h}-q^{\ell}\right)<0 .
$$

Under Case Ia,

$$
q^{h}<\frac{x_{3}}{x_{2}} \text { and } q^{\ell}>\frac{x_{3}}{x_{2}-x_{1}}+\frac{x_{1}}{x_{1}-x_{2}} q^{h}
$$

Under Case Ib,

$$
q^{h}>\frac{x_{3}}{x_{2}} \text { and } q^{\ell}<\frac{x_{3}}{x_{2}-x_{1}}+\frac{x_{1}}{x_{1}-x_{2}} q^{h}
$$

From $g<1$, equation(A.1) implies two possible cases:

Case IIa:

$$
q^{h}<\frac{x_{3}}{x_{2}} \text { and } q^{\ell}>\frac{x_{3}}{x_{2}-x_{1}}+\frac{x_{1}}{x_{1}-x_{2}} q^{h} \text { and } q^{h}<q^{\ell} \text {, or }
$$

Case IIb:

$$
q^{\ell}<\frac{x_{3}}{x_{2}-x_{1}}+\frac{x_{1}}{x_{1}-x_{2}} q^{h} \text { and } q^{h}>q^{\ell}
$$

Now we turn to $k>0$ which, together with equation (A.2) yields four possible cases:

Case IIIa:

$$
x_{2}-x_{1} g>0 \text { and } y_{1} q^{h}-y_{2}>0 \text { and } y_{2}-y_{1} q^{\ell}>0 \text {, or }
$$

Case IIIb:

$$
x_{2}-x_{1} g>0 \text { and } y_{1} q^{h}-y_{2}<0 \text { and } y_{2}-y_{1} q^{\ell}<0 \text {, or }
$$

Case IIIc:

$$
x_{2}-x_{1} g<0 \text { and } y_{1} q^{h}-y_{2}<0 \text { and } y_{2}-y_{1} q^{\ell}>0 \text {, or }
$$

Case Illd:

$$
x_{2}-x_{1} g<0 \text { and } y_{1} q^{h}-y_{2}>0 \text { and } y_{2}-y_{1} q^{\ell}<0 .
$$

Under Case IIIa,

$$
g<\frac{x_{2}}{x_{1}} \text { and } q^{h}>\frac{y_{2}}{y_{1}} \text { and } q^{\ell}<\frac{y_{2}}{y_{1}}
$$


Under Case IIIb,

$$
g<\frac{x_{2}}{x_{1}} \text { and } q^{h}<\frac{y_{2}}{y_{1}} \text { and } q^{\ell}>\frac{y_{2}}{y_{1}}
$$

Under Case IIIc,

$$
g>\frac{x_{2}}{x_{1}} \text { and } q^{h}<\frac{y_{2}}{y_{1}} \text { and } q^{\ell}<\frac{y_{2}}{y_{1}}
$$

Under Case IIId,

$$
g>\frac{x_{2}}{x_{1}} \text { and } q^{h}>\frac{y_{2}}{y_{1}} \text { and } q^{\ell}>\frac{y_{2}}{y_{1}}
$$

From $k<1$ together with equation (A.2), we have four cases:

Case IVa: Same constraints as in Case IIIa, which imply

$$
g>\frac{x_{2}}{x_{1}}-\frac{x_{1}-x_{2}}{x_{1}} \frac{y_{2}-y_{1} q^{\ell}}{y_{1} q^{h}-y_{2}}
$$

where the second term in the right-hand side is positive.

Case IVb: Same constraints as in Case IIIb, which imply

$$
g>\frac{x_{2}}{x_{1}}-\frac{x_{1}-x_{2}}{x_{1}} \frac{y_{2}-y_{1} q^{\ell}}{y_{1} q^{h}-y_{2}}
$$

where the second term in the right-hand side is positive.

Case IVc: Same constraints as in Case IIIc, which imply

$$
g<\frac{x_{2}}{x_{1}}-\frac{x_{1}-x_{2}}{x_{1}} \frac{y_{2}-y_{1} q^{\ell}}{y_{1} q^{h}-y_{2}}
$$

where the second term in the right-hand side is negative.

Case IVd: Same constraints as in Case IIId, which imply

$$
g<\frac{x_{2}}{x_{1}}-\frac{x_{1}-x_{2}}{x_{1}} \frac{y_{2}-y_{1} q^{\ell}}{y_{1} q^{h}-y_{2}}
$$

where the second term in the right-hand side is negative.

Now we turn to equation (A.3). Together with $0<f<1$ and $0<v^{d}<1$, it implies four possible cases:

Case Va:

$$
g<\frac{x_{2}}{x_{1}} \text { and } q^{\ell}<\frac{y_{2}}{y_{1}} \text { and } q^{h}>q^{\ell} \text {, or }
$$

Case Vb:

$$
g<\frac{x_{2}}{x_{1}} \text { and } q^{\ell}>\frac{y_{2}}{y_{1}} \text { and } q^{h}<q^{\ell} \text {, or }
$$

Case Vc:

$$
g>\frac{x_{2}}{x_{1}} \text { and } q^{\ell}>\frac{y_{2}}{y_{1}} \text { and } q^{h}>q^{\ell} \text {, or }
$$

Case Vd:

$$
g>\frac{x_{2}}{x_{1}} \text { and } q^{\ell}<\frac{y_{2}}{y_{1}} \text { and } q^{h}<q^{\ell} .
$$

Collecting cases II, IV, and V, we have four possible regions in $\left(q^{h}, q^{\ell}\right)$ space with corresponding ranges for $g:$

Region I:

$$
I=\left\{\left(q^{h}, q^{\ell}, g\right): q^{h} \in\left[0, \frac{y_{2}}{y_{1}}\right], q^{\ell} \in\left[\frac{y_{2}}{y_{1}}, 1\right], g \in\left(\frac{x_{2}}{x_{1}}-\frac{x_{1}-x_{2}}{x_{1}} \frac{y_{2}-y_{1} q^{\ell}}{y_{1} q^{h}-y_{2}}, \frac{x_{2}}{x_{1}}\right)\right\}
$$


Region II:

$$
I I=\left\{\left(q^{h}, q^{\ell}, g\right): q^{h} \in\left[\frac{y_{2}}{y_{1}}, 1\right], q^{\ell} \in\left[\frac{y_{2}}{y_{1}}, 1\right], q^{h}>q^{\ell}, g \in\left(\frac{x_{2}}{x_{1}}, \frac{x_{2}}{x_{1}}-\frac{x_{1}-x_{2}}{x_{1}} \frac{y_{2}-y_{1} q^{\ell}}{y_{1} q^{h}-y_{2}}\right)\right\}
$$

Region III:

$$
I I I=\left\{\left(q^{h}, q^{\ell}, g\right): q^{h} \in\left[0, \frac{y_{2}}{y_{1}}\right], q^{\ell} \in\left[0, \frac{y_{2}}{y_{1}}\right], q^{h}<q^{\ell}, g \in\left(\frac{x_{2}}{x_{1}}, \frac{x_{2}}{x_{1}}-\frac{x_{1}-x_{2}}{x_{1}} \frac{y_{2}-y_{1} q^{\ell}}{y_{1} q^{h}-y_{2}}\right)\right\}
$$

Region IV:

$$
I V=\left\{\left(q^{h}, q^{\ell}, g\right): q^{h} \in\left[\frac{y_{2}}{y_{1}}, 1\right], q^{\ell} \in\left[0, \frac{y_{2}}{y_{1}}\right], g \in\left(\frac{x_{2}}{x_{1}}-\frac{x_{1}-x_{2}}{x_{1}} \frac{y_{2}-y_{1} q^{\ell}}{y_{1} q^{h}-y_{2}}, \frac{x_{2}}{x_{1}}\right)\right\}
$$

Now we can turn to $0<\pi^{H \ell}<1$ and $0<\pi^{H h}<1$. Together these imply that $\pi^{H h} / \pi^{H \ell}>0$. From equation (8), it follows that

$$
g<\frac{x_{2}}{x_{1}}
$$

This rules out regions II and III.

From equation (9), we have two cases:

Case VIa:

$$
q^{\ell}<\frac{x_{3}}{x_{2}} \text { and } q^{h}>\frac{x_{3}}{x_{2}}, \text { or }
$$

Case VIb:

$$
q^{\ell}>\frac{x_{3}}{x_{2}} \text { and } q^{h}<\frac{x_{3}}{x_{2}} \text {, or }
$$

From equation (8), we have that

$$
\frac{\pi^{H h}}{\pi^{H \ell}}=\frac{y_{1} q^{\ell}-y_{2}}{y_{2}-y_{1} q^{h}} k
$$

which gives two other cases:

Case VIIa:

$$
q^{\ell}>\frac{y_{2}}{y_{1}} \text { and } q^{h}<\frac{y_{2}}{y_{1}}, \text { or }
$$

Case VIIb:

$$
q^{\ell}<\frac{y_{2}}{y_{1}} \text { and } q^{h}>\frac{y_{2}}{y_{1}} \text {, or }
$$

Collecting cases VI and VII together, we have two regions for $\left(q^{h}, q^{\ell}\right)$ :

Region R1:

$$
R_{1}=\left\{\left(q^{h}, q^{\ell}\right): q^{h}<\min \left\{\frac{x_{3}}{x_{2}}, \frac{y_{2}}{y_{1}}\right\}, \text { and } q^{\ell}>\max \left\{\frac{x_{3}}{x_{2}}, \frac{y_{2}}{y_{1}}\right\}\right\}
$$

Region R2:

$$
R_{2}=\left\{\left(q^{h}, q^{\ell}\right): q^{h}>\max \left\{\frac{x_{3}}{x_{2}}, \frac{y_{2}}{y_{1}}\right\}, \text { and } q^{\ell}<\min \left\{\frac{x_{3}}{x_{2}}, \frac{y_{2}}{y_{1}}\right\}\right\}
$$

Notice that the constraints from Cases I and II become redundant relative to the regions defined by $R_{1}$ and $R_{2}$.

Since we have ruled out regions II and III, it follows that $g>\frac{x_{2}}{x_{1}}-\frac{x_{1}-x_{2}}{x_{1}} \frac{y_{2}-y_{1} q^{\ell}}{y_{1} q^{h}-y_{2}}$. From equation (A.1), and $g>0$, we have that if $q^{h}<\frac{x_{3}}{x_{2}}$, then $x_{3}-x_{2} q^{\ell}-x_{1}\left(q^{h}-q^{\ell}\right)>0$. In this case, after some algebra it follows that $g$ attains this lower bound for any

$$
q^{\ell}>\frac{x_{1} y_{2}-x_{3} y_{1}}{y_{1}\left(x_{1}-x_{2}\right)}
$$

Similarly, if $q^{h}>\frac{x_{3}}{x_{2}}$, then $x_{3}-x_{2} q^{\ell}-x_{1}\left(q^{h}-q^{\ell}\right)<0$, in which case $g$ attains this lower bound for any

$$
q^{\ell}<\frac{x_{1} y_{2}-x_{3} y_{1}}{y_{1}\left(x_{1}-x_{2}\right)}
$$


This, together with $R_{1}$ and $R_{2}$ gives us

$$
\mathcal{R}_{1}=\left\{\left(q^{h}, q^{\ell}\right): q^{h}<\min \left\{\frac{x_{3}}{x_{2}}, \frac{y_{2}}{y_{1}}\right\}, \text { and } q^{\ell}>\max \left\{\frac{x_{3}}{x_{2}}, \frac{y_{2}}{y_{1}}, \frac{x_{1} y_{2}-x_{3} y_{1}}{y_{1}\left(x_{1}-x_{2}\right)}\right\}\right\}
$$

and

$$
\mathcal{R}_{2}=\left\{\left(q^{h}, q^{\ell}\right): q^{h}>\max \left\{\frac{x_{3}}{x_{2}}, \frac{y_{2}}{y_{1}}\right\}, \text { and } q^{\ell}<\min \left\{\frac{x_{3}}{x_{2}}, \frac{y_{2}}{y_{1}}, \frac{x_{1} y_{2}-x_{3} y_{1}}{y_{1}\left(x_{1}-x_{2}\right)}\right\}\right\}
$$

so the identified set for $\left(q^{h}, q^{\ell}\right)$ is given by $\mathcal{R}=\mathcal{R}_{1} \cup \mathcal{R}_{2}$. Notice that for any $\left(q^{h}, q^{\ell}\right) \in \mathcal{R}$, the implied values for $g$ and $k$ are always valid probabilities, and $v^{d}(1-f) / f>0$, and $g>\frac{x_{2}}{x_{1}}-\frac{x_{1}-x_{2}}{x_{1}} \frac{y_{2}-y_{1} q^{\ell}}{y_{1} q^{h}-y_{2}}$.

\section{A.2 Inference for the coefficients in equations (19) and (20)}

In equations (19) and (20), $\epsilon_{c t}$ and $\xi_{c t}$ are generated regressors because these residuals are recovered using not the true $\left(\boldsymbol{\delta}^{d}, \boldsymbol{\beta}^{f}, \boldsymbol{\beta}^{g}\right)$ coefficients from equations (17) and (18), but estimates of these coefficients. Thus, we must account for the sampling variation induced by our use of estimates of $\epsilon_{c t}$ and $\xi_{c t}$ on the variance of the estimator for $\left(\boldsymbol{\beta}^{k}, \kappa_{\epsilon}, \kappa_{\xi}, \boldsymbol{\beta}^{q \tau}, \gamma^{\tau}\right)$. Our derivation closely follows (Wooldrige, 2002, p. 139-141). We present below the derivation of the variance-covariance matrix for the OLS estimator of the coefficients in equation (19) only. The corresponding derivation for the OLS estimator of the coefficients in equation (20) is analogous, only simpler because while equation (19) has two generated regressors, equation (20) only has one generated regressor. Consider the log-odds equation

$$
\tilde{k}_{c t}=\mathbf{x}_{c} \boldsymbol{\beta}^{k}+\kappa_{\epsilon} \epsilon_{c t}+\kappa_{\xi} \xi_{c t}+\eta_{c t}
$$

with $\operatorname{dim}\left(\mathbf{x}_{c}\right)=K$, and re-write it as

$$
\tilde{k}_{c t}=\mathbf{x}_{c}^{*} \boldsymbol{\beta}+\eta_{c t}
$$

where $\mathbf{x}_{c}^{*} \equiv\left[\mathbf{x}_{c}, \xi_{c t}, \epsilon_{c t}\right]$, and $\boldsymbol{\beta} \equiv\left[\boldsymbol{\beta}^{k^{\prime}}, \kappa_{\xi}, \kappa_{\epsilon}\right]^{\prime}$. Using equations (18) and (21), we can now notice that $\mathbf{x}_{c}^{*}=$ $\mathcal{F}\left(\mathbf{z}_{c t}, \boldsymbol{\delta}\right)$, where

$$
\mathcal{F}\left(\mathbf{z}_{c t}, \boldsymbol{\delta}\right)=\mathbf{z}_{c t} \Delta(\boldsymbol{\delta})
$$

where $\boldsymbol{\delta} \equiv\left[\boldsymbol{\delta}^{d^{\prime}},-\boldsymbol{\beta}^{f^{\prime}},-\boldsymbol{\beta}^{g^{\prime}}\right], \mathbf{z}_{c t} \equiv\left[\mathbf{x}_{c}, v_{c t}^{d}, \overline{\tilde{f}}, \tilde{g}\right], v_{c t}^{d} \equiv(0, \ldots 1 \ldots, 0)$ is a vector of dimensions $1 \times D$ where $D$ is the number of federal districts minus one that has a 1 in the column corresponding to the district that county $c$ belongs to, and

$$
\Delta(\boldsymbol{\delta}) \equiv\left[\begin{array}{ccc}
\mathbf{I}_{K \times K} & -\boldsymbol{\beta}^{f} & -\boldsymbol{\beta}^{g} \\
\mathbf{0}_{D \times 1} & \boldsymbol{\delta}^{d} & \mathbf{0}_{D \times 1} \\
0 & 1 & 0 \\
0 & 0 & 1
\end{array}\right]
$$

Define $T_{c}$ as the number of time periods available for county $c$, and thus $N \equiv \sum_{c} T_{c}$ as the total number of observations. We have a $\sqrt{N}$ consistent estimator of $\boldsymbol{\delta}$, namely $\hat{\boldsymbol{\delta}}=\left[\hat{\boldsymbol{\delta}}_{O L S}^{d^{\prime}},-\hat{\boldsymbol{\beta}}_{O L S}^{f^{\prime}},-\hat{\boldsymbol{\beta}}_{O L S}^{g^{\prime}}\right]$, where

$$
\left[\begin{array}{l}
\hat{\boldsymbol{\delta}}_{O L S}^{d} \\
\hat{\boldsymbol{\beta}}_{O L S}^{f}
\end{array}\right]=\left(\sum \mathbf{x}_{c}^{F^{\prime}} \mathbf{x}_{c}^{F}\right)^{-1}\left(\sum \mathbf{x}_{c}^{F^{\prime}} \overline{\tilde{f}}_{c t}\right), \quad \mathbf{x}_{c}^{F^{\prime}} \equiv\left[v_{c t}^{d}, \mathbf{x}_{c}\right]
$$

and

$$
\hat{\boldsymbol{\beta}}_{O L S}^{g}=\left(\sum \mathbf{x}_{c}^{\prime} \mathbf{x}_{c}\right)^{-1}\left(\sum \mathbf{x}_{c}^{\prime} \tilde{g}_{c t}\right)
$$

We do not observe the $\mathbf{x}_{c}^{*}$ because we do not observe $\boldsymbol{\delta}$. However, we have a consistent estimate of $\boldsymbol{\delta}$, namely $\hat{\boldsymbol{\delta}}$, so we can compute

$$
\hat{\mathbf{x}}_{c}^{*}=\mathcal{F}\left(\mathbf{z}_{c t}, \hat{\boldsymbol{\delta}}\right) .
$$

It is these $\hat{\mathbf{x}}_{c}^{*}$ we use to estimate $\boldsymbol{\beta}$ in the regression equation for $\tilde{k}_{c t}$. Our OLS estimator for $\boldsymbol{\beta}$ is

$$
\hat{\boldsymbol{\beta}}=\left(\sum \hat{\mathbf{x}}_{c}^{*^{\prime}} \hat{\mathbf{x}}_{c}^{*}\right)^{-1}\left(\sum \hat{\mathbf{x}}_{c}^{*^{\prime}} \tilde{k}_{c t}\right)
$$


We can re-write equation (A.4) as

$$
\tilde{k}_{c t}=\hat{\mathbf{x}}_{c}^{*} \boldsymbol{\beta}+\left(\mathbf{x}_{c}^{*}-\hat{\mathbf{x}}_{c}^{*}\right) \boldsymbol{\beta}+\eta_{c t}
$$

and replace it above to obtain

$$
\hat{\boldsymbol{\beta}}=\boldsymbol{\beta}+\left(\sum \hat{\mathbf{x}}_{c}^{*^{\prime}} \hat{\mathbf{x}}_{c}^{*}\right)^{-1}\left(\sum \hat{\mathbf{x}}_{c}^{*^{\prime}}\left(\mathbf{x}_{c}^{*}-\hat{\mathbf{x}}_{c}^{*}\right) \boldsymbol{\beta}+\sum \hat{\mathbf{x}}_{c}^{*^{\prime}} \eta_{c t}\right)
$$

Thus,

$$
\sqrt{N}(\hat{\boldsymbol{\beta}}-\boldsymbol{\beta})=\left(N^{-1} \sum \hat{\mathbf{x}}_{c}^{*^{\prime}} \hat{\mathbf{x}}_{c}^{*}\right)^{-1}\left(N^{-1 / 2} \sum \hat{\mathbf{x}}_{c}^{*^{\prime}}\left(\mathbf{x}_{c}^{*}-\hat{\mathbf{x}}_{c}^{*}\right) \boldsymbol{\beta}+N^{-1 / 2} \sum \hat{\mathbf{x}}_{c}^{*^{\prime}} \eta_{c t}\right)
$$

Notice that

$$
\hat{\mathbf{C}} \equiv N^{-1} \sum \hat{\mathbf{x}}_{c}^{*^{\prime}} \hat{\mathbf{x}}_{c}^{*} \rightarrow^{p} \mathbb{E}\left[\hat{\mathbf{x}}_{c}^{*^{\prime}} \hat{\mathbf{x}}_{c}^{*}\right]
$$

and

$$
N^{-1 / 2} \sum \hat{\mathbf{x}}_{c}^{*^{\prime}} \eta_{c t}=N^{-1 / 2} \sum \mathbf{x}_{c}^{*^{\prime}} \eta_{c t}+o_{p}(1)
$$

The remaining term can be expressed as

$$
N^{-1 / 2} \sum \hat{\mathbf{x}}_{c}^{*^{\prime}}\left(\mathbf{x}_{c}^{*}-\hat{\mathbf{x}}_{c}^{*}\right) \boldsymbol{\beta}=-\left[N^{-1} \sum\left(\boldsymbol{\beta} \otimes \mathbf{x}_{c}^{*}\right)^{\prime} \nabla_{\delta} \mathcal{F}\left(\mathbf{z}_{c t}, \boldsymbol{\delta}\right)\right] \sqrt{N}(\hat{\boldsymbol{\delta}}-\boldsymbol{\delta})+o_{p}(1)
$$

Defining $\mathbf{G} \equiv \mathbb{E}\left[\left(\boldsymbol{\beta} \otimes \mathbf{x}_{c}^{*}\right)^{\prime} \nabla_{\delta} \mathcal{F}\left(\mathbf{z}_{c t}, \boldsymbol{\delta}\right)\right]$, we have that

$$
N^{-1 / 2} \sum \hat{\mathbf{x}}_{c}^{*^{\prime}}\left(\mathbf{x}_{c}^{*}-\hat{\mathbf{x}}_{c}^{*}\right) \boldsymbol{\beta}=-\mathbf{G} \sqrt{N}(\hat{\boldsymbol{\delta}}-\boldsymbol{\delta})+o_{p}(1)
$$

Finally, the term $\sqrt{N}(\hat{\boldsymbol{\delta}}-\boldsymbol{\delta})$ can be expressed as

$$
\sqrt{N}(\hat{\boldsymbol{\delta}}-\boldsymbol{\delta})=\sqrt{N}\left(\left[\begin{array}{c}
\hat{\boldsymbol{\delta}}_{O L S}^{d} \\
\hat{\boldsymbol{\beta}}_{O L S}^{f} \\
\hat{\boldsymbol{\beta}}_{O L S}^{g}
\end{array}\right]-\left[\begin{array}{c}
\boldsymbol{\delta}^{d} \\
\boldsymbol{\beta}^{f} \\
\boldsymbol{\beta}^{g}
\end{array}\right]\right)=N^{-1 / 2}\left[\begin{array}{cc}
\mathbf{A}_{f}^{-1} & \mathbf{0}_{(D+K) \times K} \\
\mathbf{0}_{K \times(D+K)} & \mathbf{A}_{g}^{-1}
\end{array}\right] \sum\left[\begin{array}{c}
-\mathbf{x}_{c t}^{F^{\prime}} \xi_{c t} \\
\mathbf{x}_{c t}^{\prime} \epsilon_{c t}
\end{array}\right]+o_{p}(1)
$$

where $\mathbf{A}_{f} \equiv\left(N^{-1} \sum \mathbf{x}_{c t}^{F^{\prime}} \mathbf{x}_{c t}^{F}\right)$ and $\mathbf{A}_{g} \equiv\left(N^{-1} \sum \mathbf{x}_{c t} \mathbf{x}_{c t}\right)$. Thus, we can define

$$
\mathbf{r}_{c t}(\boldsymbol{\delta}) \equiv\left[\begin{array}{cc}
\mathbf{A}_{f}^{-1} & \mathbf{0}_{(D+K) \times K} \\
\mathbf{0}_{K \times(D+K)} & \mathbf{A}_{g}^{-1}
\end{array}\right]\left[\begin{array}{c}
-\mathbf{x}_{c t}^{F^{\prime}} \xi_{c t} \\
\mathbf{x}_{c t}^{\prime} \epsilon_{c t}
\end{array}\right]
$$

and hence

$$
\sqrt{N}(\hat{\boldsymbol{\beta}}-\boldsymbol{\beta})=C^{-1}\left\{N^{-1 / 2} \sum\left[\mathbf{x}_{c t}^{*^{\prime}} \eta_{c t}-\mathbf{G r}_{c t}(\boldsymbol{\delta})\right]\right\}+o_{p}(1)
$$

The Central Limit Theorem implies that

$$
\sqrt{N}(\hat{\boldsymbol{\beta}}-\boldsymbol{\beta}) \sim \mathcal{N}\left(\mathbf{0}, \mathbf{C}^{-1} \mathbf{M} \mathbf{C}^{-1}\right)
$$

where $\mathbf{M} \equiv \operatorname{Var}\left(\mathbf{x}_{c t}^{*^{\prime}} \eta_{c t}-\mathbf{G r}_{c t}(\boldsymbol{\delta})\right)$. A consistent estimator for this asymptotic variance is given by $\left(\hat{\mathbf{C}}^{-1} \hat{\mathbf{M}}^{-1}\right) / N$, where

$$
\begin{gathered}
\hat{\mathbf{M}}=N^{-1} \sum\left(\hat{\mathbf{x}}_{c t}^{*^{\prime}} \hat{\eta}_{c t}-\hat{\mathbf{G}} \hat{\mathbf{r}}_{c t}\right)\left(\hat{\mathbf{x}}_{c t}^{* \prime} \hat{\eta}_{c t}-\hat{\mathbf{G}} \hat{\mathbf{r}}_{c t}\right)^{\prime}, \\
\hat{\mathbf{G}}=N^{-1} \sum\left(\hat{\boldsymbol{\beta}} \otimes \hat{\mathbf{x}}_{c t}^{*}\right)^{\prime} \nabla_{\delta} \mathcal{F}\left(\mathbf{z}_{c t}, \hat{\boldsymbol{\delta}}\right), \\
\hat{\mathbf{r}}_{c t}=\mathbf{r}_{c t}(\hat{\boldsymbol{\delta}}),
\end{gathered}
$$

and

$$
\hat{\eta}_{c t}=\tilde{k}-\hat{\mathbf{x}}_{c t}^{*} \hat{\boldsymbol{\beta}}
$$




\section{B Online Appendix B: Additional Figures and Tables}

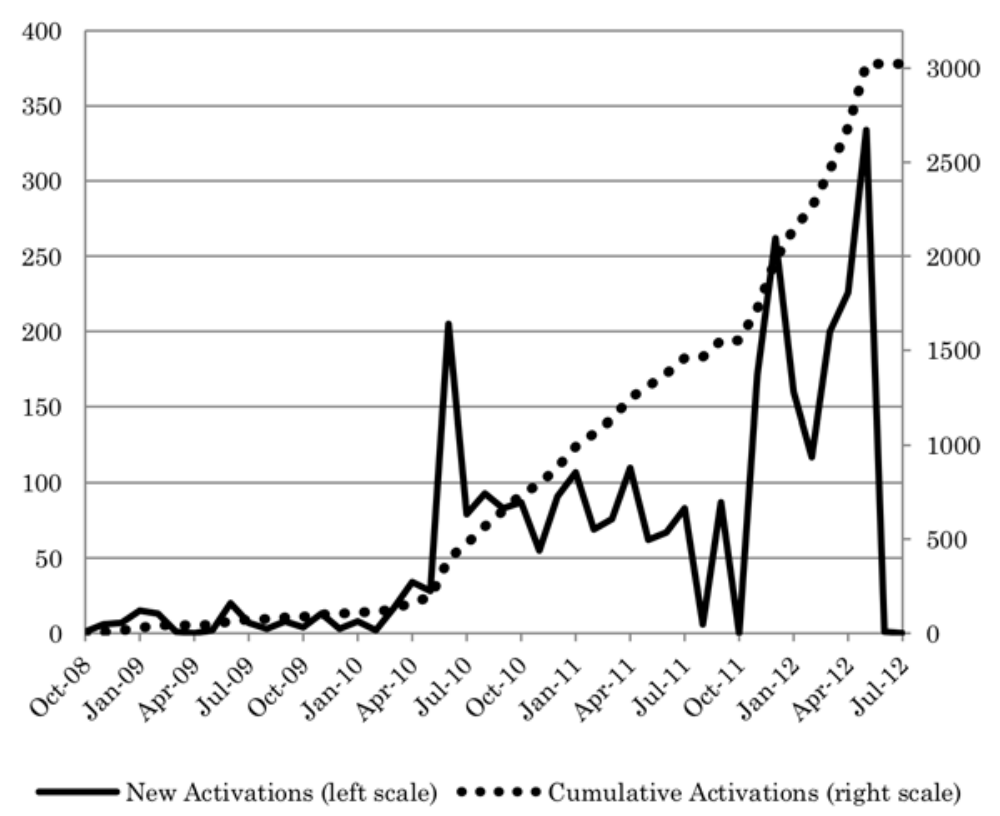

Figure B.1: County Rollout of Secure Communities Activation. The figure shows the yearly (solid line) and cumulative (dashed line) number of counties activated for Secure Communities (source: Cox and Miles (2013)). 


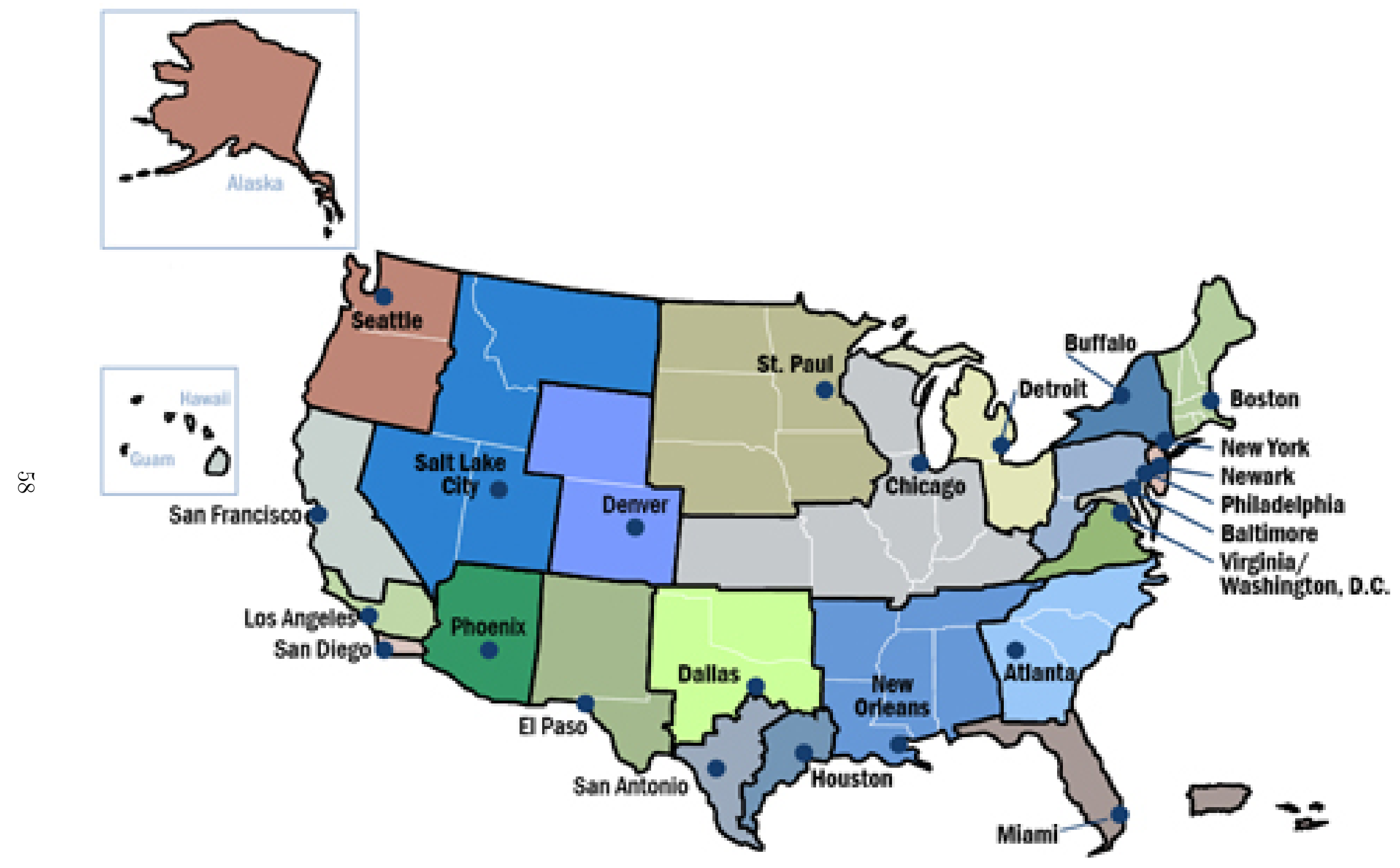

Figure B.2: Immigration and Customs Enforcement Federal Immigration Districts. The figure shows the geographic boundaries of the 24 ICE federal immigration districts and their corresponding headquarters. Source: ICE. 


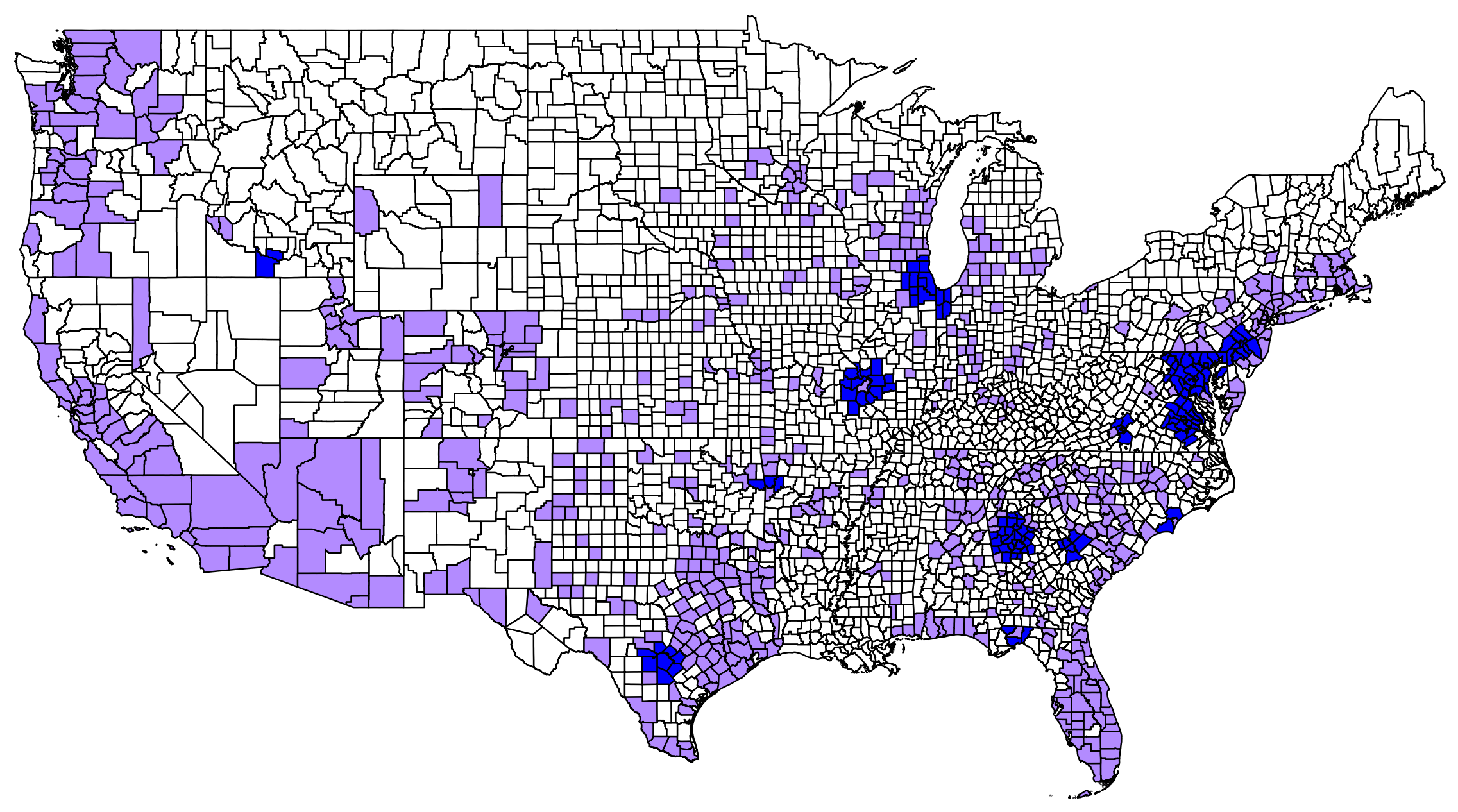

Figure B.3: Counties in the Model Estimation Sample. The map highlights the counties (in lavender) and the cbsa's (in blue) included in the sample used to estimate the model of the immigration enforcement process. 


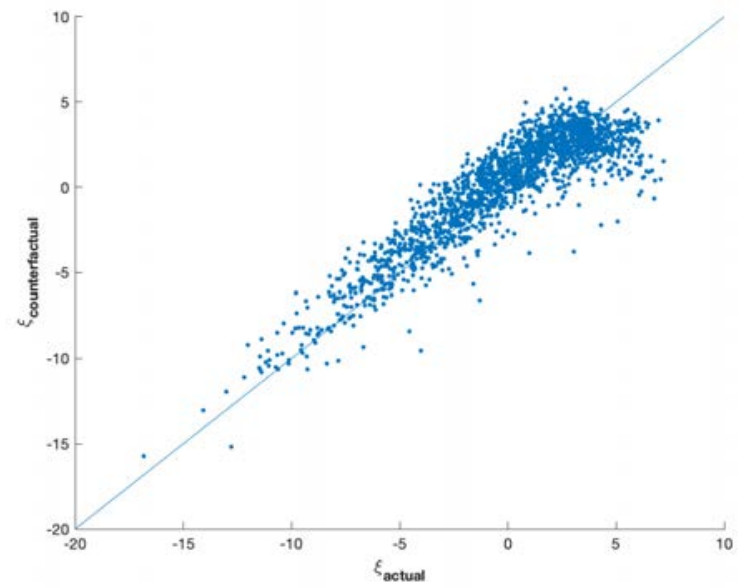

(a) Minor offenses

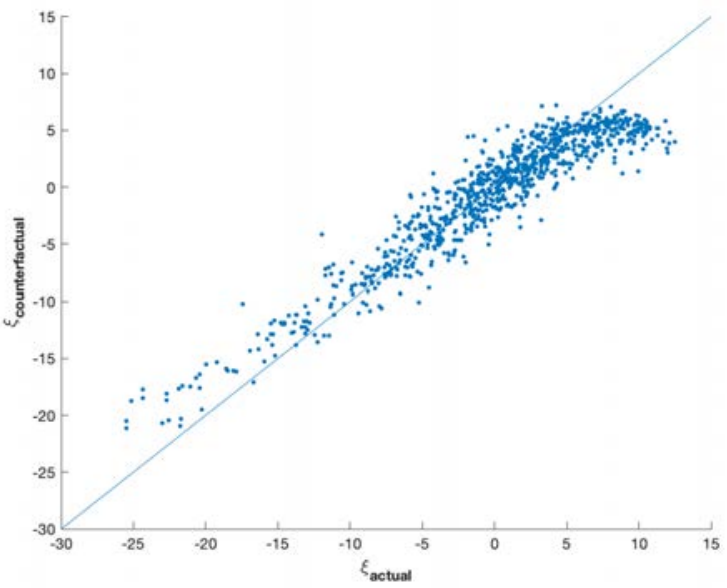

(b) Serious offenses

Figure B.4: Scatterplot of Actual vs Counterfactual Federal Efforts. Panel (a) shows a scatterplot of predicted (x-axis) and counterfactual (y-axis) federal immigration enforcement efforts $\xi^{m}$ for arrestees charged with minor (levels 2-4) offenses. Panel (b) shows a scatterplot of predicted (x-axis) and counterfactual (y-axis) federal immigration enforcement efforts $\xi^{s}$ for arrestees charged with serious (level 1) offenses. The counterfactual exercise simulates no federal policy guidelines change after 2011-II. 


\begin{tabular}{lccccc}
\hline \hline Panel A: & \multicolumn{5}{c}{ All counties above median undocumented share } \\
\hline & Mean & Std. dev. & Min. & Median & Max. \\
\hline Log population & 10.9 & 1.43 & 6.66 & 10.7 & 16.1 \\
Undocumented share & 0.017 & 0.018 & 0.0028 & 0.011 & 0.14 \\
Hispanic share & 0.12 & 0.15 & 0.00023 & 0.063 & 0.96 \\
Bachelor degree share & 0.21 & 0.100 & 0.037 & 0.18 & 0.71 \\
Democratic party share & 0.41 & 0.15 & 0.081 & 0.40 & 0.92 \\
Rural & 0.52 & 0.50 & 0 & 1 & 1 \\
Services share & 0.59 & 0.084 & 0.28 & 0.59 & 0.90 \\
Log distance ICE office & 4.87 & 1.85 & -9.97 & 5.18 & 6.71 \\
287(g) Program & 0.029 & 0.17 & 0 & 0 & 1 \\
Observations & & & 1547 & &
\end{tabular}

Panel B:

Counties in the model estimation sample

\begin{tabular}{lccccc}
\hline & Mean & Std. dev. & Min. & Median & Max. \\
\hline Log population & 11.8 & 1.25 & 8.13 & 11.8 & 16.1 \\
Undocumented share & 0.022 & 0.020 & 0.0028 & 0.016 & 0.14 \\
Hispanic share & 0.16 & 0.17 & 0.015 & 0.093 & 0.96 \\
Bachelor degree share & 0.24 & 0.10 & 0.075 & 0.22 & 0.70 \\
Democratic party share & 0.43 & 0.15 & 0.081 & 0.42 & 0.89 \\
Rural & 0.28 & 0.45 & 0 & 0 & 1 \\
Services share & 0.62 & 0.079 & 0.36 & 0.62 & 0.88 \\
Log distance ICE office & 4.57 & 2.46 & -9.97 & 5.06 & 6.65 \\
287(g) Program & 0.069 & 0.25 & 0 & 0 & 1 \\
Observations & & & 566 & & \\
\hline
\end{tabular}

Table B.1: Descriptive Statistics for the County Sample. The table presents summary statistics of the county characteristics of our sample of counties. Panel A reports summary statistics for all counties with undocumented population above median. Panel B reports summary statistics for all counties above median undocumented population that satisfy the conditions required for estimation of the immigration enforcement process model. Log Population is taken from the 2010 Census. Undocumented share is an estimate of the number of unlawfully present individuals in 2010 (its construction is described in Appendix C). Democratic party share is an average of the 2008 and 2012 Democratic Presidential vote shares, taken from David Leip's Electoral Atlas. Bachelor degree share is measured as the fraction of the adult population with at least a bachelor's degree. Hispanic share is measured as the fraction of the population who is hispanic. Services share is measured as the fraction of the employed population working in the services sector. Bachelor degree share, Hispanic share, and Services share are taken from the 2006-2010 waves of the American Communities Survey. Rural is a dummy variable indicating whether the county is considered non-metropolitan according to the National Center for Health Statistics at the Center for Disease Control. Distance to ICE office is measured as the log of the number of miles between the county centroid and the county centroid of the corresponding ICE district office seat, and computed directly by us. $287(\mathrm{~g})$ Program is a dummy variable indicating whether the county or any city in the county was ever part of the 287(g) program, taken from Steil and Vasi (2014). 


\begin{tabular}{lccccc}
\hline \hline Panel A: & \multicolumn{5}{c}{ Minor Offenses } \\
& $\xi$ & $\epsilon$ & $\zeta_{l}$ & $\zeta_{h}$ & $\pi^{H h} / \pi^{H \ell}$ \\
\hline$\xi$ & 1.00 & & & & \\
$\epsilon$ & -0.49 & 1.00 & & & \\
$\zeta^{l}$ & 0.00 & 0.04 & 1.00 & & \\
$\zeta^{h}$ & 0.00 & -0.05 & -0.12 & 1.00 & \\
$\pi^{H h} / \pi^{H \ell}$ & 0.36 & -0.37 & -0.15 & 0.13 & 1.00 \\
& \multicolumn{6}{c}{} \\
Panel B: & \multicolumn{6}{c}{ Serious Offenses } \\
\hline$\xi$ & 1.00 & & & & \\
$\epsilon$ & -0.40 & 1.00 & & & \\
$\zeta^{l}$ & 0.00 & -0.05 & 1.00 & & \\
$\zeta^{h}$ & 0.00 & -0.12 & -0.00 & 1.00 & \\
$\pi^{H h} / \pi^{H \ell}$ & 0.33 & -0.44 & -0.05 & 0.15 & 1.00 \\
\hline \hline
\end{tabular}

Table B.2: Correlation Matrix of Enforcement Efforts and Preference Alignment. The table shows the correlation matrix of selected enforcement variables. Panel A shows the correlation coefficients for minor offenses while panel B shows the coefficients for serious offenses. 


\begin{tabular}{|c|c|c|c|c|c|c|}
\hline \multicolumn{7}{|c|}{ Minor offenses } \\
\hline \multirow[t]{2}{*}{$\overline{\text { Panel A: }}$} & \multicolumn{6}{|c|}{ Pre-Policy Change (2009-I - 2011-I) } \\
\hline & Mean & Std. dev. & Min. & Median & Max. & Obs. \\
\hline $\mathrm{x} 1=\mathbb{P}($ detainer $)$ & 0.26 & 0.17 & 0 & 0.24 & 1 & 1110 \\
\hline $\mathrm{x} 2=\mathbb{P}(\mathrm{ICE}$ custody, detainer $)$ & 0.11 & 0.12 & 0 & 0.076 & 1 & 1025 \\
\hline $\mathrm{x} 3=\mathbb{P}($ removal, detainer $)$ & 0.064 & 0.10 & 0 & 0.020 & 1 & 936 \\
\hline $\mathrm{y} 1=\mathbb{P}(\mathrm{ICE}$ custody $\mid$ no detainer $)$ & 0.22 & 0.22 & 0 & 0.15 & 1 & 1098 \\
\hline $\mathrm{y} 2=\mathbb{P}($ removal $\mid$ no detainer $)$ & 0.17 & 0.21 & 0 & 0.10 & 1 & 979 \\
\hline \multirow[t]{2}{*}{ Panel B: } & \multicolumn{6}{|c|}{ Post-Policy Change (2011-II - 2014-II) } \\
\hline & Mean & Std. dev. & Min. & Median & Max. & Obs. \\
\hline $\mathrm{x} 1=\mathbb{P}($ detainer $)$ & 0.23 & 0.17 & 0 & 0.19 & 1 & 4474 \\
\hline $\mathrm{x} 2=\mathbb{P}(\mathrm{ICE}$ custody, detainer $)$ & 0.085 & 0.11 & 0 & 0.054 & 1 & 4324 \\
\hline $\mathrm{x} 3=\mathbb{P}($ removal, detainer $)$ & 0.054 & 0.075 & 0 & 0.029 & 1 & 3866 \\
\hline $\mathrm{y} 1=\mathbb{P}(\mathrm{ICE}$ custody $\mid$ no detainer $)$ & 0.23 & 0.22 & 0 & 0.16 & 1 & 4449 \\
\hline $\mathrm{y} 2=\mathbb{P}($ removal $\mid$ no detainer $)$ & 0.18 & 0.20 & 0 & 0.11 & 1 & 4312 \\
\hline \multicolumn{7}{|c|}{ Serious offenses } \\
\hline \multirow[t]{2}{*}{ Panel C: } & \multicolumn{6}{|c|}{ Pre-Policy Change (2009-I - 2011-I) } \\
\hline & Mean & Std. dev. & Min. & Median & Max. & Obs. \\
\hline $\mathrm{x} 1=\mathbb{P}($ detainer $)$ & 0.29 & 0.25 & 0 & 0.23 & 1 & 750 \\
\hline $\mathrm{x} 2=\mathbb{P}(\mathrm{ICE}$ custody, detainer $)$ & 0.20 & 0.20 & 0 & 0.14 & 1 & 634 \\
\hline $\mathrm{x} 3=\mathbb{P}($ removal, detainer $)$ & 0.083 & 0.13 & 0 & 0.034 & 1 & 584 \\
\hline $\mathrm{y} 1=\mathbb{P}(\mathrm{ICE}$ custody $\mid$ no detainer $)$ & 0.40 & 0.33 & 0 & 0.32 & 1 & 716 \\
\hline $\mathrm{y} 2=\mathbb{P}($ removal $\mid$ no detainer $)$ & 0.33 & 0.32 & 0 & 0.23 & 1 & 621 \\
\hline \multirow[t]{2}{*}{ Panel D: } & \multicolumn{6}{|c|}{ Post-Policy Change (2011-II - 2014-II) } \\
\hline & Mean & Std. dev. & Min. & Median & Max. & Obs. \\
\hline $\mathrm{x} 1=\mathbb{P}($ detainer $)$ & 0.19 & 0.16 & 0 & 0.15 & 1 & 2559 \\
\hline $\mathrm{x} 2=\mathbb{P}(\mathrm{ICE}$ custody, detainer $)$ & 0.092 & 0.11 & 0 & 0.062 & 1 & 2392 \\
\hline $\mathrm{x} 3=\mathbb{P}($ removal, detainer $)$ & 0.051 & 0.071 & 0 & 0.028 & 0.67 & 2143 \\
\hline $\mathrm{y} 1=\mathbb{P}(\mathrm{ICE}$ custody $\mid$ no detainer $)$ & 0.24 & 0.21 & 0 & 0.18 & 1 & 2539 \\
\hline $\mathrm{y} 2=\mathbb{P}($ removal $\mid$ no detainer $)$ & 0.19 & 0.20 & 0 & 0.13 & 1 & 2454 \\
\hline
\end{tabular}

Table B.3: Immigration Enforcement Pipeline: Conditional Probabilities. The table presents summary statistics for the conditional probabilities related to the immigration enforcement pipeline under Secure Communities, for the sample of observations used for estimation. We report conditional probabilities at the county-semester level of observation. All variables in panel A and B refer to minor offenses (level 2-4 under ICE's classification). All variables in panel C and D refer to serious offenses (level 1 under ICE's classification). Panels A and C report summary statistics from 2009-I to 2011-I (before the June 2011 policy guidelines change). Panels B and D report summary statistics from 2011-II to 2014-II (after the June 2011 policy guidelines change). 


\begin{tabular}{lccccc}
\hline \hline & $f$ & $g$ & $k$ & $q^{l}$ & $q^{h}$ \\
& $(1)$ & $(2)$ & $(3)$ & $(4)$ & $(5)$ \\
\hline Log population & 0.44 & -0.09 & -0.59 & -0.09 & 0.17 \\
& $(0.11)$ & $(0.20)$ & $(2.12)$ & $(0.65)$ & $(0.62)$ \\
Undocumented share & 9.08 & -7.57 & -28.73 & -9.70 & 5.95 \\
& $(6.94)$ & $(11.24)$ & $(14.30)$ & $(15.17)$ & $(13.28)$ \\
Hispanic share & 2.74 & -0.09 & 0.33 & 1.38 & 0.35 \\
& $(1.10)$ & $(1.48)$ & $(3.26)$ & $(2.51)$ & $(2.24)$ \\
Bachelor degree share & 0.78 & 1.67 & 1.58 & 0.07 & -0.96 \\
& $(1.19)$ & $(2.50)$ & $(3.41)$ & $(3.16)$ & $(3.07)$ \\
Rural & -0.38 & -0.13 & 0.48 & 0.01 & 0.16 \\
& $(0.28)$ & $(0.70)$ & $(2.20)$ & $(1.05)$ & $(0.94)$ \\
Services share & -0.53 & -1.53 & -1.18 & 1.72 & 0.64 \\
& $(2.03)$ & $(3.82)$ & $(5.06)$ & $(5.00)$ & $(4.46)$ \\
Democratic party share & -1.28 & -1.30 & 0.42 & -2.22 & -0.19 \\
& $(0.85)$ & $(1.49)$ & $(2.83)$ & $(2.09)$ & $(1.90)$ \\
Log distance ICE office & 0.14 & -0.10 & -0.11 & 0.005 & 0.006 \\
& $(0.02)$ & $(0.04)$ & $(2.11)$ & $(0.586)$ & $(0.586)$ \\
287(g) program & 0.59 & 1.74 & -1.49 & -0.82 & 1.09 \\
& $(0.33)$ & $(0.56)$ & $(2.22)$ & $(0.94)$ & $(0.98)$ \\
\hline Observations & & & 2348 & & \\
\hline \hline
\end{tabular}

Table B.4: Coefficients for the logistic regressions of the enforcement probabilities. Minor

Offenses. The table reports the $\beta$ coefficients for the logistic regressions in equations (17)-(20) for minor offenses. Democratic party share is an average of the 2008 and 2012 Democratic Presidential vote shares minus 50 percent, taken from David Leip's Electoral Atlas. Bachelor degree share is measured as the fraction of the adult population with at least a bachelor's degree. Hispanic share is measured as the fraction of the population who is hispanic. Bachelor degree share and Hispanic share are taken from the 2006-2010 waves of the American Communities Survey. Guidelines is a dummy variable indicating the semesters after the policy guidelines change under the Obama administration. Mexican share is the fraction of detainers issued against unlawfully present Mexican nationals in a given county-semester. Central American share is the fraction of detainers issued against unlawfully present Central American nationals in a given county-semester. Young share is the fraction of detainers issued against unlawfully present immigrants less than 30 years old. The Mexican, Central American and Young shares are taken from the TRAC detainers dataset. 911 calls is the log of the total number of calls to the emergency number 911 at the county-year level. Standard errors are robust to arbitrary heteroskedasticity. 


\begin{tabular}{lccccc}
\hline \hline & $f$ & $g$ & $k$ & $q^{l}$ & $q^{h}$ \\
& $(1)$ & $(2)$ & $(3)$ & $(4)$ & $(5)$ \\
\hline Log population & 1.08 & -0.09 & -1.08 & -0.10 & 0.19 \\
& $(0.28)$ & $(0.33)$ & $(7.30)$ & $(1.04)$ & $(1.00)$ \\
Undocumented share & 18.33 & 35.48 & -63.46 & -14.21 & 31.17 \\
& $(17.19)$ & $(17.48)$ & $(50.32)$ & $(20.97)$ & $(20.78)$ \\
Hispanic share & -0.06 & -0.61 & 3.86 & 0.005 & 0.68 \\
& $(2.32)$ & $(2.31)$ & $(10.19)$ & $(2.594)$ & $(2.31)$ \\
Bachelor degree share & 0.24 & 2.70 & 0.50 & -0.57 & 0.59 \\
& $(3.13)$ & $(4.39)$ & $(10.79)$ & $(4.40)$ & $(3.23)$ \\
Rural & -0.10 & -0.77 & -1.96 & -1.20 & -0.14 \\
& $(1.21)$ & $(1.79)$ & $(7.75)$ & $(2.03)$ & $(1.84)$ \\
Services share & -2.21 & -8.03 & 3.43 & 2.29 & -3.48 \\
& $(5.43)$ & $(6.47)$ & $(17.03)$ & $(7.01)$ & $(5.20)$ \\
Democratic party share & -7.72 & -6.71 & 8.75 & -0.66 & -1.45 \\
& $(2.12)$ & $(2.61)$ & $(9.20)$ & $(2.98)$ & $(2.28)$ \\
Log distance ICE office & 0.09 & 0.003 & -0.10 & 0.005 & 0.02 \\
& $(0.04)$ & $(0.075)$ & $(7.27)$ & $(0.972)$ & $(0.97)$ \\
287(g) program & -2.91 & -0.09 & 1.98 & -0.30 & 1.00 \\
& $(0.67)$ & $(0.79)$ & $(7.47)$ & $(1.29)$ & $(1.28)$ \\
\hline Observations & & & 1101 & & \\
\hline \hline
\end{tabular}

Table B.5: Coefficients for the logistic regressions of the enforcement probabilities. Serious Offenses. The table reports the $\beta$ coefficients for the logistic regressions in equations (17)-(20) for serious offenses. Democratic party share is an average of the 2008 and 2012 Democratic Presidential vote shares minus 50 percent, taken from David Leip's Electoral Atlas. Bachelor degree share is measured as the fraction of the adult population with at least a bachelor's degree. Hispanic share is measured as the fraction of the population who is hispanic. Bachelor degree share and Hispanic share are taken from the 2006-2010 waves of the American Communities Survey. Guidelines is a dummy variable indicating the semesters after the policy guidelines change under the Obama administration. Mexican share is the fraction of detainers issued against unlawfully present Mexican nationals in a given county-semester. Central American share is the fraction of detainers issued against unlawfully present Central American nationals in a given county-semester. Young share is the fraction of detainers issued against unlawfully present immigrants less than 30 years old. The Mexican, Central American and Young shares are taken from the TRAC detainers dataset. 911 calls is the log of the total number of calls to the emergency number 911 at the county-year level. Standard errors are robust to arbitrary heteroskedasticity. 


\section{Online Appendix C: Construction of Variables}

\section{C.1 Undocumented Share}

We use different sources to construct estimates of the undocumented population at the county level. Warren and Warren (2012), Passel (2005) and the Department of Homeland Security provide estimates of the undocumented population at the state level for different years and use a residual method that combine the number of people entered in the US and the number of non citizens from Census and other survey data. Estimates at substate level are almost nonexistent. One exception is Hill and Johnson (2011), who use information from tax returns to estimate the undocumented population at the county and at the zip-code levels in California. Since 1996, unauthorized immigrants, who lack social security numbers, have been allowed to file federal tax returns using a unique identifier, the Individual Taxpayer Identification Number, or ITIN. Hill and Johnson (2011) show that this measure is highly correlated with the estimates of undocumented population at the state level. This is not surprising; although many undocumented immigrants lack a social security number, they still have an incentive to file taxes in order to collect tax refunds. Our preferred measure of the undocumented population combines the number of Hispanic non citizens from the ACS, the state level estimates from Warren and Warren (2012), and the number of ITIN filers.

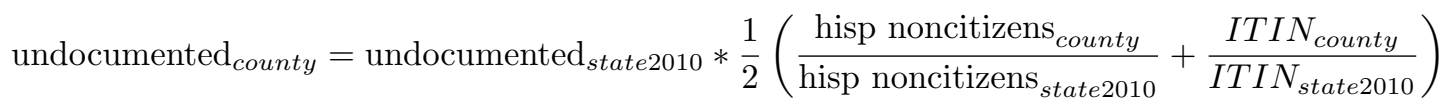

\section{C.2 Consistency between Model and Data}

\section{C.2.1 Assigning ICE Arrests to Detainer or Direct Track}

Secure Communities data on ICE arrests (custodies) do not have information on whether a detainer was issued or not. To identify custodies from detainers, we use detainers data from TRAC on the universe of detainers, which include detainers on SC as well as other detainers. TRAC detainers data include information on whether the individual ended up in ICE custody and we can apply the custody-detainer ratio to the SC detainers to recover the number of custodies from SC detainers under the assumption that SC detainers and overall detainers have a similar composition. To avoid inconsistencies in the arrests and removals data between both sources (TRAC and Secure Communities), we define $p$ as the constant such that $C=D p+(M-D) p=M p$, where $C$ is ICE custodies, $D$ is detainers and $M$ is local arrests. $p$ is the probability that an immigrant is taken into ICE custody if the probability is the same along the detainer and the direct tracks. It follows that

$$
C=D \underbrace{\left(p+\epsilon \frac{M-D}{M}\right)}_{p_{1}}+(M-D) \underbrace{\left(p-\epsilon \frac{D}{M}\right)}_{p_{2}}
$$

. Now, $\epsilon$ allows the probabilities to differ across tracks, while keeping them consistent with the observed $C$. The

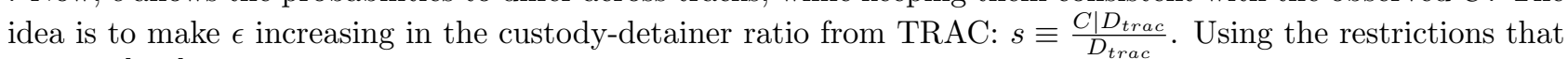
$p_{1}, p_{2} \in[0,1]$ we can recover a lower bound $\underline{\epsilon}$ and an upper bound $\bar{\epsilon}$. Additionally, we can impose the restrictions $R|D \leq C| D$ and $R|n o D \leq C|$ noD to construct the two bounds for $\epsilon$. Then, we can set $\epsilon=(1-s) \underline{\epsilon}+s \bar{\epsilon}$ where the lower bound is $\underline{\epsilon}=\max \{-C /(M-D),-(M-C) / D,-(C-R \mid D * M / D) /(M-D)\}$ and the upper bound is $\bar{\epsilon}=\min \{C / D,(M-C) /(M-D), C / D-M * R \mid n o D /(D *(M-D))\}$.

\section{C.2.2 Consolidating Counties into CBSA}

Our empirical strategy puts significant demands on the data. In particular, we need positive counts at each step of the deportation process. The number of counties that satisfy these requirements is limited (650 in the sample for minor offenses). In an effort to work with a larger sample, we group neighboring counties not in the initial sample that fall into core-based statistical areas (CBSA), a census definition that includes both metropolitan statistical areas and micropolitan areas. We are able to add 19 CBSA that satisfy the requirements for our estimation strategy, assigning them covariate values computed as weighted averages of the covariates across counties within each of these CBSA's. Figure B.3, illustrates in dark blue the CBSA's in our sample. 